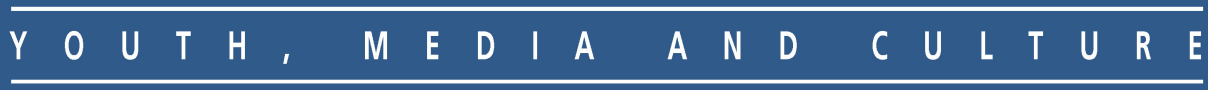

\section{Cracking Facebook}

The Importance of Understanding Technology-Based Communication

Maria Leena Korpijaakko
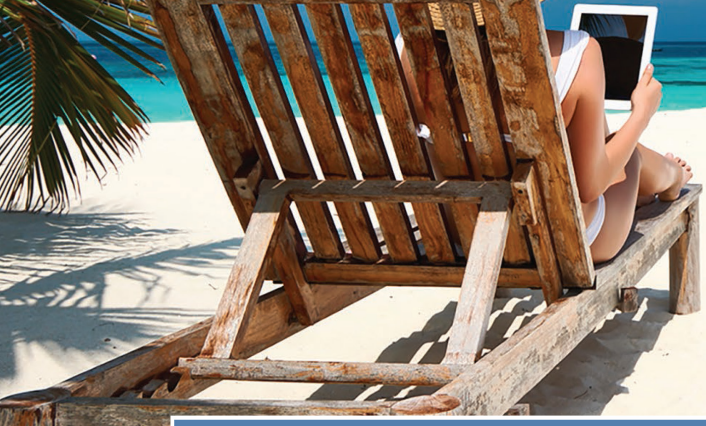

SensePublishers 
Cracking Facebook 
YOUTH, MEDIA AND CULTURE SERIES

Volume 5

Series Editors

Shirley R. Steinberg, University of Calgary, Canada

Awad Ibrahim, University of Ottawa, Canada

Editorial Board

Annette Coburn, The University of the West of Scotland

Giuliana Cucinelli, Concordia University, Montreal, Canada

Rhonda Hammer, UCLA, USA

Mark Helmsing, Michigan State University, USA

Brian Johnson, Bloomburg University, PA, USA

\section{Scope}

Taking the notion of critical youth studies, this series features top scholars in critical media and youth studies. Coupling edgy topics with a critical theoretical lens, volumes explore the impact of media and culture on youth ... and the impact of youth on media and culture. 


\section{Cracking Facebook}

The Importance of Understanding Technology-Based Communication

Maria Leena Korpijaakko

McGill University, Canada

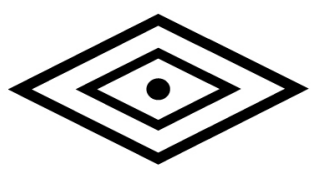

SENSE PUBLISHERS

ROTTERDAM/BOSTON/TAIPEI 
This is an open access title distributed under the terms of the CC BY-NC 4.o license, which permits any non-commercial use, distribution, and reproduction in any medium, provided the original author(s) and source are credited. Further information and the complete license text can be found at https://creativecommons.org/licenses/ by-nc/4.0/

The terms of the Cc license apply only to the original material. The use of material from other sources (indicated by a reference) such as diagrams, illustrations, photos and text samples may require further permission from the respective copyright holder.

An electronic version of this book is freely available, thanks to the support of libraries working with Knowledge Unlatched. More information about the initiative can be found at www .knowledgeunlatched.org.

A C.I.P. record for this book is available from the Library of Congress.

ISBN: 978-94-6300-209-7 (paperback)

ISBN: 978-94-6300-210-3 (hardback)

ISBN: 978-94-6300-211-0 (e-book)

Published by: Sense Publishers,

P.O. Box 21858,

3001 AW Rotterdam,

The Netherlands

https://www.sensepublishers.com/

All chapters in this book have undergone peer review.

\section{Printed on acid-free paper}

\section{All Rights Reserved (C) 2015 The Author}

No part of this work may be reproduced, stored in a retrieval system, or transmitted in any form or by any means, electronic, mechanical, photocopying, microfilming, recording or otherwise, without written permission from the Publisher, with the exception of any material supplied specifically for the purpose of being entered and executed on a computer system, for exclusive use by the purchaser of the work. 


\section{TABLE OF CONTENTS}

List of Tables vii

List of Figure $\quad$ ix

Chapter 1: Introduction: Why Technology Matters 1

Relationships with Technology 2

Living in Hyperreal Connections $\quad 5$

$\begin{array}{ll}\text { Who Are We Anyway? } & 6\end{array}$

What Is Agency in Identity Performance? 9

$\begin{array}{lr}\text { Research Aims } & 10\end{array}$

My Facebook Study 11

$\begin{array}{lr}\text { Method and Theory } & 12\end{array}$

$\begin{array}{ll}\text { Research Implications } & 13\end{array}$

$\begin{array}{ll}\text { Book Overview } & 14\end{array}$

Chapter 2: Why People Use Facebook: The Pros and Cons Associated $\begin{array}{ll}\text { with Its Use } & 15\end{array}$

$\begin{array}{ll}\text { Online Identity: Teens } & 16\end{array}$

Online Identity on Facebook: Young Adults 19

Teens and Young Adults: Similarities and Socio-cultural Implications 22

Literature on SNS/Facebook Use for All Ages 23

Reasons for Negative Consequences of SNS/Facebook Use 29

$\begin{array}{ll}\text { Conclusion } & 31\end{array}$

Chapter 3: Linking Identity Theory, Avatar Attachment Theory, and

Hyperreal Considerations to Overconsumption and Self-Fetishization

on Facebook 33

Identity Theory 33

Age Category Conceptualizations: Links to Socio-Economic Conditions 34

Age Categories, Market Exploitation, and Consumer Discourse 36

Celebrity Culture and Gendered Beauty Discourse $\quad 39$

$\begin{array}{ll}\text { Cyber Identity Performance } & 41\end{array}$

Hyperreality, Overconsumption, and Self-Fetishization 44

Debates on Personal Agency 48

Agency in Cyber Identity Performance $\quad 51$

Ensuring Agency $\quad 52$

Chapter Summary 53 
Chapter 4: Facebook Study $\quad 55$

Study Rationale $\quad 55$

Design $\quad 56$

Data Collection $\quad 59$

Data Analysis $\quad 64$

Johnson's Four-Point Model for Inquiry of a Media Site 65

Applying Johnson's Four-Point Model to My Study Results 68

$\begin{array}{ll}\text { Chapter Summary } & 71\end{array}$

Chapter 5: Facebook Study Results 73

Facebook Profile Analysis (FPA) and Survey Results 74

Facebook Study Findings: FPA and Survey $\quad 75$

E-mail Responses to Likes $\quad 97$

Eight Day Screen Shot Analysis of Home Page Advertising (Appendix C) 98

$\begin{array}{lr}\text { Chapter Summary } & 104\end{array}$

Chapter 6: A Critical Analysis of Facebook Study Findings 105

Production: Reflections of Consumer and Identity Discourse 106

Text: Structural Impacts on Production and Readings 110

Readings: How Does the Medium Affect the Reading? 115

A Critical Perspective on Agency in Facebook Use 119

$\begin{array}{ll}\text { Chapter 7: Conclusion } & 123\end{array}$

$\begin{array}{ll}\text { Future Research Directions } & 125\end{array}$

$\begin{array}{lr}\text { Theoretical Implications } & 126\end{array}$

$\begin{array}{lr}\text { Educational Implications } & 126\end{array}$

$\begin{array}{ll}\text { Limitations Incurred in This Study } & 128\end{array}$

$\begin{array}{ll}\text { Appendix A: Survey } & 131\end{array}$

Appendix B: Sample Facebook Profile 133

Appendix C: Home Page Advertising Screen Shots for 8 Days 135

$\begin{array}{ll}\text { Bibliography } & 139\end{array}$

$\begin{array}{ll}\text { Index } & 147\end{array}$ 


\section{LIST OF TABLES}

Table 1. FPA results $\quad 61$

Table 2. Facebook survey: General impressions and "friends" 77

Table 3. Facebook survey: Profile and usage $\quad 80$

Table 4. Facebook survey: Other comments 83

Table 5. E-mail responses on likes 98

Table 6. Home page advertising for 8 days 99 



\section{LIST OF FIGURE}

Figure 1. Tetrad of Facebook effects 



\title{
INTRODUCTION
}

\author{
Why Technology Matters
}

Power's construction of subjectivity and validation of particular forms of data takes advantage of the comfort of the everyday.

(Kincheloe, 2004a, p. 7)

The social network site (SNS) Facebook is a relatively new space of technology use that is explicitly connected to identity performance. It was first established in 2004 by Mark Zuckerberg and his college friends at Harvard University, and was initially open only to those attending Harvard University but slowly expanded to other ivy league schools, then to other universities, then to high schools in 2005, then finally to anyone over 13 years of age in 2006. Thirteen is still the current minimum age for registration but millions are said to violate this regulation. Because it was developed for the university student, social networking and identity performance were at the heart of its design. Its basic format compels users to express personal information about themselves while registering, and then encourages further identity performance through the posting of photos, media and corporate likes, interests, hobbies, and personal thoughts through status updates (Facebook, 2013).

However, Facebook is not only a space of individual identity performance, it is also a business. The business of Facebook involves the selling of peoples' personal information back to them, and ultimately to corporations (Grosser, 2011; van Dijck, 2013). This is achieved by having people accept Facebook's data use policy which stipulates that Facebook can share your information with service providers and use your information to "measure or understand the effectiveness of ads you and others see, including to deliver relevant ads to you" (Data Use Policy, 2014, para. 35). The socio-cultural implications of this have intensified because in 2007 Microsoft sold 1.6\% of Facebook's shares for $\$ 240$ million giving it an estimated value of $\$ 15$ billion dollars. Traffic on Facebook has been steadily increasing since. In June, 2011 statistics released by DoubleClick showed that there had been one trillion page views. According to Facebook's Newsroom (2013), there are more than one billion active users with $82 \%$ of them located outside of Canada and the U.S. Daily active users total 618 million and this number increases to 680 million with mobile products.

Facebook is often in the news these days and its use is frequently linked to negative behavior and consequences. A Google web search of 'Facebook and School' generates a multitude of articles with headings such as "Facebook bullying 
case disturbs school officials" (Hunsinger Benbow, 2014), "School district Pays \$70K to Settle Lawsuit Over Girl's Facebook Posts" (Benitz, 2014), and "School Children Should Not Have Access to Facebook" (Yaftali, 2011). A Google news search of 'Facebook and School' generates more about how Facebook is used for cyber bullying or as a forum for those about to go on a killing spree to post hateful comments (Montague, 2014; Simon, 2014). It is also being linked to increased levels of depression, anxiety, and poorer school performance (Rochman, 2011). What is actually going on? Does Facebook use lead to negative consequences and behaviour? What are the socio-cultural implications of cyber identity performance on Facebook? In this book, I explore why and how people are performing their identities on Facebook, how this might be impacting our society and culture, and how this information can be used for educational purposes to inform pedagogy, curriculum formation, and scholarly discussions in various fields of study concerned with identity and agency such as cultural studies.

\section{RELATIONSHIPS WITH TECHNOLOGY}

I was born in 1974 and I am considered to be a member of Generation X, whose members were born between 1966 and 1976 (Schroer, n.d.). I was also born right on the cusp of Prensky's (2001) "digital divide" and am referred to by him as a "digital immigrant", with "digital natives" being born after 1980. However, Zur and Zur (2011) refer to Generation X and younger as "digital natives" or those "having been born with "digital DNA" (para. 1), making technology use a natural extension of their being. Even though members of my generation are considered to be digital natives by Zur and Zur, I contend that it is not in the same way as Generation Z.

Generation Z (born between 1995 and 2012) (Schroer, n.d.) is the first generation to grow up completely surrounded by advanced technology, including the internet, and members typically do not know a life before media technology. The internet became popularized in the 1990s (Internet, 2014) and the earliest SNS, classmates. com, was launched in 1995, coinciding with the start of Generation Z.

I think of the Generation $Z$ as the starting point of a "great digital divide" because they are the first generation to grow up in with the internet and SNSs. I grew up with technology such as a television and a non-portable telephone, but I was not immersed in it, and the technology throughout my childhood and youth was nothing like it is today. A computer with Internet access entered my home in 1992 and I got a cell phone in 2001 when I was 27 . These days, I act more like a "true digital native" or those born after 1995 belonging to Generation Z. I have a personal web page, I play online games, and most of my communication is digital. In my home I have three laptops, a personal computer, an iPad, a play station, and two smart phones. No matter where I am, I have immediate access to the Internet and spend most of my Internet time on the social network site (SNS) Facebook, but I remember how identity performance, communication, and relationships were before this hyperreal immersion. Because of this, I contend that my peer group is able to reflect more 
critically on its immersion because members easily acquire new technology and remember a time before them, whereas Generation $\mathrm{Z}$ may not have such critical insight into their technology use due to their full immersion. Therefore, I refer to my peer group as the "Cusp Generation" and "part digital native" because we are more digitally native than Prensky would imply and less than Zur and Zur claim.

By defining my peer group as members of the Cusp Generation, I am able to question if those born with SNSs as a part of their everyday lives are affected differently by them than we are. Joining a SNS is natural for "digital natives" because they "prefer to connect via text, chat, Facebook, online games, etc." (Zur \& Zur, 2011, para. 23) but I contend that this refers more specifically to Generation Z, and so although I am regularly on Facebook, and consider myself to be "part digital native", my definition of the Cusp Generation allows me to question my immersion. Why am I on Facebook? Are my relationships different online than offline? If so, how are they different? Do my online interactions impact my offline interactions with the same people? Why am I consuming Facebook and do I have agency in determining my cyber identity performance?

Most of the literature on cyber identity performance published between 2007 and 2012 focused on teens and young adults which includes Generation Y (those born between 1977 and 1994 (Schroer, n.d.) and Generation Z members. I am interested in the online lives of the Cusp Generation of SNS users, and wonder about the differences in cyber identity performances between those who grew up with the internet and those who did not. My study's participants are all those born between 1945 and 1993. However, the average age is 38, which just happens to coincide with the fastest growing demographic on Facebook (Turkle, 2011) and I question: if my peer group is being impacted by the hyperreal nature of Facebook use (its simulation of offline reality), then what does this imply for Generation $\mathrm{Z}$ and future generations who have grown up with this type of normalized technological hyperreality?

I have always been intrigued by the relationship between consumerism and identity performance and Facebook exemplifies this relationship through its business model and its basic format, as mentioned in the introduction. It has been established that the mass media has a profound influence on identity through its uses and manipulations of popular culture. Lule (2012) states:

Historically, popular culture has been closely associated with mass media that introduce and encourage the adoption of certain trends. We can see these media as "tastemakers"- people or institutions that shape the way others think, eat, listen, drink, dress and more. (...)Along with encouraging a mass audience to keep an eye out for (or skip) certain movies, television shows, video games, books, or fashion trends, tastemaking is also used to create demand for new products. Companies often turn to advertising firms to help create a public hunger for an object that may have not even existed six months previously. (paras. $6 \& 7$ ) 
Lule hints at the connection between capitalism and identity and Hoechsmann (2010) directly classifies consumption as a mode of identity performance, stating that:

[p]articularly in Northern nations, but increasingly on a global scale, consumption has become an important determinant of our social selves, a primary site of self- and group- identity. Consumption is not simply an act of compliance but is rather a complex mediation of self- and group- identity with everyday needs and desires. (p. 24)

If, as Hoechsmann contends, consumption is an important way that people perform their identities, then what happens when the self is the object being consumed? Facebook relies on people marketing themselves and it successfully taps into their wants and desires to be noticed and to belong; as noted in studies by Nadkarni and Hofmann (2012) and Mehdizadeh (2010). Hence, with the constant tinkering of a profile on Facebook, a person is inadvertently utilizing his or her identity to connect with others while Facebook uses their information for business purposes. Facebook's use of a user's personal information is the first layer of consumption. This differs from offline consumption for purposes of identity performance because it "transforms individuals into instruments of capital" (Grosser, 2011, p. 2) making them both producers and consumers. I feel this is different than Jenkins' (2006) conceptualization of participatory culture, where individuals are termed "prosumers" in the Web 2.0 atmosphere of first consuming published media then remixing and joining together other media to create something 'new', because what is being "prosumed" is the individual's self. However, is that all that is going on? There are other layers of consumption occurring simultaneously on Facebook. People "consume" other people's profiles for cues on how to perform identity, they consume advertising on their home page, and they consume social and political causes, news, and popular culture being promoted through Facebook. Not all of this consumption is negative; some consumption, such as social surveillance, may involve looking at other people's profiles simply to catch up on what has been going on in other people's lives. However, the socio-cultural implications of Facebook identity performance and socialization needs to be explored since people are becoming ever more immersed in SNSs. According to Internet World Stats (2014), in 2012 there were 937,407,180 Facebook subscribers worldwide and these numbers keep increasing.

Not only am I interested in the impact Facebook is having on individual identity performance, but I am also interested in how it is affecting relationships with others. It is my relationship with my mother that has led me to a deeper questioning about how a SNS impacts people's connections with each other. She, too, is now online and a member of the same SNS, Facebook, and I feel my relationship with her is shifting because of this. When she first joined I had a moment of panic wondering what she would think of me based on her interpretations of the pictures I have posted and the comments I have made on Facebook. By giving her access to another side of me, I was uncertain about how this might change our relationship. I was worried about her criticism and about her seeing me differently. After all, I have come to see 
her in a different light. When she posts status updates I sometimes wonder if this is the same woman that I talk to in person. I am seeing a different side of my mother and I cannot help but speculate how it is changing our interactions and relationship with each other. There have been both positive and negative experiences as a result of our Facebook friendship. I get more frequent updates from her and it has made her seem closer since she moved to Northern Finland from the Montreal area. Yet, when I post a picture and get numerous "likes" but none from my mother, it makes me angry. I see her "liking" other people's photos, so I wonder why not mine? We have a fairly open relationship so when I have asked about this she claims that she does not want to seem like she is boasting about her child online. This has left me wondering why I care so much and what happens to people who do not talk to each other about these and similar issues that arise from Facebook use. I have had other negative feelings arising from my Facebook use such as feelings of jealousy, annoyance, and loneliness and I wonder if my friends are having the same experiences and how it might be affecting our relationships. These questions are the impetus of this book.

With the changes I have experienced in my relationships with my mother and other people on Facebook, I have become wary of the influence a social network site is having on my subjectivity and my life. I question how virtual relationships shape and reflect "real" ones and whether or not this distinction is still helpful in the contemporary moment in which online and offline worlds seem to coexist seamlessly. Baudrillard's (1993, 1995, 1996) definition of the "hyperreal" argues that any technology that distances people from face-to-face communication reduces a person's efforts, and diminishes meaning; it results in a hyperreal form of communication because it is a simulation of authentic communication. He argues that most people are not aware of the hyperreal nature of this type of communication and its impacts on relationships. It propels people to over consume in a search for meaning because they are unaware that the source of their discontentment stems from hyperreal, meaningless, or inauthentic communication. Drawing on Baudrillard, I question whether the discontentment I have experienced in my relationship with my mother is because communication through Facebook disrupts or distorts authentic communication because of its hyperreal nature.

\section{LIVING IN HYPERREAL CONNECTIONS}

Capitalism's impact on community structure, in its promotion of the individual over group, has meant changes to our offline world. This has propelled people to seek community online through SNSs like Facebook because offline exchanges and spaces of community are lacking (Agger, 2004; Turkle, 2011). Facebook use is on the rise. A Pew study reports that for those aged 18 to 29, nine percent were on a social network site on 2005 and this rose to 83\% in 2012 (Grimes \& Fields, 2012). The same study shows that usage increases with age. I am 39 and the average age of my Facebook friends is 35 . Of my close circle of friends, there are only a few who are not on Facebook. Many of us are perpetually there. I know this from the 
constant updates I get from some of my friends. I know this from how often I check for updates and notifications because my smart phone has made me more of an addict. Am I there because something is lacking offline? Am I creating a stronger community for myself by being on Facebook?

Much of the research on Internet networking in general focuses on teens (boyd, 2008; Gee, 2007; Stern, 2008), and research specifically exploring Facebook centres on young adults in universities (Back et al., 2010; Ellison et al., 2007; Grimes \& Fields, 2012; Ito et al., 2009; Joinson, 2008; Zhao, Grasmuck, \& Martin, 2008). Only recently has the literature turned to the positive and negative implications of SNS usage for people of all ages.

As much as people love the hyperreal (Eco, 1986; Turkle, 2011), they also feel that they are losing something (Boon \& Sinclair, 2009; Larose, Kim, \& Peng, 2011). Marche (2012) documents the rising condition of loneliness in North America and links it "to numerous interconnected trends in American life: suburban sprawl, television's dominance over culture, the self-absorption of the Baby Boomers, the disintegration of the traditional family" (para. 16). He questions if Facebook alleviates or aggravates the situation and states:

Yet within this world of instant and absolute communication, unbounded by limits of time or space, we suffer from unprecedented alienation. We have never been more detached from one another, or lonelier. In a world consumed by ever more novel modes of socializing, we have less and less actual society. We live in an accelerating contradiction: the more connected we become, the lonelier we are. We were promised a global village; instead we inhabit the drab cul-de-sacs and endless freeways of a vast suburb of information. (para. 3)

While isolation and loneliness may be some of the ill effects of Facebook use, ironically, so too are feeling more connected and becoming more politically active (Kavador, 2012; Marichal, 2013). I admit to never having been a part of so many social causes nor having been so highly informed about human rights issues, the environment, health, or being able to support friends in times of crisis that I would never have known about. There is potential to harness Facebook as a social media and communication device for greater good. Evidence of this has been seen with the Occupy movement which began in Tunisia in December, 2010 (\#OccupyTogether, n.d.). The Occupy movement deals with issues related to corporate profits, student debt, wrongful foreclosures, healthcare, and wages. Its success has been largely due to social media awareness. I am personally a great fan of avaaz.org which spreads information about social and environmental causes and gathers signatures for petitions. I often share the latest cause on Facebook, hoping to generate more support.

\section{WHO ARE WE ANYWAY?}

Capitalist production and consumption have been guaranteed by linking commodity consumption to the defining of one's self(Sandlin \& McLaren, 2010; Morrow \& Torres, 
1995). This link is rooted in a history of object fetishization where commodities have been promoted as representing idealized realities and with the promise of happiness or meaning for those buying them (Benjamin, 1982/1999; Eco, 1986). For example, a particular table set may represent a particular aspect of your identity. Eco contends that this has resulted in a preference for the hyperreal or simulations because they are momentarily "perfect" representations; however, due to the momentary or transitory nature of the happiness or perfection found in the simulation, people tend to overconsume commodities in a search for meaning. I contend that the ultimate form of commodity fetishization is the simulated self; a social network site like Facebook allows users to consume their identity through cyber identity performance, which may result in self-fetishization and overconsumption.

I deliberate on how much of my own cyber identity performance on Facebook might be the result of dominant discourses based on a broader ideology of consumption and further motivated by a love of the hyperreal. I think about who I am, how I perform my identity, and how much agency I have in choosing who I want to be. In this section, I briefly introduce some key concepts tied to the topic of online identities, which I elaborate upon in Chapter 3. I start with the term identity before moving onto cyber identity performance and agency. Even though the research presented in this book is focused on cyber identity performance, the scholarship into cyber identity performance reveals a need to investigate what is meant by identity performance more generally. This also demands an examination of age categories as social constructs, largely influenced by consumerism today, that impact the way people view and perform identity (Buckingham, 2000, 2008; Kincheloe \& Steinberg, 2004).

Cyber identity performance, especially on an online social network site, is a new area of research. It is, therefore, necessary to explore how offline theorizing about the effects of dominant discourses on identity performance can apply to cyberspace, and where it is lacking. It might be that the effects of dominant discourses become more exacerbated in the hyperreal nature of cyberspace because hyperreality has the tendency to confuse people over what is real or authentic and this confusion may make consumption in this space subject to less critical analysis. The research in this book investigates if cyber identity performance on Facebook is (in) authentic or meaningful for identity performance and relationships with others, and if and how much of it reflects dominant discourses related to identity and consumerism.

\section{Identity}

Employing a cultural studies lens, identity, or the psyche, cannot be separated from the socio-political realm (Steinberg, 2010). I consider how socio-cultural discourses on age-related categories impact discourses on identity (Buckingham, 2008; Jenkins, 1998). It is no longer feasible to talk about identity performance solely in traditional terms where a person's identity is formed against or for a physical group of people or person, since the group in our current society now also includes the market and the 
media. For the purpose of this study, I relate the age-related category of adultescent (Barber, 2007; Crawford, 2012) to the current phenomenon of those in their 30s using Facebook, wondering if my peer group and I are victims of the discourse related to it. Most literature focuses on how the age-related categories of child and teen impact their related identity discourse and identity performances; however, there has been less attention paid to the construct of "adult" and its impact on identity performance by members of the Cusp Generation.

\section{Identity as Performance}

I use the term identity performance to describe a form of storytelling which is always directed at an "other", can be constantly reconceptualised, has multiple facets, and is affected by the larger culture. It is a human psychic function arising from social necessity, desire, and cultural codes in an ever-shifting environment. I come to this definition by drawing on three conceptualizations of identity. The first is from Butler (2001) who, drawing on psychoanalysis, states:

Let us remember that one gives an account of oneself to another, and that every accounting takes place in the context of an address. I give an account of myself to you. Further, the context of address, what we might call the rhetorical context for responsibility, means that I am engaging not only in a reflexive activity, thinking about and reconstructing myself, but also in speaking to you and thus instituting a relation in language as I go. (p. 31)

In this sense, performing one's identity is the telling of one's identity for and to an "other." For Taylor and Spencer (2004), people have multiple social selves and identity is both personal and collective because it is "a negotiated space between ourselves and others; constantly being re-appraised and very much linked to the circulation of cultural meanings in a society. Furthermore identity is intensely political. There are constant efforts to escape, fix or perpetuate images and meanings of others" (p. 4). Lastly, for Thomas (2007) identity is about the body and how it represents gender, age, race and ethnicity, emotions, relationships, and the appropriation of cultural symbols of belonging.

\section{Cyber Identity Performance}

The concept of identity performance becomes augmented and more problematic in cyberspace. As I stated earlier, I contend that cyberspace is more hyperreal than our offline world and this makes identity even more about staging or performance. This claim is argued in much of the current literature on online identities and avatars (Morrison, 2010; Turkle, 2011; van Dijck, 2013). The "other" that people perform their identity for or against can be conceived as a hyperreal "other" in cyber space. This hyperreal "other" may come to seem "more real" or more desirable with potential socio-cultural implications. As Turkle (2011) states: 
we expect more from technology and less from each other. (...) Overwhelmed, we have been drawn to connections that seem low risk and always at hand: Facebook friends, avatars, IRC chat partners. If convenience and control continue to be our priorities, we shall be tempted by sociable robots, where, like gamblers at their slot machines, we are promised excitement programmed in, just enough to keep us in the game. At the robotic moment, we have to be concerned that the simplification and reduction of relationship is no longer something we complain about. It may become what we expect, even desire. (p. 250)

It is important to note that I do not argue that our cyber identities are "unreal". I am concerned that people may be fetishizing themselves through cyber identity performance, shaped by capitalist discourses and a love of the hyperreal. I also wonder what the ramifications of this might be for the individual.

\section{WHAT IS AGENCY IN IDENTITY PERFORMANCE?}

Within offline identity performance and cyber identity performance, the notion of agency is contested (boyd, 2008; Kincheloe \& Steinberg, 2004). The literature on identity performance shows many scholars speculating on whether or not one's habitus, the internalized codes of practice people pick up from their surroundings (Bourdieu, 1986), or the dominant culture, leave people with any personal power to choose whom they will become (Boon \& Sinclair, 2009; Nadkarni \& Hofmann, 2012). Definitions of agency are varied. I am interested in agency in identity as a kind of critical awareness of how dominant discourses, such as those related to gender and consumerism, impact identity performance. This awareness could lead to more power in deciding how one performs their social and political identities. As noted above, Baudrillard's and Eco's conceptualizations of hyperreality also reveal the necessity of exposing hyperreality's connection to economy and power. The creation of the hyperreal sees its roots in capitalist production (Benjamin, 1982/1999), and capitalist production relies on an ideology of consumption that links group and individual identity to commodity consumption (Fiske, 2010; Hoechsmann, 2010). With a better understanding of the relationship between knowledge, power, and the economy, people can become aware of the forces that could be constraining their agency (Steinberg, 2010). I contend that control over one's cyber identity performance means to have some agency over dominant discourses by, at the very least, being aware of them and hopefully not merely internalizing them. Freire (Freire \& Shor, 2003) would term this as critical conscientization or the means to take control and have agency in one's life.

Although many of the theories I draw on predate the phenomenon of social media and social networking sites, I deliberately consider them from a new perspective. This is especially true with regards to the hyperreality of cyberspace, given Baudrillard's assertion that anything removed from face-to-face contact results in the destruction of human relations. I contend that this too may impact the agency 
in the identity performance occurring there if a person is unaware of how the hyperreality of cyberspace might be impacting communication and relationships, while also encouraging the fetishization of the self. It is possible that people become so engrossed in the hyperreal, as Eco claims, that a lack of meaningful connections becomes normalized in the addictive overconsumption of one's self or fetishization of one's cyber identity. Anecdotally, I see evidence of this with individuals' postings on Facebook with constant profile picture updates and self-absorbed status updates about things like how they are feeling with no contextualization to seemingly just generate attention. Postings like these do not appear to be about creating meaningful connections but are more about a constant emoting about one's cyber self. It is these types of occurrences that I find myself being subjected to more and more on Facebook and I often find myself eliminating people from my newsfeed. When this happens, I am left wondering what function Facebook serves.

From the perspective of the hyperreal, cyber identity performance is problematic as it is further removed from the physical world. My conceptualization of agency in identity makes this research investigation into Facebook use all the more imperative, because as I find my friends and I spending more and more time on it, I question if we have agency in our cyber identity performances, if we are fetishizing ourselves, and if the relationships we nurture there are meaningful.

\section{RESEARCH AIMS}

It is difficult to keep current research up to pace with cultural practices, particularly when these involve technology. The intent of this book is to explore the sociocultural implications of cyber identity performance on Facebook for those born in the Cusp Generation. It is critical to see whether Facebook use promotes positive socio-cultural outcomes or more negative ones, including those that simply benefit capitalist forces. In order to determine what the socio-cultural implications may be for this generation, I deliberate over the following:

1. How do those born in the Cusp Generation, who are part digital native, perform cyber identity on the social network site Facebook? This question allows me to explore links between age categorizations and dominant discourses.

a. How does a surveillance culture play into considerations of identity representation? I consider whether homogenous cyber identity performances stem from internalized codes of behaviour or from structural impositions of Facebook and what this says about agency.

b. How does my peer group communicate on Facebook and how does this compare to a younger demographic? This question links identity and consumer discourse to age categorizations.

c. In what ways does gender contribute to cyber identity performance on Facebook and what does it add to theories on identity discourse? I consider shifts in gender discourse and how they relate to consumer discourse. 
2. What do theoretical considerations of hyperreality and agency contribute to an understanding of the socio-cultural implications of Facebook? This question allows me to consider whether or not my study participants and I experienced authentic relationships, meaningful exchanges of communication, and had agency in our cyber identity performances.

\section{MY FACEBOOK STUDY}

The study presented in this book on Facebook works to illuminate the negative effects of Facebook and to better understand why they are there, and it considers how to make the most of its positive effects. It is important to make clear that I am not advocating for people to give up their Facebook use due to negative experiences or possible constrictions on agency; I am simply bringing attention to these issues. As Weber and Mitchell (2008) state: "As technologies become more deeply integrated into ever-widening areas of our lives, their roles as mediators of identities and learning are likely to be taken for granted, perhaps becoming almost invisible" (p. 44). It is important to make visible the role and effects of Facebook in people's lives and technology use in the moment.

In this study, I worked to ascertain whether or not the negative and positive claims being made in the current literature and research are also relevant to the Facebook use of my demographic. The study involved three elements: a Facebook Profile Analysis (FPA), a survey (Appendix A), and an analysis of eight days of advertising on my own Facebook profile (Appendix C). I recruited participants by e-mail through Facebook. To maintain anonymity, I sent out 150 individual invitations to participate in the survey and FPA. In the end, I analysed 99 Facebook Profiles and received 18 surveys from people aged 20 to 68 , averaging 37 and 39 respectively. I also questioned seven people about why they had liked a specific corporation when it came up on my newsfeed. My intention was to see how people perform their cyber identities, how advertising impacts my own subjectivity, and the purpose of liking corporate brands.

I compiled statistics on the various production modalities that cyber identity is performed through on Facebook. These include, but are not limited to, the profile picture, status updates, and photo albums. I assessed the results (Chapter 5) before looking at the survey data. I analysed the survey results through a coding frame to "detect common patterns or tendencies" (Hoechsmann \& Poyntz, 2012, p. 79). This gave me an idea of how people are reading themselves and others. The Facebook Profile Analysis (FPA) and survey results are presented in Tables 1, 2, 3, and 4. I then compared the FPA and survey results to see how an audience reading (survey) compares with a textual analysis of production (FPA). I did this to have a more authentic understanding of cyber identity performance. These results were then analysed through Johnson's four-point model which analyses media sites through the points of production, text, readings, and cultural life. I discuss this further below. This model also considers previous literature and research and theories rooted in cyber identity performance from a cultural studies perspective. 
Through-out, I also draw upon my own experiences as a Facebook user, given that these were a part of the impetus for the study, and that I am a member of the Cusp Generation demographic in question. While this is not an autoethnography per say, my own informal observations of my Facebook use, and that of my "friends", complement the more formal study. In addition, I draw on my own experiences with Facebook more formally through an eight day analysis of advertising on my Facebook homepage.

\section{METHOD AND THEORY}

I approach the socio-cultural implications of Facebook use for those born in the Cusp Generation and the analysis of my Facebook study from a cultural studies perspective; it provides both the method and the theory for its analysis. It is somewhat like bricolage, a method which draws on multiple perspectives, theories, and disciplines to ensure complexity and rigour in research and that concerns itself with revealing how power functions (Kincheloe \& Berry, 2004). Cultural studies, like bricolage, highlights context (Grossberg, 2009) to enable deeper insights into the workings of various power structures. I contextualize Facebook use by analysing my peer group in order to explore how dominant discourses related to identity and consumerism might be impacting cyber identity performances, relationships, subjectivity and agency, and our society and culture.

The method I employ to analyse my Facebook study is Richard Johnson's fourpoint model for analysing a media site (Hoechsmann \& Poyntz, 2012; Johnson, 1986-1987). This model looks at how cultural products link to codes of behaviour and performance from four different angles: the text of the media site and how it influences production and readings; production in the media site and the various factors that might be influencing how people produce cultural forms; readings of the media site or the factors that influence how people read the text or each other; and cultural life or how our socio-cultural reality both influences and is influenced by cultural products. These four points simultaneously impact and feed into each other but allow for momentary considerations of various factors influencing a cultural form.

The theories I draw on within these four points to analyse my study results are derived from a cultural studies perspective. As discussed earlier, they include considerations of avatar attachment theory, the conceptualization of the adultescent, considerations of agency, and the notion of hyperreality. The last three all take into account the impacts of identity and consumer discourse.

I also approached the Facebook profile data collection from a textual approach of content analysis based on Johnson's four-point model. This is because in order to understand how and why cyber identity performances are produced on Facebook I had to first look at the end product - the text. 


\section{RESEARCH IMPLICATIONS}

Since most studies and theories on social networking concern themselves with teenagers and young adults born after the Cusp Generation and look at types and functions of its use from a social capital and psychological ramifications perspective, it makes this study on my peer group (late 30's) significant. Turkle (2011) cites that the adult aged between 35 and 44 is the fastest growing demographic on Facebook. I find this curious since Facebook use is most often associated with identity exploration (Thomas, 2007; Turkle, 1995) - a characteristic connected to being a teenager or young adult. So I question what my friends and I are doing on Facebookare we reliving our teenage years or is something else going on?

The impacts of commodification on cyber identity performance on Facebook are also in need of more research. As much as there is literature citing how Facebook exploits individuals through retargeted advertising, there is a lack of scholarship on the socio-cultural implications of this exploitation and how it could be thwarted. I am concerned with the lack of scholarship, and as much as I have been submersed in critical media literacy, I have not thought to question my own Facebook use from this angle. I question whether I have fallen victim to dominant discourses related to identity and consumerism, if I am fetishizing myself, and how my agency is being impacted.

This book works to fill a void and start an academic conversation about the effects of identity and consumer discourse on cyber identity performance on Facebook, and also theorizes about my peer group's immersion in it. I look at the link between our social and economic reality and how it impacts cultural production on Facebook as I question whether or not agency is possible within such a commodified space. I also question whether an over-proliferation of social justice issues leads to apathy (Baudrillard, 1996; Marichal, 2013) and compromises peoples' agency.

Although the study presented in this book focuses on the Cusp Generation, adults in their 30's, it is relevant to adult education as well as education more generally in that this group of people are, after all, parents and the predominant group of educators today. They should be aware of how their subjectivities are being impacted by highly commodified, hyperreal, cyberspaces in order to have a better understanding of how children, teens, and young adults are being impacted. This study can also inform the pedagogies and practices of those teaching in secondary and post secondary institutions in its consideration of using Facebook to teach critical media literacy (Chapter 7), including how to critique the structure of Facebook and how to have more agency in one's cyber identity performance. I draw on Hoechsmann and Poyntz's (2012) considerations of what is missing in current critical media literacy. Through an examination of the history of media education, they show that earlier models need to be merged with more recent models and that: 
media literacy must always involve an analysis of media texts and dominant and powerful institutions, in conjunction with opportunities for creative media production that speaks to and builds from the challenges, dreams, and visions that are a part of young people's lives. (p. 13)

I show that critical media literacy involving Facebook is important for people of all ages as more and more people of different ages perform their identities on SNSs like Facebook. As a component of critical media literacy, I also explore how Facebook can be harnessed for socio-political purposes by drawing from Davis III et al. (2012), Kavador (2012), Marichal (2013), and Turkle (1995).

This research also adds to scholarly discussions in cultural studies in its reconsideration of the concept of adult by questioning how and why adults, like me, use SNSs such as Facebook. I draw on theories related to cyber identity performance to explore these questions such as avatar attachment theory (Delwiche, 2007), the concept of adultescent, agency (Foucault, 1982; Kincheloe \& Steinberg, 2004), and hyperreality (Baudrillard, 1993, 1995, 1996; Benjamin, 1982/1999; Eco 1976, 1986).

\section{BOOK OVERVIEW}

Chapter 2 reviews the literature on Facebook. I summarize the literature on teen SNS use in general, and young adult, university students' Facebook use specifically, and claims being made about the positive and negative effects associated with Facebook use. In Chapter 3, I discuss the theories I employ to discuss cyber identity performance and analyse my study results, which are rooted in identity theory. These include avatar attachment theory, the notion of adultescent, the conceptualization of agency, and the idea of self-fetishization derived from considerations of hyperreality. This generates a framework of analysis for my study. Chapter 4 examines my methodology and is split into two parts. The first part describes my Facebook study: its rationale, my autobiography, description of participants, how the data was collected, and how the data was analyzed. The second part elaborates on Johnson's four-point model for inquiry into a media site, describing each point and how I applied it to my study's results. Chapter 5 relates the results of my Facebook profile analysis, survey, eight days of advertising screen shot results, and respondent's reasons for likes showing up my newsfeed. Many of these results are depicted in tables that are then broken down into points of analysis. Chapter 6 interprets the results of Chapter 5 through Johnson's four-point model for inquiry into a cultural text. It considers current literature and research and applies Chapter 3's theoretical framework. Finally, Chapter 7 reflects on the study's findings one last time. I consider its limitations, future research directions, theoretical implications, and educational applications. 


\title{
WHY PEOPLE USE FACEBOOK
}

\author{
The Pros and Cons Associated with Its Use
}

These days, whether you are online or not, it is easy for people to end up unsure if they are closer together or further apart.

(Turkle, 2011, p. 14)

This chapter explores the literatures on the uses and effects of Facebook, and of social networking sites (SNSs) more generally. It is divided into two sections. In the first section, I discuss the literature on online identity and what teens are doing on SNSs. Two of the studies I discuss in this section include some findings on Facebook though they target the new media ecology (Ito et al., 2009) and sites with an underlying socialness (Grimes \& Fields, 2012) in general. One study also includes children as young as five (Grimes \& Fields, 2012), while two others discuss their research age demographic as involving younger youth. One study defines youth as the late teenaged years and also includes young adults up to age 30 (Ito et al., 2009) and the other discusses youth to age 21 (Stern, 2008). Therefore, there is some overlap in their findings for the category of young adult even though the majority of these studies focus on teens. This is followed by a discussion of Facebook use specifically through the examination of three studies that were conducted on Facebook involving young adults in university. I then summarize key findings on teen SNS use and young adults on Facebook, and discuss current trends in Facebook use. This section demonstrates the lack of scholarship on older adults. It also has me ask, how and why is the Cusp Generation on Facebook?

In the second section, I examine the literature on the positive and negative claims associated with Facebook use for all ages. I divide these claims into three types: those that impact individuals (both psychologically and personally), those that impact communities, and those that have larger socio-cultural effects. Lastly, I examine literature that discusses the possible reasons for the negative effects of Facebook. There are two dominant ways of explaining the causes of them: the structure of Facebook and people's psychological predispositions. I examine these later in relation to my study findings in Chapter 6. Lastly, I discuss the direction of my study in relation to this research background. 


\section{ONLINE IDENTITY: TEENS}

A part of the reason I decided to explore the socio-cultural implications of Facebook use for my peer group (those in their 30s) was because the literature on online identity in general had very little to say about this age demographic. Instead, most studies focus on the online lives of teens and young adults. We know that teens are very active users of communication technologies, including:

new communication forms such as instant messaging, e-mail, and text messaging, as well as communication-oriented Internet sites such as blogs, social networking, photo and video sharing sites such as YouTube, interactive video games, and virtual reality environments, such as Second Life. (Subrahmanyam \& Greenfield, 2008, p. 120)

However, what are they doing in these online spaces, and why are they there?

The literature suggests that teens are using the web as a space of identity exploration. Stern (2008) states younger people create personal web pages two times more than adults and most youth start their personal web pages out of curiosity or a feeling of a necessity because they see older youth doing it. More particularly, they create home pages on social networking sites (SNS) and in 2007 visits to SNSs surpassed all other categories of teen online activity (Tancer, 2008). Stern draws from a "growing body of literature exploring adolescent development, youth expression practices, and online publishing, but, centrally, from the interviews I have conducted over the past several years with hundreds of authors ranging in age from twelve to twenty-one years" (p. 96). Her study found that even though youth agency online may be romanticized, it does allow them some freedom to explore themselves. One interviewee stated it helped her lay out her values and beliefs. She found that most of her interviewees rejected the idea that their personal home pages reflect identity 'experimentation' because they are reflections of their actual selves; and for some their online presence felt more real than their offline self. Yet, there was a lot of contradiction in her findings as many also viewed themselves "as incomplete and evolving" (Stern, 2008, p. 112).

SNSs are a venue for teens to monitor their self-growth and to reflect on who they are and who they are becoming. One girl in Stern's (2008) study explains “my blog keeps tabs on me" (p. 103). The personal web page provides a place to deal with identity issues. It also provides a space to speak about matters that are considered taboo in the dominant culture such as homosexuality, depression, and violence. This allows for freedom of identity exploration.

Grimes and Fields (2012) also found SNSs can help encourage forms of social and identity development. "Kids" were using them to build and maintain their interpersonal relationships resulting in identity construction and informal learning.

As much as teens are avid users of technology, some feel technology-based relationships also create stress. A ten country study conducted between 2001 and 2005 by Katz and Aakhus entitled Perpetual Contact shows that mobile usage 
is filled with paradox (Stald, 2008). A mobile phone, and these days, especially, smart phones, enable constant contact. On the one hand, constant contact is seen as necessary by teens for maintaining useful relationships. On the other hand, it is seen as stressful and teens feel that they need face to face contact. The paradoxes attributed to technology use are examined further in Chapter 6. Brenner's (2013) Pew report shows that adults are also connecting through mobile phones with $40 \%$ accessing a SNS through their phone and 28\% logging in daily. The statistics are higher with younger adults aged 18 to 29 at $67 \%$, but $50 \%$ of adults aged 30 to 49 also access SNSs through their mobile phone. They also rise with Black and Hispanic ethnic groups and higher annual incomes. Pew studies conducted in 2013 show that access to smart phones and tablets are increasing along with increased access and frequency to SNSs like Facebook, making SNSs more pervasive in people's lives (Device ownership, 2014; Social Networking Factsheet, 2014). Even though my study does not engage in smartphone and tablet web-enabled culture specifically, it is an important reminder of how connected people have become and the importance of understanding its socio-cultural implications.

Today's teens socialize and "hang-out" on SNSs. Ito et al. (2009) looked at the media practices of a diverse population of teens and young adults aged 13 to 30 around the U.S. through a three-year ethnographic study conducted between 2005 and 2008. They wanted to discern "young people's participation in the new media ecology" (p. xiii) and how social interactions and learning were being affected by it. They term SNS usage as being:

friendship driven learning (...), a familiar genre of peer-based learning, in which online networks are supporting those painful but important lessons in growing up, giving youth an environment to explore romance, friendship, and status just as their predecessors did. (Ito et al., 2009, p. 24)

Similar to Stald's (2008) findings, Ito et al. (2009) also found that mobile connections played a big role in their social lives. Teen and young adult media practices included hanging out online with friends or even being offline with friends while being connected through a mobile phone to others.

Today's teens also develop social norms through the context of public participation in a SNS like Facebook; it is a form of peer-based learning. Youth culture is described as being connected to a networked public. Ito et al. (2009) contend that media engagement is not just about an audience consuming something but rather "the term networked publics foregrounds the active participation of a distributed social network in the production and circulation of culture and knowledge" (p. 23). The production and circulation of knowledge seems to be only social in nature in this report with youth looking at each other's profiles for cues on what to imitate and what to avoid. Ito et al. refer to this as being "hypersocial", signifying that media content has become essential in teens' everyday communications and identity practices. Participation in SNSs has also become a way to display media-related symbols that are used to articulate identity. 
SNSs are also used for forming relationships and maintaining romantic relationships. Flirting was identified as one of the key reasons young males were joining SNSs (Subrahmanyam \& Greenfield, 2008). Flirting and dating through a SNS is very common and has resulted in "the construction of deliberately casual forms of online written communication, and the negotiation of norms of how to display friendships and romantic relationships online" (Ito et al., 2009, p. 30). This allows people to protect themselves if feelings are not reciprocated. The public nature of some types of communication, like posting on people's walls, lends to the casualness of the communication. They also use the SNS to find out more information about the person they are interested in. Becoming "Facebook official" (Ito et al., 2009 , p. 35), or changing one's relationship status and indicating the person's name is another function of SNSs. When a relationship ends a "digital housecleaning" (Ito et al., 2009, p. 35) occurs, where relationship statuses are changed, pictures are deleted, and perhaps even friends of friends. The function of flirting and dating is even more important for GLBT (Gay, Lesbian, Bisexual, and Transgendered) because a SNS site like Facebook allows for flirting and dating in a safer or more accepting environment.

SNSs allow teens to build friendships and a support network (Ito et al., 2009). Their friends list includes close acquaintances and a "broader peer group" (Ito et al., 2009, p. 31). The study found that teens tend to only directly communicate with close friends and romantic partners and that communication with the broader peer group was more passive. With some users, communication was so constant that the term "tele-cooning" was applied to them. It describes a deeper form of contact in a "full-time intimate community" (Ito et al., 2009, p. 32).

Using Facebook was reported to help with children and youth with low selfesteem and help migrant children feel connected to old offline ties while establishing new ones. Grimes and Fields (2012) investigated children and teens aged five to 18 and their socializing on online sites with an "underlying social-ness to them" (p. 3) including Facebook. They found that "kids" who are not a part of the "in" crowd offline can be in the loop of gossip online, making them feel less excluded. Even though these types of friendships were deemed "weak ties", they were considered important for making kids feel more "in the know". For some children and teens it allowed for continued contact with friends after having migrated elsewhere. They found that SNSs helped migrant children and teens maintain ties with old friends while establishing a new social network. The same was reported by Ito et al. though the context was online gaming.

SNSs also allow teens to escape from the high regulation and the surveillance of public spaces (boyd, 2008). Public spaces were once much freer but things changed between the 1920s and 1950s as a result of shifting age categories and their associated discourses (Giroux, 2001; Kincheloe \& Steinberg, 2004). Children and teens were segregated from adults, and the former were socialized into a non-adult society while the latter were vilified as delinquent. Their days became highly structured by school and home, and they were deemed in need of control. This has left children and teens 
today with limited freedom and spaces for identity exploration, making the Internet one of the few spaces free from adult regulation.

Another function online identity on SNSs serves for teens is seeing different perspectives. Many claim that there is an important form of agency occurring online through the ability to interact with various people and explore different aspects of one's identity (Gee, 2007; Thomas, 2007). Some scholars feel it enables teens to learn from different cultures. Grimes and Fields (2012) contend that SNSs lend to the development of new perspectives, if the broad peer circle includes people of diverse backgrounds.

While scholars agree that there are many positive functions related to teen online identity on SNSs, there is a possible negative function related to another dimension of life online: celebrity worship culture. The consumption of popular images, particularly of celebrities, may be adding to the appeal of online identity on SNSs as a venue for exploring sexiness (Weber \& Mitchell, 2008) and beauty. Ito et al. noted that males and females use SNSs differently, and though they do not explain the differences, it may be because of gender discourses which I discuss in Chapter 3 . They also concluded that it is important to study if the embedded design choices of Facebook function as forms of regulation.

Statistics on SNS use show that its use has been increasing by percentage, age group, and on Facebook specifically - according to a European Union report and a Pew Study - since it became available to the general public (Grimes \& Fields, 2012). A study by Benenson Strategy Group conducted in 2009 shows that most teens check their SNS daily and more than $51 \%$ check it more frequently. A European Union report published in 2011 on teen Internet usage shows that of the group aged between 13 and $16,77 \%$ are on a SNS, and of them, 46\% said they use Facebook the most. In the following section, I look at studies on Facebook use specifically which center on the young adult years (18 to 30 ) because they are focused on university students.

\section{ONLINE IDENTITY ON FACEBOOK: YOUNG ADULTS}

Research indicates that social networking site (SNS) use has increased with younger adults. A Pew study reports that in $2011,83 \%$ of those aged 18 to 29 who use the internet also use a SNS. This is a very large increase from 2005 when the statistic sat at $9 \%$ (Grimes \& Fields, 2012). Statistics on SNS usage indicate that this is also rising with my peer group (Brenner, 2013) and even though the teens of those mid 2000s studies are adults by now, there are even older adults, who did not have SNSs in their teenage years that are now active on SNSs. It has me question what is behind this phenomenon.

It is no coincidence that research looking at Facebook use specifically involves young adults in university students since Facebook was initially developed for them (Facebook, 2013). Some of their findings extend the idea of identity experimentation/exploration past the teenaged years and I come to consider if it is 
also being extended into the Cusp Generation. There are three studies that I draw from to discuss information related to this age group on Facebook. In the following section, I summarize the findings of these studies and I discuss the gaps in their research that drive my study on my peer group.

The first study found that Facebook provides social and emotional support to its users. Joinson (2008) conducted a two-part study in July, 2007 to examine the relationship between offline social capital and Facebook. The first part involved Facebook users with a mean age of 26.3, and included 53 males and 88 females in July, 2007 and was termed an "exploratory stage" (p. 1028) to determine a general feel for what people like about Facebook and find most valuable about their experiences with it. The second part involved 241 Facebook users with a mean age of 25.97, and included 80 males and 161 females. Participants were asked to rate "46 uses and gratifications derived from Study 1" using a seven-point Likert scale. In this study it appears that Facebook functions as a community and can be used as an information resource and for connecting to others.

Joinson's research found that seven unique uses and gratifications dominated the spectrum of Facebook use: social connection, shared identities, content, social investigation, social network surfing, and status updating. In his first study, Joinson found that keeping in touch with people who are far away was one of the main uses of Facebook followed by social surveillance, or passive people-watching, reacquiring lost contacts, and communicating with offline friends through pokes, private messages, and wall writing. These findings also support findings by Ito et al. and Grimes and Fields that demonstrate the importance of peer-driven learning and identity development, and the maintenance of social capital. Joinson's (2008) second study found that $38.8 \% \log$ on daily and $27.5 \% \log$ on more than once a day. It also revealed that those who rank social investigation as a primary motivation for use would login frequently and those who ranked content gratification highly would spend more time on Facebook.

The primary purpose of being on Facebook was found to be social connectedness by Zhao et al. (2008), with making new friends and dating being cited as the top motivator at $41.3 \%$. They did a content analysis of 63 Facebook accounts of university students in a North Eastern U.S. city. This study delves deeper into online identity presentation than the other two studies in this section and their survey was designed to see how identity is constructed in an online environment "where relationships are anchored in offline communities" (p. 1820). What differs in this study is the focus on discerning how Facebook identity is enacted specifically.

Group and consumer identity was emphasized more than a personally narrated identity in Zhao et al.'s study. Users were more about "show" rather than "tell," meaning that posting pictures was more important than a personally narrated identity. The self that was being depicted was a "socially desirable" self so that even though some had overtly posed profile pictures and others had rougher shots, all 
were an attempt to seem socially desirable. Group identity was emphasized through the self as a "social actor" (p. 1824) and often linked to being socially desirable. For example, being popular was of particular concern (fierce competition about the number of friends was reported) and was connected to group identity and being the best possible self. Group identity emphasis and popularity was evidenced in profile pictures with $38.19 \%$ showing a group photo. It was also substantiated through photo albums; the average number of albums was 4.5 , and most of these depicted fun with friends. Online identity was also depicted through the "about me" blurb and quotes which also showed that being well-rounded and thoughtful were linked to being socially desirable. Consumer identity was exhibited through interests and hobbies. The authors refer to it as "the self of consumption preferences and tastes" (p. 1825).

The third and final study found that Facebook was being used to form and maintain social capital or a strong social network. Ellison et al. (2007) surveyed 286 undergraduates at Michigan State University to examine the relationship between offline social capital and Facebook. They found that the average time spent on Facebook was ten to 30 minutes per day, with an average number of friends ranging from between 150 to 200. Ninety-six percent indicated the high school they had attended. The researchers found this to be an indication of the maintenance of their offline friends, hence, social capital. Facebook was also being used as a resource for information, organizing groups, and accessing a larger circle of people (weak ties) for employment opportunities. They suggest that because Facebook may provide users with social capital through the maintenance of close (strong ties) and distant (weak ties) offline relationships, whether distant by proximity or intimacy, it makes a person's self-presentation all the more important. Increased social capital and the ability to use Facebook for mobilizing people and opportunities leads to psychological well-being, a conclusion also drawn by Grimes and Fields, because it is linked to better health care, lower crime rates, and more efficient financial markets. Because of a widespread decline in social capital, Ellison et al. feel people have become victims of social disorder, lessened participation in civic activities, and a general wariness of other community members. With the building of social capital through Facebook, survey respondents cited increased psychological well-being, improved self-esteem, and more satisfaction in life. This was especially noted through the building of social capital through weak ties that increase a person's social circle.

There were some noted gender differences in these studies. Two studies, Joinson (2008) and Ito et al. (2009), mentioned differences in use between male and female users. Joinson states that females see the social connection aspect and posting of pictures as more important than males. A MANOVA test showed that there were considerable differences between males and females on their scoring of the seven uses and gratifications of Facebook. Females scored social connection and photographs as more important than males and status updating only slightly higher. They also restricted their privacy more than males. 


\section{TEENS AND YOUNG ADULTS: SIMILARITIES AND SOCIO-CULTURAL IMPLICATIONS}

The literature on Facebook use, SNSs, and other media sites with an underlying socialness to them shows that these were being used by teens (primarily) for identity exploration, building friendships and relationships, socializing, developing new perspectives, and social and emotional support. Users are also developing social norms and using these spaces to escape from a highly regulated public space. The studies on young adults in university showed that Facebook was also being for social and emotional support, social connectedness, and building social capital.

There are some similarities and differences between the literature on teens and young adults. Social and emotional support in the university focused studies was not just about connecting to other people; they were also a by-product of Facebook functioning as an information resource and community (Joinson, 2008). Building friendships and relationships were described in these studies in terms of the importance of "social connectedness", which was also described as being the primary motivation of using Facebook (Zhao et al., 2008), whereas the primary motivation for joining Facebook for teens was for identity exploration and development. Yet, there were elements of identity development in the university students' Facebook use. For instance, Zhao et al. found that group and consumer identity were emphasized on Facebook, which is about showing one's self as a socially desirable social actor. This was achieved through looking "nice", popular, and well-rounded through photos, a large circle of friends, posting inspirational quotes, and stating hobbies and interests, which are linked to consumer preferences. To achieve this requires constant identity development or performance. Joinson's (2008) study showed that shared identities, social network surfing, and social investigation were three of seven uses and gratifications associated with Facebook use, and I contend that they function to instill social connectedness and to see how others present their identities which serve as models for identity presentation. The fact that consumer identity is also emphasized (Zhao et al., 2008) is reminiscent of how teens use media symbols for identity articulation (Ito et al., 2009). Lastly, using Facebook to increase social capital through weak and strong ties (Joinson, 2008 ) is similar to Ito et al.'s (2009) finding that "friends" lists included both close acquaintances and a broader peer group. According to Joinson, increased social capital was said to promote psychological well-being, as was also claimed by Grimes and Fields.

Socio-cultural implications were also discussed by some of these studies. They included:

- changes in youth literacy;

- systemic and long-term changes in sociability and culture reconfiguration of communication, self-expression, and play;

- changing definitions of youth culture; 
- transformation in the terms friend and friendship as both enabling and awkward (some felt closer to their friends and others felt online communication was affecting offline relationships negatively);

- networked publics becoming the primary institution of youth culture (Ito et al., 2009);

- the persistence of technology traces causing more consequences and persistence of social life lessons (Ito et al., 2009; Grimes \& Fields, 2012); and

- "an increased awareness of others' actions has potentially important implications for how we relate to others, and understand ourselves" (Joinson, 2008, p. 1035).

This literature review on teen online identity on SNSs in general and young adult, university students on Facebook specifically, points to areas for further research. All age groups are on SNSs and a lot has changed since these studies were conducted. According to Turkle (2011), the fastest growing demographic on Facebook is the adult aged 35 to 44 , yet, not much research has been done on this group, giving validation for my study on the Cusp Generation.

A Pew Internet study from September, 2013 (Brenner, 2013) reports the following statistics: $90 \%$ of 18 to 29 year olds, $78 \%$ of 30 to 49 year olds, $65 \%$ of 50 to 64 year olds, and $46 \%$ over 65 year-olds are on a SNS. Household income, race, and urbanity have little bearing on these figures. Of all the SNSs being used, $71 \%$ spend their time on the SNS Facebook. This same Pew Internet study also shows that $46 \%$ of adults "post original photos or videos online that they themselves created" and $41 \%$ "take photos or videos they found online and repost them" (Brenner, 2013, para. 11). The function it serves for adults is not explored in this study. However, it is an "important arena for politics" (Brenner, 2013, para. 12) for some users. This is also stated by Davis III et al. (2012) who feel that social media technology can been used in post secondary contexts for recruitment and student engagement due to its proven ability to strengthen and reinforce grassroots efforts on a global scale. This is an area in need of more research. In order to further delve into why my peer group might be on Facebook, which may also be applicable to other age groups, I also look at literature that discusses Facebook use in more general terms.

\section{LITERATURE ON SNS/FACEBOOK USE FOR ALL AGES}

In her book Alone Together, Turkle (2011) captures the inherent paradox of technology-based communication in the following quote:

During their Skype conversations, Ellen and her grandmother were more connected than they had ever been before, but at the same time, each was alone. Ellen felt guilty and confused: she knew that her grandmother was happy, even if their intimacy was now, for Ellen, another task among multitasks. I have often observed this distinctive confusion: these days, whether you are online or not, it is easy for people to end up unsure if they are closer together or further apart. (Turkle 2011, p. 14) 
On the one hand technology allows for increased connections at a distance, yet, on the other hand it may lead to feelings of loneliness. There is much literature associating both positive and negative results of SNS/Facebook use for individuals, communities, and for society. I begin by exploring the positive claims.

\section{Positive Claims: Individual Benefits}

I divide the literature on individual benefits claims into personal benefits and psychological benefits. One of the personal benefits associated with SNS is connected to identity presentation in MUDs (multi-user domains) and other socially connected cyber domains - the agency or freedom to explore taboo subjects or different aspects of one's self. Thomas (2007) relates that one of her young participants "spoke much of the power she exercised in online communities, power she did not have access to in offline contexts" (p. 185). This power was in relation to her being able to tinker with different aspects of herself. This is similar to Stern's (2008) finding that youth can project things about themselves on personal web pages that they may be uncomfortable doing offline and findings by Grimes and Fields (2012) who state that social network forums (SNFs) provide a space to explore gender and sexuality. boyd (2008) discusses this teen agency as a freedom from the highly regulated offline world of adults. She maintains that is one of the primary motivations for teens joining SNSs.

Another personal benefit, claimed by Dematteo (2011), is the ability to use Facebook for job searches. He specifically cites the cover photo on a person's profile page as being a place where "the graphically inclined folks will be able to toss in an infographic resume into their cover photo" (para. 8), a portfolio, and include links to online resumes.

The psychological benefits associated with Facebook use for individuals correlate to the community benefits of being connected to others. These were mentioned earlier in my discussion of the studies on Facebook and include social and emotional support (Ellison et al., 2007) and helping with low self-esteem (Grimes \& Fields, 2012). These two benefits arise as a result of a person's social network, increased communication with others, and obtaining access to the lives of more popular people and feeling less excluded.

\section{Positive Claims: Community Benefits}

Increased connectivity on SNSs is said to lead to increased connections with others. This is important because scholars contend that it compensates for fragmented communities offline. Agger (2004) claims that one of the social problems brought out by modernity is estrangement from each other. He questions whether or not "the Internet can replace churches and synagogues as sites of meaning, intimacy and community" (p. 60). Turkle (1995) cites in her research predating Facebook that her research participants were using MUDs (multi-user domains) to "counter 
social fragmentation" (p. 235) and boyd (2008) discusses the popularity of SNSs as a reaction to living "in a time of perceived fragmentation and uncertainty" (p. 161). Whether or not social fragmentation is perceived or real, SNSs are claimed, as mentioned earlier, to build and sustain stronger relationships with each other.

Another positive communal outcome of SNS usage is related to social capital. It is claimed that a person's social capital is increased through the building and sustaining of strong relationships and this ends up having a positive effect on the larger community. Ellison et al. 2007 state:

Social capital broadly refers to the resources accumulated through the relationships among people (Coleman, 1988). (...) Social capital has been linked to a variety of positive outcomes, such as better public health care [and] lower crime rates (...). (p. 1145)

\section{Positive Claims: Socio-Cultural Benefits}

The societal benefits associated with Facebook use are the extension of democracy, increased political and social awareness, and the ability to create change by using Facebook as a platform for generating awareness. Turkle (1995) states: “(...) today many are looking to computers and virtual reality (.) to extend democracy" (p. 244) and Kavador (2012) feels that "social media platforms have the potential to invigorate political participation" (p. 28). This is because social media platforms can make individual voices more visible through the help of particular organizations that help spread messages, such as Avaaz. Avaaz is a transnational organization that relies on an extensive, interconnected web of networks and derives its missions or goals from individual activists who instigate campaigns. Anyone can appeal for a campaign on Avaaz and "ideas for campaigns are tested on 10,000-member random samples and only those that garner strong support are forwarded to the full membership" (p. 52), or followed through on. Once a campaign has been selected, Avaaz spreads the message on various social media platforms and solicits electronic signatures for petitions and funding. All of their funding comes from private individuals and they have had many successful campaigns ranging from environmental to human rights issues (Avaaz, 2014).

Marichal (2013) states: "The growth of social networking sites (SNS), like Facebook, has caused many to rethink how we understand political activism and citizen engagement" (para. 2) because it has been used as a "revolutionary tool" in its ability to mobilize people. He cites such examples as The Iranian Green Revolution and the Arab Spring Revolutions. However, he feels that political activity on Facebook is more about the performance of political identity that helps a person connect to a collective identity. Even if political activism through Facebook is not for the direct purpose of social change, it does not "invalidate their political purpose" (para. 7) and the positive offline effects. Marichal (2013) also maintains that: 
By providing users opportunities to reveal a political position or an opposition to a candidate, SNS sites help encourage the formation of political identities that may force users to reflect more deeply on themselves as civic beings. It allows them to try an activist identity on for size and it allows users to offer themselves as political subjects to interested others. (para. 27)

Lastly, there are potential benefits in using social media technology (SMT) in post secondary contexts for various intentions such as recruitment and enhancing student engagement. Davis III et al. (2012) state:

SMT as a whole shows immense promise to enable connections with people, places, and things through the support of the most fundamental of human behaviors, sharing. When used correctly, SMT provides the opportunity to broadcast messages to a larger and more diverse audience than ever before [and has] provided the tools to maximize the social connectivity of the broader world. (p. 23)

They cite such as examples as the ways in which SMT has been used to mobilize support in various grass roots efforts and to generate more involvement of young people in elections. Davis III et al. (2012) feel that this shows that SMT has become indispensable in "a socially enabled world" and that how people are "doing social" in these types of environments should be assessed because "we can use this tool to achieve desired academic, social, occupational, political, and other ends" (p. 23).

Many of the claims associated with the positive benefits of Facebook use were based on studies and literature that centred on teens and young adults with the exceptions of Facebook being used as a job search tool and as a platform for socio-political engagement. However, much of the literature on the negative effects associated with Facebook use, which I refer to as drawbacks, concern the population in general, and are far more common within current popular discourse.

\section{Negative Claims: Individual Drawbacks}

The negative psychological drawback of loneliness associated with Facebook use is connected to the creation of false communities and superficial relationships (Marche, 2012). Loneliness is cited by Turkle (2011) as stemming from a search for "authentic" connection. She states:

When online life becomes your game, there are new complications. If lonely, you can find continual connection. But this may leave you more isolated, without real people around you. So you may return to the Internet for another hit of what feels like connection. (p. 206)

Not only is loneliness a consequence of meaningless connections, it also results from hyper-connectivity. By always being connected, people no longer receive the psychological benefits of solitude, "the kind that refreshes and restores" (Turkle, 
2011, p. 20) I take this to mean that if a person can feel comfortable being alone, then they will be more centred and happy.

Hyper-connectivity is connected to two other often cited psychological drawbacks of Facebook use: anxiety and addiction. Ellison et al.'s (2007) study showed that people had some degrees of habit formation while Larose et al. (2011) state that "Internet usage disorder has been proposed as a new category of mental illness" (p. 59). Turkle $(1995,2011)$ links it to disconnection anxiety. She feels that even though SNSs may help people feel connected, when they disconnect they feel anxious. Anxiety is also related to self-presentation. Turkle (2011) questions, "What are the truth claims in a Facebook profile? How much can you lie? And what is at stake if you do?" (p. 67), and one of her research participants answers,

On the one hand, low stakes, because no one is really checking. Then, with a grimace, she says, No, high stakes. Everyone is checking. A few minutes later, Nancy comes back to the question: Only my best friends will know if I lie a little bit, and they will totally understand. Then she laughs. All of this, it is, I guess, a bit of stress. (p. 167)

Lastly, unhappiness is another psychological consequence of Facebook use, according to Philips and Moberly (2013). Unhappiness results from people negatively comparing themselves with other people's status updates. It makes them feel envious of other peoples' lives.

Other personal drawbacks of Facebook use are said to be pressure, exhaustion, wasting time, and being exploited. Boon and Sinclair (2009) state that there is a pressure to be on Facebook by peers and academics. This is then linked to people feeling like they are wasting their time and, for others, feeling exhausted by the pressures of performance (Turkle, 2011).

Personal exploitation is carried out by corporations through Facebook. Facebook allows corporations to access users' personal information, turning them into instruments of capital (Grosser, 2011). Philips and Moberly (2013) contend that:

caught up in narcissistic competition, users engage in self-production and self-commodification. They acquiesce reluctantly to changes in Facebooks terms of usage that grant increasingly invasive exposure to their data-but they acquiesce nonetheless, using Facebook logins as shortcuts across other sites. All the while, Facebook owns the data that users create as they perform the work of assembling themselves as commodified objects. (para. 35)

Another type of personal exploitation is carried out by Facebook scientists who can access personal information for research without obtaining consent (Globe staff, 2014). There is only one documented case of this, but one cannot presume that it is a singular occurrence. While corporations exploit Facebook users for capital purposes, this experiment exploited people's emotions to test whether or not emotional contagion occurs outside of in-person interactions. Emotional contagion has been established in in-person interactions and this study confirms "there is evidence for 
massive-scale contagion via social networks" (Kramer et al., 2014, pp. 87-88). This study not only personally exploited close to 700,000 unknowing participants, it did so at a time that using personal information for research purposes was not a part of the Facebook's user agreement or terms of service (Reed, 2014). This policy was added in May, 2012 (Schonfeld, 2014) and the study by Kramer et al. (2014) was conducted from January 11, 2012 to January 17, 2012, and because it used random participants, it may have included minors. It is unclear what purpose this study serves for Facebook. The COO of Facebook, Sheryl Sandberg, claims it was conducted to help improve Facebook services (Anwar, 2014). It has me question if they feel they should be in control of people's emotional states of being.

\section{Negative Claims: Community Drawbacks}

Boon and Sinclair (2009) state "Facebook seems to encourage us to create essentially false communities of superficial relationships. That is not to say that the medium is never used to maintain strong communities of meaningful relationships, but rather that these seem to be in the minority" (p. 104). Grosser (2011) equates the communities created through Facebook to "gated communities" in that everyone looks the same. This is viewed as negative because it implies that individuals cannot personalize their online identities.

The creation of superficial relationships on Facebook is commonly cited in the literature, though in various ways. Turkle (1995) feels that when humans are reduced to information, the human is lost. Therefore, if relationships with others are developed through information, these relationships are somewhat superficial. Ito et al. discuss superficiality as an awkwardness generated by what is meant by friend on SNSs. They quote a study participant as saying "Suddenly they go from someone you've met once but also connected with in some weird Facebook way. And now that you've connected, you have to acknowledge each other in person sometimes" (2009, p. 37).

Weak ties are promoted by Facebook (van Dijck, 2013), which comprise most people's Facebook friends lists. Ellison et al. (2007) and Grimes and Fields (2012) maintain that weak ties help bolster the look of popularity and consequently social capital. They are not intended to build strong ties or relationships. Turkle (2011) states that, that people rarely have each other's attention, so, building a strong relationship would be difficult. Philips and Moberly (2013) overtly state that:

Facebook as a social medium also cultivates relations of cruel optimism because the very connectivity that draws people into contact with one another thwarts the connectivity that people seek when they create pages, post updates, upload pictures, tag each other, and invite one another to games. Facebooks capacity to alienate its users and the cruelty of its proffered optimism is particularly observable when Facebook users friend strangers met only through Facebook and then use Facebook as a platform for both finding and maintaining these 
friendships. The modes of attachment that draw us to Facebook cheat us of the intimacy of sharing even as this intimacy is intimated by the function of sharing itself. (para. 28)

Lastly, not only is it claimed that Facebook creates false communities and superficial relationships, it is also asserted to affect offline relationships (Grimes \& Fields, 2012; Joinson, 2008). Ito et al. discuss this as a spill-over effect of Facebook. Turkle (2011) gives an example of this through one of her participants who tells the story of an online argument with a good friend:

She explains, I said something I shouldn't have. I apologized. If it had happened at a party, it would have ended in five minutes. But she had said it on the Internet, its own peculiar echo chamber. For Audrey, the hurt from this incident, six months in the past, is still raw: We were really good friends, and now we dont even look at each other in the hall. (p. 180)

\section{Negative Claims: Socio-Cultural Drawbacks}

The positive claims in this area centred on creating more political awareness, social mobilization, and the development of political identity; however, Morozov (2011) states that online political activity is a form of slacktivism, which does not translate to "real", on the ground, activism. This is somewhat similar to Turkle's (1995) earlier considerations: "If politics of virtuality means democracy online and apathy offline, there is reason for concern" (p. 244). For Morozov it is a cushy kind of activism where people feel like they are activists when they are in fact not because they do not engage in efforts that bring about concrete changes. Kavador (2012) makes only slight negative critique of Avaaz in that she feels that interaction with other supporters is limited, which Gladwell (2010) notes is necessary for maintaining social movements.

\section{REASONS FOR NEGATIVE CONSEQUENCES OF SNS/FACEBOOK USE}

The structure of Facebook is cited as being the primary cause of limiting identity performance, exploiting individuals, and even addiction. Grosser (2011) asserts that the format of Facebook results in homogenous identity performances that limit personal expressions of identity. He feels that this may also be due to the fact that it was developed by a homogenous group of white males. Biddle (2013) claims that personal identity is further limited by Facebook's ability to recycle peoples' likes. What he means by this is that if a person liked a corporate brand a few years ago, Facebook can advertise it at any time on the newsfeed. Biddle feels that this recycling of likes misrepresents peoples' identities because a person might not like that particular corporate brand anymore and it may have been an aspect of a past self. 
The format of Facebook also makes data mining easy and results in exploitation (Grosser, 2011). van Dijck (2013) targets the timeline aspect of Facebook's structure for increasing exploitation because it "combin[es] spontaneous memories and emotions with consciously released new personal data" (p. 205). The timeline draws on people's emotions and memories, making people want to enter more personal information. O'Dell (2011) claims this is because the timeline was developed around the idea of scrapbooking. They examined how people create scrapbooks, which are used for reminiscing, and modeled the timeline around this emotional experience. This may also explain the popularity and addictive nature of Facebook.

Psychological predispositions are another way current literature explains some of the negative consequences associated with Facebook use. Larose et al. (2011) suggest that the addiction and depression associated with Internet use are linked to pre-existing offline psychological conditions. Their study looked at media habits through socio-cognitive theory to examine the reasons for deficient self-observation, associated with depression, and deficient self-reaction, associated with addiction. They found that "deficient self-reaction, an indication of the lack of intentionality and lack of controllability of media habits, emerged as the single most powerful predictor of negative life consequences" (p. 73). They also found that an increased repetition of the media activity could lead to less perception of it being a problem as it becomes normalized and that "negative life consequences cause individuals to become more attentive to their media consumption behavior, causing deficient self-observation to increase" (p. 74). They claimed that people eventually start selfregulating and that more attention should be paid to why particular media become favorite activities more than whether or not they lead to negative consequences. They also state that Facebook and other SNSs are no more prone to problematic behaviors than other media sites, making the way people use technology and for what purpose it is used an important area of research.

Greater online activity, or addiction, is also correlated to higher levels of offline low self-esteem and also to narcissism. Mehdizadeh (2010) states, "research by Buffardi and Campbell confirmed that narcissism predicted higher levels of social activity in the online community and more self-promoting content in several aspects of the social networking Web pages" (p. 358). The study she is referring to was published in 2008. Nadkarni and Hofmann (2012) assert that the reason most people are on Facebook is due to a need to belong and to self-present their selves. Through their review of current literature they, too, conclude that "that a high level of extraversion, low self-esteem, high levels of neuroticism, narcissism, and low levels of self-esteem and self-worth are associated with high FB use" (p. 245).

Emotional contagion is another factor to consider in some of the negative reactions associated with Facebook use (Kramer et al., 2014). Through the previously cited experiment on Facebook, it has been established that people are affected by the emotional postings of others, and these effects may last for several days. 


\section{CONCLUSION}

In this chapter, I discussed the functions of teen online identity presentation in general; related statistics on Facebook and its demographics; explored three studies that centred on young adults in university Facebook use; and discussed what is known about adult Facebook used. This was followed by a review of literature that looked at the positive and negative claims associated with Facebook use and other SNSs for the individual, for the community, and for society. Lastly, I examined literature that spoke to some of the possible reasons behind the associated negative effects.

I draw on the literature and studies examining online identity presentation and SNS use in general and Facebook specifically to validate why I conduct a study on my peer group. I also draw on this literature to consider whether or not my peer group presents their online identities in the same ways as teens and younger adults do and for the same reasons. I use the literature review on the positive and negative claims associated with Facebook to further consider the socio-cultural implications of Facebook use for those born in the Cusp Generation. In Chapter 6, I discuss whether or not my participants had similar and/or different reactions and experiences as cited in this literature, and I consider the socio-cultural implications of these results. 



\section{LINKING IDENTITY THEORY, AVATAR ATTACHMENT THEORY, AND HYPERREAL CONSIDERATIONS TO OVERCONSUMPTION AND SELF-FETISHIZATION ON FACEBOOK}

The way in which the subject constitutes himself in an active fashion, by the practices of the self, these practices are nevertheless not something that the individual invents himself.

(Foucault, 1991, p. 11)

In this chapter, I develop a multi-faceted model of inquiry that allows me to explore the socio-cultural implications of Facebook use for the Cusp Generation. In order to understand how this generation present themselves online, I draw on offline identity theory that conceptualizes identity as a performance. I explore the social construction of age-related categories, their relation to market strategies, and links to identity and consumer discourses to further the conceptualization of identity performance.

Next, I conceptualize online identity presentation as cyber identity performances. I then draw on avatar attachment theory (Croft, 2011; Delwiche, 2007; Gee 2003; Lahti, 2003) to consider the popularity of cyber identity performance on Facebook and how it might be a factor in its addiction for some people.

In the final section, I turn to Baudrillard (1993, 1995, 1996) and Eco's (1976, 1986) conceptualization of hyperreality to further develop the notion, introduced in Chapter 1, of cyber identity performance on Facebook as potentially resulting in a form of self-fetishization and overconsumption. This leads to a discussion on how I come to deliberate agency in cyber identity performance.

\section{IDENTITY THEORY}

In Chapter 1, I defined identity as a type of performance. I derive this definition from Butler's (2001) discussion on identity. She maintains that a person thinks about his or her identity in relation to another person or thing and, therefore, in the narration of the self to the other, it becomes a form of storytelling. Butler (2001) explains, "it is important to remember, the desire to be, the desire to persist in one's own being (...) is only fulfilled through the desire to be recognized" (p. 28). She connects identity to recognition and recognition to an "other." When there is an "other" around which identity is conceptualized it requires a narrative involving an "I" and a "you." This identity storytelling can be personal or collective (Taylor \& Spencer, 2004) 
and performs the internalization of discourses related to gender, age, race, politics, along with cultural symbols (Butler, 2001; Thomas, 2007). Furthermore, identity is something that can be constantly reconceptualised and has multiple facets that shift occasionally into contradictory subject positions according to the group or other being performed for (Walkerdine, 1993).

While identity performance is often discussed in relation to group identity, the group in the contemporary context has changed from its traditional sense (Buckingham, 2008; King, 2004). Whereas once the family and other social institutions were the primary group against which identity was performed, cultural studies has been exploring the ways the media has now become a part of the group, expanding its conceptualization. Traditionally, identity is performed around the beliefs and practices of the home, church, and state but these are decreasing in influence in modern society because of dominant identity discourses circulated by the media (Giddens, 1991). This makes the traditional notion of a fixed identity no longer valid, with the other against which or for whom people perform their identity being increasingly "found not in the context of everyday life but in the media representations of everyday life" (King, 2004, p. 184), which are ever-changing. Taylor and Spencer (2004) explain that "[i]dentity is a work in progress, a negotiated space between ourselves and others; constantly being reappraised and very much linked to the circulation of cultural meanings in society" (p. 4), and cultural meanings are predominantly circulated by the media (Stern, 2008).

While this conceptualization of identity performance is primarily socio-cultural, I will also draw upon Geary and Bjorklund's (2000) evolutionary developmental psychology approach to identity in Chapter 6 to provide insight into the gender differences that are brought up through my study.

\section{AGE CATEGORY CONCEPTUALIZATIONS: LINKS TO SOCIO-ECONOMIC CONDITIONS}

The cultural studies perspective on identity contends that all age categories are socio-historical constructs (Buckingham, 2008; Kincheloe \& Steinberg, 2004). Larkin-Leiffers (2010) states:

Because biological immaturity is a universal phase there is a tendency to think that, to a large extent, childhood is a common experience. But how we view this time of life, and how we experience it, are culturally and socially based.

(p. 76)

This perspective counters what is deemed to be a narrow perspective on child and youth identity theorizing in the area of developmental psychology, where noncritical theorists tend to draw heavily on Piaget. The Piagetian perspective stipulates a taxonomy of development that indicates where people should be developmentally according to their age. Contrarily, Kincheloe (2005) opposes this taxonomy by asserting that developmental stages differ individually, and according to geographic 
location, culture, and the various living conditions that come with differing socioeconomic classes. Therefore, developmental stages are historically, socially, and culturally contingent and reinforced.

The creation of age categories enables societal determinations over what a person should be doing and when. The definition of age categories is linked to social and political policy and can be demonstrated through a historical examination of the concepts of childhood and teenager, which shows how these concepts change meaning in accordance with socio-economic conditions (Kincheloe \& Steinberg, 2004). A critical engagement with the social construction of age categories is important for my research on adults, given this category is also tied to socio-economic imperatives.

Prior to the industrial era, there was not a fundamental difference between childhood and adulthood; children took part in the adult world by learning vocational skills, hands-on, from their elders (Kincheloe \& Steinberg, 2004). This changed about 150 years ago when the traditional or contemporary notion of childhood was developed as organic conceptions of community melted away, the stratified industrial work force came in to being and modern compulsory schooling was implemented to fill the breach. This reconceptualization of life categories based on age was later expounded upon by Piaget whose taxonomy of development reconceptualised childhood as a developmental age related to a period of innocence and in need of protection.

The further historical development of the age category of "adolescence" or "youth" to represent the period between childhood and adulthood is implicitly connected to mid 20th century economic imperatives (Buckingham, 2000, 2008; Kincheloe \& Steinberg, 2004; Willett, 2008). Today's age conceptualization of youth in North America can be traced to the reconfiguration of job markets after WWII when job positions occupied by young adults had to be freed up for men returning from overseas. This resulted in the creation of labour laws that were justified through a reconceptualization of youth that deemed them non-adults in need of protection, much like children. This had the effect of othering youth from adults, which also resulted in vilifying them as delinquents and reinforcing the need for their control.

From a psychological perspective, the adolescent years are characterized as tumultuous period, described by Erikson (1968) following Piaget's stage theory, as a conflicted stage between identity and role confusion, resulting in self-reflection and self-discipline. This stage is also characterized as a time for identity experimentation. Similarly, boyd (2008) describes this period as a time of crucial development that requires social interaction and social affiliation; however, she does not refer to it as a conflicted stage. The concept of identity as performance is closely connected to the category of youth or teen because it is contended that this stage in life serves to transform youth into adult through identity experimentation. This experimentation is seen as essential because if teens do not experiment with or explore their identities, they are at risk of remaining a delinquent.

The historicization of the age categories of child and teen reveals that they are socio-cultural constructs that have arisen from economic imperatives. The creation of 
age categories goes hand-in-hand with socio-cultural discourses on what is deemed to be the defining characteristics and correct behaviour for each age category. In fact, it appears as though political and social needs have been the main driving force behind these changing conceptualizations.

There are negative consequences related to age-related categorizations. The current construct of "child" as innocent and in need of protection results in a loss of their agency and they are "disqualified, especially when [they] represent(...) nondominant diverse backgrounds and cultural values" (Cannella, 2002, p. 4). Teens are characterized as fragmented with an inability to focus (Jacobs, 2006) and whether or not this stems from role confusion or raging hormones (Buckingham, 2008), it removes agency from youth by typifying them as fragmented, confused, and out of control.

I contend that the loss of agency related to the identity discourses of early childhood and the teenage years may become internalized and may have implications for adults. If people grow up feeling that they need protection and they are powerless and fragmented, this may affect their behaviour as adults. This perspective on the socio-cultural construction of age categories allows for reconsideration of childhood and the stereotyped teenager, and, consequently, what it means to be an adulttraditionally thought of as the opposite of child.

\section{AGE CATEGORIES, MARKET EXPLOITATION, AND CONSUMER DISCOURSE}

The conceptualization of age categories naturally produces discourses on their related behaviors and needs, and these discourses may result in constraints on agency as they dictate how identity is performed (Buckingham, 2008; Cannella, 2002; Jacobs, 2006). These constraints on agency become intensified through market-related discourses, disseminated by the media, which reinforce and expand on age category conceptualizations and promote age-related consumerism.

A historical examination of childhood shows how its commercialization has been a major driving force in its conceptualization and reinforcement, affecting even the concept of adult. This can be seen in Hollywood dichotomies of the child-like adult and adult-like child which exploded after the 1950s (Giroux, 1999; Kincheloe, 2011). Adults became consumers of Walt Disney based fantasies of childhood, both for themselves and for their children. This is because not only are adults buying into what childhood is for their children, but they are also buying into their own "lost" childhood. Childhood becomes romanticized through the media and reinforced by adults who consume media-related childhood discourse.

Corporations similarly took advantage of youth conceptualizations around the same time. The term teen arose around the 1950s through a corporate produced youth culture that encouraged rebellion through consumption. Society at that time did not recognize that teen rebellion was produced and encouraged by sociocultural construct; instead, rebellion was felt to be an inherent problem of youth. 
Corporations developed specific venues and cultural symbols around youth culture for their consumption. It resulted in a new youth culture that has continued to be perpetuated by new genres of media, all for the purpose of promoting identity-based consumerism.

The reinforcement of age categories and their related consumer behaviors is profitable for corporations. Corporations are successful at the marketing of agerelated consumer discourses because they effectively colonize and commodify the resultant psychological ramifications associated with each socially constructed age category and disseminate age-related consumer discourse through the media. They are essentially buttressing the socially constructed consciousness of children, teens, and adults (Cannella, 2002; Kasturi, 2002; Kincheloe \& Steinberg, 2004). These discourses also enhance the conceptualization of identity as a performance because they regularly encourage new forms of consumption which require changing performances. They also erode children's and teens' agency from determining who they are, what they need, and who they will become. Moreover, it has implications for the concept of adult. First, it changes the construct of the adult parent because marketrelated identity and consumer discourses erode parents' roles as the primary giver of sustenance and well-being, and role model to their children. Second, stemming from the commercialization of childhood, because adults consume childhood discourse it has not only given the media more power in deciding what childhood should be but it has also affected the conceptualization of adult; the adult started becoming the adultlike child through a consumption of child-related media, buying into the idea of their own lost childhood (Buckingham, 2000, 2008). Furthermore, this has led to the more recent age category of adultescent, which is important for my study because I use it to consider whether some of the negative consequences associated with Facebook use are rooted in its related discourse, and what the long term implications will be of a society with increasing numbers of adultescents performing their identities on SNSs like Facebook.

The research and theorizing on adultescence (Barber, 2007; Buckingham, 2008; Kincheloe \& Steinberg, 2004; Koslow, 2012; Tierney, 2004) links the age category of adultescent to both economic conditions and capitalist dominant discourses related to identity and consumer culture, with implications for what is meant by adult behavior and consumerism. Even though the adultescent is rooted in the socioeconomic conditions that gave rise to conceptualizations of childhood and teen, the adultescent truly emerges as an age category in the 1990s linked to the socioeconomic factors of rising educational and housing costs.

The term adultescent first appeared in 2004 to describe the adult who is "too busy playing Halo 2 on his Xbox or watching SpongeBob at his parents' house to think about growing up" (Tierney, 2004, para. 1). It is also referred to as a "Peter Pandemic" and other characteristics include marrying late in age, living with one's parents until their mid-30s, and having lots of disposable income (Koslow, 2010). 
The literature questions whether behaving like an adultescent is the result of an escapist desire or whether the divide between children and adults has disintegrated. The escapist desire would be rooted in childhood discourse, with adults trying to relive their childhoods and not wanting to take on adult roles and responsibilities. The disintegration of the divide between child and adult may well be a fictitious divide on the level of wants and desires; however, if the divide that is disintegrating is on the level of social roles and responsibilities then there will be socio-cultural implications such as less social and community involvement because adultescents will be more concerned with themselves then the larger society in which they are members.

Marketers began targeting the adult group with adultescent discourse around 1996 (Barber, 2007). However, the seeds of adultescent discourse were already sown with adults consuming the child-like adult discourse. The category may also be a by-product of children growing up with "need to be protected" and "stay innocent" childhood discourses followed by a fragmented youth discourse that does not encourage agency. These seeds may have lead people to shirking adult roles and responsibilities, to never really "grow up", and as adults to remain child-like, exhibiting adolescent behavior, behaving like an adultescent. The popularity of children's animated films such as Wall-E with adults is seen as further evidence of the existence of the adultescent (Crawford, 2012; Giroux, 1999; Kincheloe, 2011).

The media has been complicit in the reinforcement of adultescent through shows like Seinfeld, where adults are still living as though they are teenagers, not wanting to get married or "settle down", and never, seemingly, working. This discourse promotes a care-free life of consumerism. Barber (2007) contends that adultescents are children who grew up being targeted as consumers and now do not want to act their "adult" age, products of a dichotomy of the old wanting to be young and the young wanting to be old.

I draw on the conceptualization of adultescent to consider why and how adults are on Facebook by comparing it to how youth explore their identities. Wikipedia defines an adult as:

a human being or other organism that has reached sexual maturity. In human context, the term adult additionally has meanings associated with social and legal concepts. In contrast to a minor, a legal adult is a person who has attained the age of majority and is therefore regarded as independent, self-sufficient, and responsible. (Adult, 2014, June 29, para. 1)

The adultescent is, thus, almost the opposite of the adult - they are irresponsible and still dependent on their parents. I deliberate whether or not the adultescent represents a particular segment of the population or if the concept of adult, which is also a socially constructed age category with a related discourse of behavior, needs to be reconsidered and/or reconceptualised. I also use the concept of adultescent to explore whether or not some of the ill effects associated with Facebook use, such as narcissistic behavior and addiction, might be tied to adultescent behavior. 


\section{CELEBRITY CULTURE AND GENDERED BEAUTY DISCOURSE}

Dominant discourses involving identity and consumerism may be impacting child, youth and adult offline and online identity presentations. There are two specific discourses related to consumer identity that I discuss in this section that are theorized as impacting youth online identity presentations on SNSs like Facebook: a discourse of self-promotion related to celebrity culture and a gendered discourse on beauty.

While adultescent discourses promote self-indulgent behaviour, including excessive self-promotion (Barber, 2007), celebrity culture has also been theorized as encouraging the cultural obsession with self-promotion (Weber \& Mitchell, 2008) and the marketing of one's self in SNSs (Boon \& Sinclair, 2009; Nadkarni \& Hofmann, 2012; van Dijck, 2013). Stern (2008) discusses the emulation of celebrity culture in her research on youth online expression. She states:

Some young people view personal sites as avenues to participate in, or respond to, a culture that valorizes publicity as an end in itself. (...) This does not mean that young authors uncritically buy into the dominant messages about celebrity and pop culture that persist in mainstream media, but rather that many have recognized the cultural value of self-promotion and are motivated to publish online in consequence. (p. 101)

She contends that this may be because they consume their age-related discourse of fragmented identity and draw on examples of celebrity self-promotion to model their own online expressions. Weber and Mitchell (2008) are more critical and maintain that the practice of self-promotion is not simply about drawing from celebrity online culture as a template, but rather that it results in prosuming in which "the processes of producing, consuming, and being consumed or shaped by digital media are intertwined and often simultaneous" (p. 29). They cite examples of young participants who post pictures as:

signpost[s] to who they think they are or who they want you to think they are or who they would like to become. (...). they are presenting themselves, performing their bodies, and trying on looks. The choice of photographs of their idols can also be viewed as an extension or projection of their bodies, a desiring or coveting of anothers appearance. (pp. 30-31)

The theorizing on the discourse arising from celebrity culture and its emphasis on self -promotion often discusses youth, not adults. However, adults may be similarly affected, whether discussing adults in the traditional sense or as adultescents. I make this conjecture by drawing on some relevant statistics. There are high levels of internet activity by adults on celebrity gossip sites like perezhilton.com where $74 \%$ are older females, and 33\% are those who earn more than $\$ 150$ 000/year (Tancer, 2008). The famous TV show host Oprah has a website whose visitors are $72 \%$ female of which $66.4 \%$ are over 35 years old. These statistics just happen to coincide with the largest growing age group on Facebook, those in their 30's 
(Turkle, 2011) and there may be a link between adult Facebook use and celebrity culture consumption.

The gendered discourse on beauty may also be a factor in how females perform their online identities. This discourse is directly linked to consumerism. Fiske (2010) points out that there is a highly problematic relationship between economic profit and popular culture, and this is evidenced in advertisements in women's magazines. These advertisements are geared to changing female bodies, and this seems to be more so in magazines aimed at lower, socio-economic classes. Advertisements in "middle" class magazines speak more about physical health and energy. Yet, in both socio-economic demographics, "beauty has been harnessed as a metaphor for the socially dominant" (p. 81) and "beauty" has become a form of social capital.

Advertisements influence offline identity performance because they encourage consumption as forms of self-expression. They do this by linking specific product consumption to "being normal" and, therefore, influence self-identity. Attick (2008) states "a 16 year old cannot cognitively or psychologically defend themselves against television advertising" (p. 53). Not all scholars agree that youth are so defenceless against media disseminated discourses related to identity. Kelly, Pomerantz, and Currie (2005) discuss the phenomenon of "skater girlhood" as evidence of the way girls develop their own discourse on femininity even within sexist skater culture. They state:

Skater girlhood can be seen as part of a larger category, alternative girlhood. By alternative girlhood, we mean the range of ways that girls consciously position themselves against what they perceive as the mainstream in general and against conventional forms of femininity in particular. (p. 130)

Children, youth, and adults are bombarded by mainstream identity discourses. Ten billion dollars a year is spent on advertising across multiple formats and on multiple platforms that depict what the hottest trends are. This has become a way for youth, and I contend adults as well, to stay informed about what is cool, what will make them cool, and what being socially acceptable looks like (Attick, 2008).

The gendered commodification of childhood and youth occurs on a more subtle level through the guise of third wave feminism, which capitalist mainstream media promotes to target young girls. At first glance, television shows targeted at young girls seem to be empowering females, but the females in these shows are controlled by males lurking behind the scenes. The role of the female is still all about "constructing themselves as objects for the male gaze" (Chang-Kredl, 2007, p. 401). This is exemplified in the television show The Powerpuff Girls where three female superheroes are still depicted in "traditionally feminine and objectified codes of appearance and behavior" (Chang-Kredl, 2007, p. 401) even though they are supposed to be empowered. There is also a lot of highly profitable tie-in merchandise on offer, so while girls consume the messages from these programs, they also consume their products. Young girls are being targeted by commodity 
feminism. The media influences gender discourse through its promotion of beauty as the ultimate articulation of female. Levin and Kilbourne (2008) note the disturbing trend of sexualizing female childhood through aggressive marketing strategies drawing on popular culture and pop stars. This may explain Mehdizadeh's (2010) finding, discussed in Chapter 2, that "gender differences were found to influence the type of self-promotional content presented by individual Facebook users" (p. 357). This compounds the effects of beauty discourse and I contend it will have long term implications into adulthood for online identity presentation.

The literature review in Chapter 2 on online identity presentation showed that there is a link between social desirability and group and consumer identity because social desirability is attained through a display of popularity (group identity) and being "into" the same things as others (consumer identity). This makes social connectedness and consumption important for being popular and for increasing social capital. These findings suggest that dominant identity discourses are a part of participant's online identity presentations. Identity discourse related to celebrity culture encourages self-promotion and a gendered beauty discourse elevates a promotion of a flawless self through the modeling of celebrity culture, consumerism, and self-promotion. Personifying these discourses elevates social desirability since the general society is receiving the same message on how to perform identity.

In this book, I break new ground by exploring how these consumer-related discourses also affect adult online identity presentations. I draw on this related research to consider how socially reinforced developmental stages may be affecting adults' online identity presentations on Facebook in two ways: First, the development of agency during one's childhood and youth may be limited by their age-related discourses and this constrained agency development may be carried over into adulthood. Second, youth-related age categorizations and their related identity discourse might be extended into adulthood influencing how adults present themselves on Facebook. My study aims to discern whether or not some or all adult self-presentations on Facebook signify the blurring of the divisions between teen and adult or the consumption of the more recent adult-related discourse of adultescent.

\section{CYBER IDENTITY PERFORMANCE}

Thus far, I have spoken about online identity presentation in relation to Facebook and other SNSs as the literature in this field commonly does. However, at this point, after having conceptualized identity as performance due to its storytelling nature and in relation to media disseminated discourses on identity and consumerism, I refer to online identity presentation as cyber identity performance. A central concept for further understanding online identity as a performance is that of the avatar. I begin by examining the roots of the term avatar and then discuss the usefulness of applying avatar attachment theory to better understand the general popularity of Facebook and the negative drawback of addiction associated with SNS use. 
Avatar

The word avatar comes from Sanskrit denoting the visible form Hindu gods take to present themselves to mortals. Though people commonly think of an avatar as a virtual representation of a person in digital form (Cooper, 2007; Turkle, 2005), it is actually more basic than that. The moment a person goes online and represents him or herself with some type of information it is the start of avatar creation (Jordon, 1999). Typically, cyber identity begins with the entering of one's name for an e-mail account, but more substantial cyber self-definition occurs with the creation of an online name and the sketching of an identity or distinct personal style (Mulligan \& Patrovsky, 2003).

The term avatar became linked to video gaming with its use in online culture in the 1985 video game Ultima $I V$, however, it is more often accredited to the creators of the online game Habitat which operated from 1986 to 1988 (Sandifer, 2009) with characters in the game being called "Avatars". Credit is also given to Stephenson (1992) for inventing the term avatar in his novel Snow Crash to describe the populace of Metaverse. As its semantic roots suggest, avatars are seen as people's godlike or immortal virtual embodiments. This conception has interesting implications for my research; I draw on this when I discuss how people present themselves on Facebook.

This is where the common conceptualization of an avatar as a two- to threedimensional representation of a person in a virtual world originates from (Sandifer, 2009; Stephenson, 1992). For the purpose of this research it is necessary to distinguish between this avatar definition and the way I use the term. While avatars are generally conceptualized as perfected forms and imagined alternative identities (Lankshear \& Knobel, 2003, 2006; Thomas, 2004, 2007), in my study they are actual representations of people and are not linked to gaming. Whether or not they are "perfected" images of one's self will be discussed in Chapter 6. I employ the term avatar in this research to denote a person's cyber identity performance on Facebook, distinguishing it from its common conceptualization. The profile picture on Facebook is a person's immediate avatar representation, which may be digital or a photograph, whereas the entire profile is the information about the person and embodies the entire avatar.

I break new ground by referencing the Facebook profile as a person's avatar. The profile is a representation of a person and may be as true as possible to one's offline self or an idealized version. Some may even choose to have a profile picture that has nothing to do with their physical self. Avatars, both digital and non-digital, link to the concept of identity performance because they are used to perform a cyber identity, whether in a gaming venue or on a SNS.

\section{Avatar Attachment Theory}

The majority of the literature on avatar attachment theory comes from research on video gaming (Croft, 2011; Delwiche, 2007; Gee, 2003; Lahti, 2003). For example, 
a girl in Thomas' (2007) study centering on video games explains that "you can get so into character that pulling yourself out hurts- that when you're not in the world you wonder- you find yourself thinking as that character would at the oddest moments" (p. 87). I contend that this may also be occurring on Facebook through people becoming attached to their Facebook avatar.

Avatar attachment theory considers the effects of different media, from reading a book to watching television, on people's subjectivity (Delwiche, 2007). However, there are four mechanisms of effectiveness that impact one's identity more so in video games than in any other media. They are:

1. Immersion. The perception of bodily movement results in players viewing their avatars as a physical extension of themselves. Transportation occurs with focused attention and results in a temporary break from the "real world".

2. Intense engagement. Highly motivated, focused attention results in the ideological content of the game becoming more influential.

3. Identification. The video gamer identifies bodily with their avatar and psychologically with their avatar's actions in connection to the game's narrative. This also occurs with films. Gee (2003) cites three forms of identification that occur while gaming- "virtual identity, real-world identity, and a projective identity that synthesizes both" (p. 55).

4. Interactivity. It is felt through how virtual objects react, how they impact the avatar, and how it affects the overall narrative of the game.

Avatar attachment is heightened in a massively multiplayer online game (MMO) context (Croft, 2011), and results in the avatar becoming a part of people's identities and impacting their subjectivity (Wolfendale, 2007). I contend that avatar attachment also occurs on Facebook; it can be intense and may be somewhat due to the reasons indicated for video game digital avatar attachment:

1. People identify strongly with their Facebook identity because it is a bodily and psychological extension of themselves; physically through pictures and psychologically through postings, likes, and status updates. Lahti (2003) states "the representation of an avatar's body form is an important dimension of our desire for immersion in the fictional world of a game" (p. 165). I question what happens when a person has more control over their cyber identity's or avatar's body form on a SNS such as Facebook. While the appearance of an avatar in video games is restricted by the software, the Facebook profile picture avatar is controlled by you. However, "control" is somewhat inaccurate as the structure of Facebook imposes constraints on cyber identity performance, and will impact the overall Facebook profile avatar.

2. It is about one's self; therefore, it receives intense engagement from the user because it is personal.

3. Participants could feel total immersion through their frequency of use and its constant presence through mobile technology. Turkle (2011) finds "Most of the 
time, we carry that technology with us. In fact, being alone can start to seem like a precondition for being together because it is easier to communicate if you can focus, without interruption, on your screen" (p. 144).

4. Lastly, strong attachment may occur because of the interactivity that takes place via people's liking and commenting on postings, status updates, and photos, along with other forms of communication.

The four mechanisms of effectiveness that bring about avatar attachment are present on Facebook just as they are in video games making avatar attachment on Facebook strong. This is exemplified by a 16 year-old research participant of Turkle's (2011) who states:

If Facebook were deleted, Id be deleted. All my memories would probably go along with it. And other people have posted pictures of me. All of that would be lost. If Facebook were undone, I might actually freak out. That is where I am. Its part of your life. Its a second you. (...) Its your little twin on the Internet. (p. 175)

Her participant articulates how much her cyber identity performance on Facebook has become an extension of herself. Her attachment to her Facebook avatar is strong and represents a part of her identity.

\section{HYPERREALITY, OVERCONSUMPTION, AND SELF-FETISHIZATION}

I have discussed how I employ the age category of adultescent and avatar attachment theory to consider how and why adults might be performing cyber identities on Facebook. In this next section I explore how Facebook may be resulting in the overconsumption of cyber identity performance, self-fetishization, and a communication break-down because of its hyperreal nature. When simulation occurs through advanced technology it becomes even more hyperreal and desirable, especially when it involves the self directly. This is based on Eco $(1976,1986)$, Benjamin (1982/1999) and Baudrillard's (1993, 1995, 1996) theories on the relationship between cultural production, capitalism, object fetishization, and hyperreality.

Eco (1976) asserts that the relationship between culture and objects is rooted in "signification and communication" (p. 22), where objects are used to communicate cultural or social relationships. When objects are produced or exchanged for monetary value instead of for the establishment of relationships, it results in the creation of falsified needs for consumption (Eco, 1986). This type of meaningless production is rooted in capitalism. The economic structure of capitalism requires a flourishing consumer culture that is achieved through persuading people to consume, as Adorno (1991) articulates: "The dream industry does not so much fabricate the dreams of the customer as introduce the dreams of the suppliers among the people" (p. 93). 
In order for people to consume objects or products of no significant value, a broad ideology of consumerism (Sandlin \& McLaren, 2010) must promote this type of meaningless consumption. This ideology links consumption to individual and group identity (Hoechsmann, 2010) and is reinforced through neo-liberal discourse (Rose, 1999). A component of neo-liberal discourse, which is based on a government organized around economic logic instead of on social welfare, persuades people that they need to articulate "individuality" through consumer choices. It results in the expression of individuality at the expense of community as opposed to individual articulation within a group setting because this type of consumerism is all about self. It affects people's agency in identity performance because the internalization of this discourse has them believe that consumerism will bring meaning, while their consumerism reinforces relations of capitalist production.

Fiske (2010) exemplifies how identity is performed around consumerism through an examination of jeans. He demonstrates that the buying and wearing of jeans is an act of identity performance that has been nurtured by advertisers' use of popular images. So, even though the act of buying jeans may on the surface seem like an individual act arising from personal needs, wants, and desires, it feeds capitalist production needs because "the economic system, which determines mass production and mass consumption, reproduces itself ideologically through its commodities" (p. 10).

Eco (1986) argues that as a result of consumer ideology, Americans have become obsessed with iconic realism, where the fake is preferred over the original because it is "perfected." Turkle (1996), for example, cites her disappointment as a young girl at the Brooklyn Botanical Gardens when an employee was unable to fulfill her request of making the flowers open quickly; her Walt Disney or hyperreal version of biology felt authentic to her and more exciting than the real thing. This obsession with perfection has resulted in the artificial or hyperreal feeling more real or momentarily more satisfactory than the original and is rooted in the discourse that was promoted in the first public arena for object fetishization, the Arcades Project (Benjamin, 1982/1999). The Arcades Project in London, 1851, depicted commodities and technologies as vehicles for overcoming social and economic afflictions and were, thereby, fetishized with mythic attributes. It has gotten to the point that even art museums are filled with fakes for it is no longer about authenticity as much as it is about information. Eco (1986) states that "(...) the frantic desire for the Almost Real arises only as a neurotic reaction to the vacuum of memories; the Absolute Fake is offspring of the unhappy awareness of a present without depth" (pp. 30-31). This has led to confusion over what is valuable and an ensuing overconsumption of objects in a quest for meaning because people no longer know where to find meaning. It has also led to individual alienation from the group because objects are no longer used or produced for the establishment of relationships or symbolic exchanges.

It is not only the present era, or that described as beginning in the latter half of the nineteenth century, that copies artefacts of the past; this has been going on for the thousands of years. Ancient civilizations were always copying each other, especially 
after conquest. What differs today, I feel, is the "present without a depth"; while one can pay homage to other civilizations through iconic replications or pacify a newly subordinated people through them, today the function appears to be more about production and profit through the selling of an idealized reality. People want to buy into this "reality", most easily seen at Walt Disney World where cultures are reproduced to show a nostalgic, inaccurate portrayal that pleases the psyche. Fantasies are brought to life through the selling of "genuine" merchandise. Eco (1986) claims that what is really faked "is our will to buy, which we take as real, and in this sense Disneyland is really the quintessence of consumer ideology" (p. 43). It has resulted in object fetishization or the attribution of mythic qualities to mundane objects that will somehow bring us meaning through their consumption. This love of the hyperreal leading to overconsumption in a search for meaning is similar to Baudrillard's assertion that capitalist production results in an overproduction because of industrialised needs, and overconsumption because of a lack of fulfillment. The idea that capitalism produces products for human needs is seen as a farce, a:

creation of the political economy itself [and that] consumption has nothing to do with physical satisfaction or happiness. (...) [Baudrillard] sees it as a system of meaning and communication, of social hierarchy and distinction, and a means of social integration and control. (Merrin, 2005, p. 18)

This links economic production to consumer discourse, which persuades people to consume meaningless objects in order to keep capitalism thriving, and social control. Howe and Strauss (2000) theorize that youth internalize age-related discourses by believing that they should behave in particular ways which results in self-policing. Similarly, Willett (2008) contends consumer discourse constrains the very meaning of individuality and constrains individual agency. She feels that:

Consumerism can be seen as a technology of the self-a mechanism through which people present and police their identities in society. From this perspective, people are seen to regulate their behavior, expression, and view of themselves in accordance with the surrounding texts and practices-for example, advertising and make-over features (...). (pp. 54-55)

Baudrillard contends that media technology results in the overconsumption of hyperreal forms of communication because they lack authentic meaning, much like the overconsumption of fetishized objects. In Chapter 1, I discussed his argument that communication that occurs through a technology is merely a simulation of authentic communication and is, therefore, hyperreal. Since most people are not aware of this, they continue to seek connections through various medium to find meaningful connections and end up over consuming these media in their search. Kincheloe (2005) states that:

New forms of culture and cultural domination are produced as the distinction between the real and simulated is blurred. This blurring effect of hyperreality 
constructs a social vertigo characterized by a loss of touch with traditional notions of time, community, self, and history. (pp. 56-57)

Drawing on Baudrillard, I contend that communication and cyber identity performance on SNSs like Facebook may be resulting in a break-down of relationships and selffetishization, both of which lead to the overconsumption of SNSs. First, the breakdown of relationships results in an overconsumption or use of the SNS because of a search for meaningful communication. Baudrillard (1996) describes the lead-up to this situation arising from the media shaping people's entire everyday life and dominating communication, and turning all communication into a form of non-communication. Communication through a technology becomes even more hyperreal than person-toperson communication because it so far removed from the everyday while promising "meaningful communication." Any communication that occurs through technology simplifies efforts and investments and, thus, is a form of non-communication. Through this theory, Baudrillard proposes that technology is breaking down human communication and relationships. Merrin (2005) rearticulates this social reality as:

A world whose proliferating digital technologies simultaneously represent a much vaunted and almost epochal increase in communication and the simultaneous systematic destruction, reduction, simplification and replacement of human relations. Our refusal to even see this paradox indicates the extent to which the technologies have penetrated our lives, placing themselves and their effects beyond question. (p. 23)

If this is so, I question what types of cyber identities are being performed on Facebook and what the socio-cultural implications would be in line with this theory.

Second, hyperreal depictions of the self may result in self-fetishization due to preferring an iconic self over an offline self, or overproduction of the self in a search for meaning. Fiske (1996), drawing on Baudrillard, explains, "Information devours (itself) (...) It exhausts itself in the act of staging the communication. Instead of producing meaning it exhausts itself in the staging of meaning" (p. 215). Meaning is lost in cyber identity performance because the hyperreal nature of the technology has people overproduce their performance in a search for perfected meaning; it slowly becomes more about the performance than the meaning behind the performance. As Ellison et al. (2007), Thomas (2007), and Turkle (2011) contend many seem to prefer their hyperreal version of self. This may be a reason for the addictive nature of Facebook that I discuss in Chapter 2.

The consumption of a technology that is tied to one's identity is a fantastic act of commodity fetishization because it results in even more consumption; not only is the consumer consuming his or her self, he or she is simultaneously consuming the technology or online platform to consume his or her self through. So while seeking meaningful connections and communications online, a person may also get swept up in the performance of their hyperreal self, which may result in overconsumption and, possibly, self-fetishization. 
For Baudrillard, hyperreality cannot serve to promote anything meaningful. Baudrillard's theory argues that "a mortal dose of publicity [leads to] asphyxiation" (Merrin, 2005, p. 64) and virtual reality is creating a "deep-seated virtualization of human beings" (Merrin, 2005, p. 72). This will result in us becoming "machines, enslaving ourselves in our own virtualized reality, as well as the 'double agents' that ensure the virtual's continuation" (Merrin, 2005, p. 130). The concept of enslavement raises important challenges to notions of agency in cyber identity performance.

\section{DEBATES ON PERSONAL AGENCY}

Foucault (1982) asserts that power is not a possession but a relation and it is not always readily visible. Power shifts between people, yet, there is always an overriding dominant culture that wields power over how people will behave and perform their relations with each other. This culture becomes embedded in people's subjectivities and affects people's individual natures and desires. Power categorizes the individual through socio-cultural constructs, makes the person attach to his or her own identity, and creates a subject. As Foucault (1982) explains:

There are two meanings to the word subject: subject to someone else by control and dependence, and tied to his own identity by a conscience or selfknowledge. Both meanings suggest a form of power which subjugates and makes subject to. (p. 781)

Foucault (1982) suggests that discourses constitute a type of policing of people that reduce people's agency in two ways: a discourse on identity impacts people's subjectivity by making them feel they should behave in particular ways, and a panoptic gaze results in people self-policing to conform to a dominant discourse of ethics. It becomes internalized and in this light, what agency can a person have?

I now examine some key works theorizing the limits of agency to speculate on whether or not it is completely constricted, as suggested by Foucault $(1980,1982)$. I consider this by drawing on the works of cultural theorists Raymond Williams (1961) in The Long Revolution, an interview Stuart Hall gives to Fiske (Fiske, 1996), and Paul Willis (1977) in Learning to Labour.

\section{Raymond Williams}

Williams (1961) looks at the concepts of the individual and agency from the perspective of creative activity. He historicizes the term creative and concludes that all attempts at being creative have a component of imitation of reality to them, and reality is a human creation. This is similar to Eco's theory of culture through the semiotic approach in which culture is closely linked to production; however, for Williams culture is linked to rules of seeing reality. He states: 
The evolution of the human brain, and then the particular interpretations carried by particular cultures, give us certain rules or models, without which no human being can see in the ordinary sense at all. (...) But, further, there is not only variation between cultures, but the individuals who bear these particular cultural rules are capable of altering and extending them, bringing in new or modified rules by which an extended or different reality can be experienced. (p. 34)

While Foucault sees agency as limited by dominant discourse and the panoptic gaze, Williams views culture as a creative activity with the ability of individuals to create change. The problem for Williams arises with the relationship of the individual to society; people strive to fit into society, learn its rules and how to behave, therefore, an individual will want to behave in keeping with a given socio-economic system while promoting his or her psychological satisfaction. This is much like Foucault's panoptic gaze.

Williams (1961) questions "what is the source of the individual character that can diverge from the social character?" (p. 97). He draws on Benedict who points to individual temperament stating that even though social character or cultural patterns, which form a society, teach "learned systems of behaviour and attitudes" (p. 98), there is still something unique to the individual that cannot be completely restrained. There will always be cooperation, conflict and tension. Still the question remains, how much agency is this really? Is it the type of agency that serves to infuse capitalism with the competition it requires for its own survival, but not so much that it changes the system? McLaren and Scatamburlo-D'annibale (2004) contend that capitalism requires competition to stimulate production. Competition and rebellion are healthy for capitalism as long as it they occur within the dominant discourse.

For Foucault, it is hard to overcome dominant discourse and self-surveillance. It is here that Baudrillard and Foucault overlap in their conceptualizations of agency; both seem to agree that even though it may seem on the surface that the masses or sub-social groups have presence and a say in popular culture, it is mostly a façade of agency. For Baudrillard, most socio-cultural participation (which today increasingly occurs through technology) is a meaningless sign exchange that spurs overconsumption, alienation, and people's unwitting participation in overconsumption. For Foucault, any seeming agency is usually one that is unconsciously constricted by dominant discourse and results in a self-policing of a person's words and actions, which he terms as a panoptic gaze. However, he does offer a theory of resistance that comes from people becoming aware of the social mechanisms of power and this awareness leading to the possibility of self-determination. However, there will always be a power struggle. Foucault (1982) states:

In effect, between a relationship of power and a strategy of struggle there is a reciprocal appeal, a perpetual linking and a perpetual reversal. At every moment the relationship of power may become a confrontation between two 
adversaries. Equally, the relationship between adversaries in society may, at every moment, give place to the putting into operation of mechanisms of power. (p. 794)

\section{Stuart Hall}

Hall (as cited in Fiske, 1996) fights the severity of Baudrillard's view of unwilling overconsumption and Foucault's panopticism, by stating that there should not be a "monosemic view of dominant ideology" (Fiske, 1996, p. 218). He posits that dominant ideology does not say the same thing to everyone at the same time; it becomes worked through in cultural production. He gives MTV as an example; while a rock commercial can be seen as reinforcing consumption, it can also "articulate (speak) resistance to, and evasions of, the capitalist social machine" (Fiske, 1996, p. 218). Hall then points out that there might not be any link to radical politics. The cultural and the political are not always related. I question what type of agency he is referring to. Is it simply a moment of potential resistance, a self-constrained resistance, a resistance that does not know how to proceed, or a resistance so futilely entrenched in its own panopticism that it becomes stagnant or so enthralled with hyperreality's false promises and so fails to follow through on a more meaningful path?

Perhaps the crux of the issue is access to discursive and economic resources. Hall (Fiske, 1996) states that expressions of resistance occur within hegemonic constraint and limited access to resources; sub-social groups rarely get as much media representation as dominant groups. Perhaps the problem is two-fold: limited access to resources along with constrained agency resulting from the effects of dominant discourses and panopticism.

Hall contends that Foucault takes away the political element of dominant discourse (Grossberg, 1996). He suggests that ideology can be produced by dominant classes as well as by subordinate classes (Fiske, 1996). He points to occasions where an "organic ideology" can create a transformative class consciousness, for example, Feminism. Either way, both Hall and Foucault are concerned with the way dominant ideology and dominant discourse affect people.

\section{Paul Willis}

The issue of agency and resistance is also highlighted by cultural theorist Willis (1977) in his well known ethnographic study of working class, rebel boys at a school in England. Drawing on the works of Bowles and Gintis (1976), who stipulate that education in capitalist America serves to perpetuate the inequalities necessary for labour power, Willis (1977) uses a contextualized approach to show that structural conditions constrict what I term agency and he terms symbolic resistance. The seeming resistance of the boys, that were interviewed by Willis, to school, mental work, and authority led only to the maintenance of their social class. While there 
may be resistance to dominant ideology, this resistance tends to be "repressed, disorganized, and prevented from reaching [its] full potential or a political articulation by deep, basic, and disorienting divisions" (p. 145). Ideology always contains a "them" and "we" coming from "the largest social unit to the individual" (p. 169). Willis shows "how systems of intelligibility are produced within cultural formations and how ideological hegemony is maintained internally to specific group cultures within identifiable historical moments such as the present era of disaggregated and fragmented identities" (McLaren \& Scatamburlo- D'annibale, 2004, p. 48). There is hope for resistance to dominant ideology to a make real impact because ideology and culture feed each other, but, for the most part, "resistance" is constrained and non-threatening to social order.

\section{AGENCY IN CYBER IDENTITY PERFORMANCE}

Given this discussion of the constraints on human agency tied to dominant discourses and power structures, including consumer culture in particular, how possible is agency in cyber identity performance in the hyperreal space of Facebook? This question holds socio-cultural implication because if agency is as constrained as Williams, Hall, and Willis contend it is, then, it is affecting people's liberties and subjectivities. As discussed throughout this chapter, offline agency is deemed to be constricted through:

- age categorizations that affect how people feel and behave;

- a broad ideology of consumerism and neo-liberal discourse;

- the market exploitation of age categories and the dissemination of age-related consumer discourses that connect identity performance to consumerism;

- gendered discourses of commodity feminism;

- the worship and emulation of celebrity culture that encourages self-promotion; and

- a love of the hyperreal and fetishization of objects that results in overconsumption in a search for meaning.

Turkle (2011) asserts that when one discusses problems associated with technology use the technology itself represents a symptom of an underlying problem. She says, "If there is an addiction here, it is not to a technology. It is to the habits of mind that technology allows us to practice" (p. 259). Agency in cyber identity performance is further compromised, I contend, due to avatar attachment, which may result in people over-consuming their SNS profile, the blurring of a sense of self and community because of the hyperreal nature of technology resulting in overconsumption, loneliness, addiction and depression, and the possibility to self-fetishize due to a "prosuming" of one's self (Jenkins, 2006) coupled with a love of the hyperreal. A hyperreal sense of self and a hyperreal community may lead to many of the negative drawbacks discussed in Chapter 2, and may also result in diminished agency in a person's cyber identity performance and relationships with others. 
My argument is not that all technological consumption is essentially problematic, only that people should be wary of Facebook's connections to capitalism and consumer culture. People should be critical of how popular culture operates in the interests of capital, while reflecting the interests, wants, and desires of mainstream culture (Fiske, 2010; Lule, 2012). Facebook is a site of popular culture and it deserves critique because even though one of its functions may be to overcome the fragmentation of offline community, it also serves corporate interests. Its potential negative impacts on personal and group identity are also heightened by its hyperreal nature. I seek to discover if and how a fetishization of cyber identity has resulted in diminished agency over one's identity and the nature of one's relationships with others.

\section{ENSURING AGENCY}

What with all of these limitations on agency, one possible version of it is connected to a critical awareness of the forces that constrict it. As discussed in Chapter 1, I define agency in this book as having a critical awareness of how dominant discourses related to identity and consumerism impact identity performance because if people are aware of how subjectivities are written for them, it will give them agency to create alternate forms (Foucault, 1982). Williams (1961) and Willis (1977) contend that individuals can make transformative changes in society if they can rise above their need for belonging and Hall (Fiske, 1996) feels that change can be brought about through the development of alternative ideologies that produce transformations in class consciousness. I am not calling for a revolution; but critical awareness may slowly start to change the nature of cultural production through a focus on more important things than defining one's self through consumerism.

Ensuring agency must also involve a critical awareness of the effects of hyperreality on subjectivity and relationships and the connection between hyperreality and power and economy. This recognition not only problematizes cyber identity performance, it elevates the investigation of agency within cyber identity performance to a critical level by making cultural production on Facebook an area of critical research for cultural studies. Kellner (2002) contends that a new critical awareness is needed to counter the dominant discourse being expounded by technology and media. Steinberg (2010) contends that people must become aware of how popular culture constructs consciousness, and Facebook is a site of popular culture. This is a literacy issue because the socio-economic aims of dominant discourse are linked to knowledge production (Kincheloe \& Berry, 2004; Sim \& Van Loon, 2001). In Chapter 7, I formulate a critical media literacy drawing on Hoechsmann and Poyntz (2012) and based on my study results. 


\section{CHAPTER SUMMARY}

In this chapter, I examined offline identity theory and performance in order to conceptualize cyber identity performance. I began by looking at the social construction of age categories, their connection to market strategies, and the connection of identity performance to a broad ideology of consumerism and particular identity and consumer discourses. I then defined cyber identity performance through an examination of the term avatar and avatar attachment theory. This was followed by a discussion of hyperreality and its effects on cyber identity performance through a consideration of self-fetishization and impacts on the self and community. Lastly, I explored theories on agency, its limits, and further constraints produced by the hyperreal nature of cyberspace. I then discussed how agency can be fostered through critical literacy involving an awareness of the effects of dominant discourse and hyperreality. 



\section{FACEBOOK STUDY}

In the pluralistic logic of the bricolage we seek large-scale interconnections.

(Kincheloe, 2004c, p. 66)

In this chapter, I describe how I develop my study on Facebook (Chapter 5) and analyse the study's results (Chapter 6). I begin with the study's rationale, its design, a description of my participants, and the data collection process. This is followed by a description of Johnson's four-point model for inquiry of a media site/text (Hoechsmann \& Low, 2008; Hoechsmann \& Poyntz, 2012; Johnson, 1986-1987; Johnson et al., 2004), which I use as both a starting point for data collection and a tool for its analysis. Johnson's model enables me to connect avatar attachment theory, identity and consumer discourses, hyperreal considerations of Facebook use, and deliberations on agency constrictions within cyber identity performance to the study's results. I achieve this by examining Facebook use through four points of cultural production in a media site that simultaneously impact each other: production, text, readings, and cultural life. This model also allows me to consider the reasons behind some of the negative drawbacks of Facebook use I brought up in Chapter 2: the structural format of Facebook (Biddle, 2013; Grosser, 2011; O’Dell, 2011; van Dijck, 2013), psychological predispositions (Larose et al., 2011; Mehdizadeh, 2010) and emotional contagion (Kramer et al., 2014). Lastly, under the focal point of cultural life in Johnson's four-point model, I utilize McLuhan's (McLuhan, 1988) tetrad which allows for a more nuanced reading of Facebook's socio-cultural implications and helps to shed light on how Facebook use is changing society and culture.

\section{STUDY RATIONALE}

I started this research with an interest in looking at how people's identities and relationships with others were being affected by increased communication and presence on Facebook. As explained in Chapter 1, this interest comes from personal experiences I have had on Facebook with family and friends but most significantly with my mother. I have found my relationship with her changing positively and negatively since I added her to my Facebook friends' list. I have also experienced changes in my friendships and with other family members due to my reactions to their postings or lack of interactions. I find myself wondering why a SNS like Facebook, which is supposed to bring greater connectivity with others, is also making me feel 
depressed and annoyed at times and I question whether or not it is due to its structure, an increased awareness of other people's lives, or miscommunication.

As shown in Chapter 2, research on youth and young adults showed that Facebook and other media sites with an underlying socialness to them were being used for identity exploration, flirting, dating, maintaining friendships, and promoting psychological well-being. What I term cyber identity performance was being done mainly thorough the projection of group and consumer connections. The literature concluded that sociability and culture were changing but it did not conjecture at the long term changes nor were connections made between these findings and broader social, cultural, and economic issues that might be driving these changes.

I then looked at literature that discussed Facebook use for all ages. This literature mostly discussed the negative drawbacks of Facebook use. The positive claims, discussed above, also included greater political and social awareness and activity. However, the negative claims included depression, anxiety, jealousy, addiction, corporate and psychological exploitation, false friendships and communities, and disingenuous social and political activity. This literature showed that my personal negative experiences with Facebook were also being experienced by others and validated my need to explore them further.

The studies conducted specifically on Facebook use did not focus on the fastest growing demographic of adult Facebook users, aged 35 to 40 (Marche, 2012; Turkle, 2011), which coincides with my age group at the time of reading these studies and literature. I realized my interest happened to coincide with one of the least researched demographics that is coming to be one of the dominating populations on Facebook. After conducting this literature review, I was now interested in knowing, why are my peer group and I on Facebook? How much of our cyber identity performances mimic that of younger populations? What does this say about people my own age?

The theoretical framework that I developed in Chapter 3 is intended to explore the socio-cultural implications of Facebook use for my peer group of older adults - those born before Generation Z. Through the lens of identity-related discourse analysis, avatar attachment theory, hyperreality, and deliberations on constraints on agency, I aim for a complex and rigorous analysis (Kincheloe \& Berry, 2004) of my study in Chapter 6. I seek to discover whether or not my participants perform cyber identity similarly to youth, young adults, and university students and what significance this has for identity discourse, age categorizations, general socio-cultural implications, and educational research.

\section{DESIGN}

Before reading the specific studies on Facebook, as an avid Facebook user, I knew the types of things I wanted to investigate in my study. I wanted to analyse people's profiles to see how they were performing their cyber identities. Drawing on my own Facebook profile, I knew I would be investigating the types of pictures people use for their main profile picture, their cover photo, and what they post in picture albums. 
I would also be looking at what people write or post as status updates. I wanted to see whether or not the types of postings and pictures that people use to perform their cyber identities somehow reflect dominant discourses on consumerism and identity. However, Facebook profiles can only tell me so much; they cannot tell me about the impacts of hyperreality on my participant's relationships with others or their sense of self. They also cannot tell me if people are aware of the impacts of dominant discourse, nor whether they are aware and have some type of agency despite of it. Therefore, I designed a survey (Appendix A) to complement my Facebook profile analysis so that my participants could articulate for themselves how they perform their cyber identities, their positive and negative experiences with Facebook use, and how advertising affects them.

\section{Participants}

Conducting a study which includes my own experiences and those of my friends on Facebook, some of whom I am close to offline as well, demands that I acknowledge my biases and view points towards technology and Facebook use. I have attempted to do this in Chapter 1. Additionally, because I know many of my participants, I had to step back from presuming that I knew why they performed their cyber identity in particular ways and what might be shaping their survey responses. Kincheloe (2004d) states, "as I highlight the voices of my ethnographic research subjects, I always contextualize their perspectives within the frames of macro-social, political, and economic concerns, the insights of social theory, and the discernment of critical hermeneutics" (p. 84). This contextualization of participant's voices speaks to the importance of considering a wide variety of socio-cultural factors that affect people's experiences. Applying hermeneutical sensitivity to analyzing my participants' responses means also questioning how people communicate and how communication is read. I have to try to remain as neutral as possible in my analysis.

As concerned as I was about my ability to remain unbiased in my analysis due to the familiarity I have with my participants, it was precisely that familiarity that made it possible to accomplish two things that occurred during the data collection from both the Facebook profile analysis and survey responses: 1. I had knowledge of these people online and offline, or at the very least I had observed them from time to time. This made my data mining quite revealing because I found things in some profiles that I did not expect. For example, some individuals included corporate likes on their pages in direct contrast to their open aversion to corporate marketing. Such contradiction allowed me to question how people perform their cyber identity and whether they are aware of the impacts of consumer and identity discourse, and; 2 . The survey responses revealed many things about individuals that I never would have known. One participant, whom I always thought seemed confident both online and offline, wrote about her feelings of inadequacy stemming from Facebook use. This revelation also had me consider the nature of how people perform their cyber 
identities. In the end my offline familiarity with my some of my participants gave me insight I might not have had if I had not known them in some context before this research. This is unlike the previous studies on Facebook I examined on Facebook where participants were not acquaintances of the researchers. Armed with this insight, I can more clearly see how the structure and format of Facebook might also be impacting some of the ways cyber identity is performed and read.

Furthermore in order to remain as neutral as possible, I first conducted the Facebook profile analysis and generated data and preliminary analyses before looking at the survey results. I did not want my assumptions about people's cyber identity performance to drive my final conclusions. I wanted to "read" the FPA results from an "audience" perspective (Hoechsmann \& Poyntz, 2012) before getting readings from the participants; this would help me ascertain whether my participants were reading their cyber identity performance and those of others as I was. Discrepancies between readings could be indicative of different life experiences, personal backgrounds, predispositions, and degrees of agency, all of which I consider through Johnson's four-point model in Chapter 6.

The survey was sent out with the request for participation in the middle of May, 2013 and I began collecting data from Facebook profiles in July 2013. I gathered data from 99 Facebook profiles, 37 males and 62 females, with an average age of 37. Of the females 54 are Canadian: 44 are people I grew up with in a small, Anglophone town in Quebec, two are family members, and eight are people I met through my university studies in Montreal, Quebec (two of which are francophone). The remaining eight represent international friends I met travelling or at university and family members: four are in Finland, one is British, one is South Asian, and one is Italian. The racial make-up is: 58 white, one African-American, two Asians, and one south-Asian. Of the 37 males: 32 are Canadian, 28 of which grew up with me, three I met at university, and one is a new acquaintance. The remaining six include three family members in Finland, one American I met at university, one Brit through university. The racial make-up is: 34 white, one Asian, and two southAsian. This represents quite a homogeneous group. Most participants come from a very small town where everyone knows each other $(73 \%)$ and are predominately white $(93 \%)$.

I received 18 surveys from 14 females and four males with an average age of 39. Of the 14 females, 11 are people I grew up with, one is a family member from Finland, one I know through university who now resides in England, and one lives in the US. 13 are white and one is African-American. Of the four males, three I grew up with and one I know through university; all are white. This sample also represents a relatively homogeneous group with $94 \%$ white and $78 \%$ coming from the same town. Another important note is that all the people who participated in my survey also agreed to the FPA, therefore, the survey population is also represented in the Facebook profile analysis population. The sample size and homogeneity limit the generalizability of these findings; however, they offer an entry point into better understanding the Facebook use of this age demographic. 


\section{DATA COLLECTION}

The structure of Facebook is always changing, as are the ways people perform their cyber identities. The Facebook profile analysis is a snap shot of 99 people's profiles in July, 2013 along with an analysis of their profile history; or at least the parts that have not been deleted. The deletion aspect is important to consider because there is no way of knowing what has been "posed" for data collection. The survey responses also represent a moment in time from June to July of 2013 and reflect how my peers were feeling at that time based on their experiences.

Facebook is always changing its format and structure. At the time of the data collection, cover photos had been around for close to two years with the introduction of the timeline feature on September 29th, 2011 (Dematteo, 2011). Some view the cover photo feature as beneficial for job seekers who can use it to display a portfolio. Essentially it is a "visual statement" (Walker, 2014) about the person and the first thing anyone will see because it dominates the profile page in size. It is also a public photo, unlike your profile picture. After my analysis, it seems that the function it serves is to promote a person's social desirability by reflecting something inspirational or drawn from nature. I discuss this in Chapter 5. The timeline feature allows people to scroll through their profile page history, highlight items, delete items, and manage who a person wants to be able to see items posted on their page (McDonald, 2011). New features have arisen since, such as the timeline slideshow which uses a program to mine the pictures that generated the most feedback on your profile and then turns them into a slideshow.

To evaluate the Facebook profile data collection, I conducted a content analysis; a textual approach to the study of media (Hoechsmann \& Poyntz, 2012). My goal was to see how people perform and read their projected cyber identity, and those of others, in order to assess the potential socio-cultural implications. My data set is the textual artifact of production because the prosumer's production choices are reflected in the content of the text. This type of content analysis is rooted in the earlier works of George Gerbner and Larry Grossberg's (Gerbner \& Gross, 1974) work on television content analysis. They established the importance of "message system analysis" which involves monitoring and coding symbols that function as "messages in cultivating conceptions of social reality" (p. 462). For the purpose of my study, this means that the production modalities of cyber identity performance on Facebook reflect underlying social, cultural, and economic relationships and processes. My particular interest was to see to what extent these production modalities reflect consumer and identity discourses arising out of a broad ideology of consumerism (Sandlin \& McLaren, 2010).

The content analysis of media involves "breaking down texts into their constituent parts in order to detect common patterns and tendencies" (Hoechsmann \& Poyntz, 2012, p. 79). In the case of cyber identity performance on Facebook, it means analyzing the visual and written production modalities that represent a person's avatar. These production modalities are a part of Facebook's basic format. 
Therefore, based on Facebook's basic format, I create a coding frame to detect trends or patterns of cyber identity performance by compiling statistics on the visual and written production modalities in Table 1. These statistics are generated to see if there are general tendencies in people's cyber identity performances that are indicative of hegemonic discourses and/or structural constraints.

The production modalities on Facebook include all the areas of a person's Facebook page that can be used to perform cyber identity (I provide a sample Facebook profile, my own, in Appendix B). I began by creating an excel chart with the following column headings: Facebook name, real name used (yes or no), age stated (yes or no), age otherwise known, profile picture (yes or no), type of profile picture, history of types of profile pictures (done by clicking on the profile picture and simply scrolling through all the pictures that have been uploaded for this purpose), cover picture (yes or no), number of friends, status update types (gleaned through history- this is done by scrolling down a person's profile page and goes on until they joined Facebook), number of likes, types of likes, number of albums, types of photo albums. It is necessary to analyse these categories because they directly reflect how cyber identity is performed through the basic format of Facebook. These categories also reveal information related to identity discourses involving beauty, self-promotion, consumerism, and social desirability. Next, I created another chart separated by gender. I felt this was important because I wanted to see if cyber identity is being performed differently by males and females and how this might connect to gender discourse. Therefore, separated by gender, I broke down the results of my initial data collection into a coding frame as follows:

- For types of profile pictures the codes were: natural, posed, self only, with child, with friend or partner, animal, nature, child, art/object.

- For history of profile pictures the codes were: no other picture, with a celebrity or brand, with a hobby or interest, religious, political, in nature, glamorous or professional photo of self, self only, work, quote, funny/comedic self, travel, and friends/family.

- For cover photo: none, more than one, nature, kids/friends/family, sexy, animal, political, cultural objects, celebrity, breastfeeding.

- For number of friends: lowest number, highest number, and average number for entire gender group.

- For number of likes: lowest number, highest number, and average number for entire gender group.

- For types of likes: books, weird/silly, health, social-political-cultural, shopping, grassroots, TV, farming/gardening, sports/hobbies, cooking/food, celebrity, restaurant, religious/spiritual, career related, music, travel, fashion/make-up.

- For \# of albums: lowest number, highest number, and average number.

- For types of albums: It was so standardized that I did not make statistics on it. They were mostly new baby, family, pets, travel, wedding, and other events.

- For status updates: A statistic on the percentage who had one. 
- For types of status updates: videos, pictures, everyday activity updates, birthday thanks, quotes, well-wishing, location updates, socio-political, socio-cultural, music links, sports related, game related, career related, news, posters, sexy, humour, life event, parenting links, children's pictures.

I then went through each participant's profile on the first chart of collected data and then counted how many times each item occurred. I indicated how many people had performed each coded item and what the corresponding percentage was. For example, I found that 30 females had a natural profile picture and this represented $48 \%$ of my participant population. The codes and percentages are depicted in Table 1.

Table 1. FPA Results

\begin{tabular}{lll}
\hline & 62 Females & 37 Males \\
\hline Age Indicated & $31 \%$ & $41 \%$ \\
Full Name Stated & $92 \%$ & $100 \%$ \\
Profile Picture & $100 \%$ & $100 \%$ \\
Natural- no audience intention & $48 \%$ & $35 \%$ \\
Posed-intentioned for an audience & $52 \%$ & $65 \%$ \\
Type of Profile Picture & & \\
Self Only & $34 \%$ & $49 \%$ \\
With Child or Family Member & $16 \%$ & $14 \%$ \\
With Animal & $3 \%$ & $0 \%$ \\
Animal Only & $3 \%$ & $5 \%$ \\
Self in Nature & $6 \%$ & $0 \%$ \\
Nature Only & $3 \%$ & $0 \%$ \\
Child Only & $11 \%$ & $0 \%$ \\
Art/Object & $3 \%$ & $16 \%$ \\
History of Profile Pictures & & \\
No Other Picture & $3 \%$ & $19 \%$ \\
With Celebrity or Brand Name & $3 \%$ & $5 \%$ \\
Hobby/ Interest & $8 \%$ & $30 \%$ \\
Religious & $3 \%$ & $3 \%$ \\
Political & $3 \%$ & $0 \%$ \\
Glam Shot/Professional Photo & $6 \%$ & $0 \%$ \\
Only Self & $11 \%$ & $0 \%$ \\
Work & $3 \%$ & $10 \%$ \\
\hline & & \\
& & \\
\hline
\end{tabular}

(Continued) 
Table 1. (Continued)

\begin{tabular}{|c|c|c|}
\hline & 62 Females & 37 Males \\
\hline Quotes & $3 \%$ & $0 \%$ \\
\hline Funny/Comedic of Self & $8 \%$ & $17 \%$ \\
\hline Travel & $15 \%$ & $13 \%$ \\
\hline Friends/Family & $73 \%$ & $73 \%$ \\
\hline \multicolumn{3}{|l|}{ Cover picture } \\
\hline None & $23 \%$ & $43 \%$ \\
\hline More Than 1 & $19 \%$ & $16 \%$ \\
\hline Nature & $42 \%$ & $16 \%$ \\
\hline Children/Family/Friends & $27 \%$ & $16 \%$ \\
\hline Sexualized & $4 \%$ & $2 \%$ \\
\hline Animal & $6 \%$ & $2 \%$ \\
\hline Political & $2 \%$ & $0 \%$ \\
\hline Cultural Objects & $6 \%$ & $14 \%$ \\
\hline Average \# of Friends & 358 & 322 \\
\hline Lowest \# & 40 & 24 \\
\hline Highest \# & 1255 & 733 \\
\hline Average \# of Likes & 105 & 54 \\
\hline Lowest \# & 2 & 1 \\
\hline Highest \# & 346 & 586 \\
\hline 0 likes & 2 & 3 \\
\hline \multicolumn{3}{|l|}{ Types of Likes } \\
\hline Books & $20 \%$ & $12 \%$ \\
\hline Weird/Silly & $12 \%$ & $15 \%$ \\
\hline Health & $13 \%$ & $3 \%$ \\
\hline Socio-Political-Cultural & $22 \%$ & $15 \%$ \\
\hline Shopping & $35 \%$ & $6 \%$ \\
\hline $\begin{array}{l}\text { Grassroots Organizations/Friend's } \\
\text { Businesses }\end{array}$ & $35 \%$ & $17 \%$ \\
\hline TV & $22 \%$ & $35 \%$ \\
\hline Farming/Gardening & $5 \%$ & $6 \%$ \\
\hline Sports/Hobbies & $22 \%$ & $15 \%$ \\
\hline Cooking/Food & $7 \%$ & $6 \%$ \\
\hline
\end{tabular}


Table 1. (Continued)

\begin{tabular}{|c|c|c|}
\hline & 62 Females & 37 Males \\
\hline Celebrity & $2 \%$ & $3 \%$ \\
\hline Restaurant & $3 \%$ & $0 \%$ \\
\hline Religious/Spiritual & $2 \%$ & $0 \%$ \\
\hline Career Related & $3 \%$ & $12 \%$ \\
\hline Music & $50 \%$ & $59 \%$ \\
\hline Travel & $12 \%$ & $6 \%$ \\
\hline Fashion/Make-Up & $10 \%$ & $0 \%$ \\
\hline Alcohol & $0 \%$ & $12 \%$ \\
\hline Poker & $0 \%$ & $9 \%$ \\
\hline \# of Albums on Average & 23.0 & 6.7 \\
\hline Lowest \# & 1.0 & 1.0 \\
\hline Highest \# & 89.0 & 40.0 \\
\hline 0 Albums & 5.0 & 2.0 \\
\hline Status Updates & $100 \%$ & $89 \%$ \\
\hline Video & $29 \%$ & $27 \%$ \\
\hline Picture & $89 \%$ & $42 \%$ \\
\hline Everyday Activities & $60 \%$ & $52 \%$ \\
\hline Birthday Thanks & $50 \%$ & $6 \%$ \\
\hline Quotes & $19 \%$ & $3 \%$ \\
\hline Well Wishing & $2 \%$ & $12 \%$ \\
\hline Location Updates & $4 \%$ & $15 \%$ \\
\hline Socio-Political & $21 \%$ & $18 \%$ \\
\hline Socio-Cultural & $23 \%$ & $4 \%$ \\
\hline Music Links & $10 \%$ & $15 \%$ \\
\hline Sports Related & $4 \%$ & $15 \%$ \\
\hline Game Related & $0 \%$ & $9 \%$ \\
\hline Career Related & $6 \%$ & $15 \%$ \\
\hline News & $8 \%$ & $12 \%$ \\
\hline Sexualized & $0 \%$ & $3 \%$ \\
\hline Humour & $35 \%$ & $33 \%$ \\
\hline Life Events (wedding, death, birth) & $50 \%$ & $6 \%$ \\
\hline Pictures of Children & $60 \%$ & $6 \%$ \\
\hline
\end{tabular}


The data collection and statistical break-down took approximately three weeks in the month of July, 2013. In August, 2013, I read the survey responses and created a coding frame for the open-ended questions based on the general tendencies in responses, along with the few exceptions. I did this by charting the responses to each question, which were also split by gender. When a similar response was given by a different participant I chose a word to best describe the type of response. For time, frequency, and numerical quantity related questions I created coding frames to best represent the general tendencies for all similar questions. These coding frames are seen in Tables 2 and 3 (Chapter 5). The last question was left open to participants to say whatever they liked about Facebook. Because there were only 18 respondents I was able to chart the responses most relevant to my research as anonymous quotes, since everyone had something different to say in Table 4 (Chapter 5). However, general tendencies can still be seen in these responses and their socio-cultural significance is discussed in Chapter 6.

After conducting the Facebook profile analysis and examining the survey response I realized that I was not able to discern whether consumer-related discourses were impacting my participants' cyber identity performances. In April 2014, I tracked corporate likes on my newsfeed for one week. Every time I saw that one of my participants had liked a brand I e-mailed them and asked them if they were aware they had liked the brand, when they had done so, if it was related to some type of promotion or if it was self-motivated. I e-mailed 11 people that showed up on my newsfeed, which included nine females and two males. The two males averaged 40 years of age, and the nine females, aged 30 to 70 , averaged 47 years of age. One male and six females responded. These are represented in Table 5 (Chapter 5). To further my analysis of consumer discourse on Facebook, I tracked my newsfeed for 8 days in mid June, 2014 to see how I was being targeted by advertising. Each day I took a screen shot of the advertising on my newsfeed, Appendix C, and I discuss the results in Chapter 5 and analyse them more critically in Chapter 6.

\section{DATA ANALYSIS}

The data in this study is examined in two parts. The first part, Chapter 5, relates the statistics generated by my Facebook profile analysis, survey responses, responses to why people liked corporate brands, and the results of my advertising screen shots. I consider how my results compare to the literature review in Chapter 2. The second part, Chapter 6, is a critical analysis of these results through Johnson's four-point model of inquiry into a media site/text (Hoechsmann \& Poyntz, 2012; Johnson, 1986-1987; Johnson et al., 2004) along with Marshall McLuhan's tetrad (McLuhan, 1988). Johnson's model explores the socio-cultural, economic, and psychological factors involved in cultural production, while McLuhan's tetrad allows for a reading of how Facebook is changing society and culture. 
Johnson's model for examining a media site allows me to explore whether or not power in the economic sphere is impacting my target group's subjectivity and cyber identity performances on Facebook through consumer-related discourse, age category conceptualizations, effects of hyperreality, and possible constraints on agency. I do this by filtering the study results through Johnson's model which allows me to consider all the different variables involved in cultural production. Johnson's model enables rigorous research through diverse perspectives and considerations in how culture is produced, which is necessary due to the complexity of power and knowledge production (Kincheloe, 2004b). Contextualization is also important in uncovering the workings of power in cultural to production and this study is an attempt to contextualize Facebook use and relate it to broader socio-cultural issues. Kincheloe (2005) explains:

(t)he key to successful counter-hegemonic cultural research involves: (a) the ability to link the production of representations, images, and signs of hyperreality to power in the political economy; and (b) the capacity, once this linkage is exposed and described, to delineate the highly complex effects of the reception of these images and signs on individuals located at various race, class, gender, and sexual coordinates in the web of reality. (p. 57)

Johnson's four-point model allows me to link cyber identity performance on Facebook to power in the political economy through multiple perspectives on cultural production. Within cultural studies, culture is conceived as a domain of struggle, in part due to capitalism which has given rise to a consumer culture necessary for feeding capitalist (re) production. It becomes hard to see power relations at the cultural production level as many are unaware of the influence dominant discourse, through various media, may be having on them. Drawing on cultural studies analytic tools, I am able to examine Facebook as a site of cultural reproduction within popular culture and to consider the socio-cultural implications of cyber identity performance on it for my target group.

\section{JOHNSON'S FOUR-POINT MODEL FOR INQUIRY OF A MEDIA SITE}

Johnson was a director of the Centre for Contemporary Cultural Studies (CCCS) at the University of Birmingham in the 1980s (Schulman, 1993). In an apt vein for this study, Johnson et al. (2004) developed a methodological model of inquiry of a media site to overcome the essentialist approaches that had preceded him by recognizing multiplicity, open-endedness, and the subjective nature of the cultural. His model takes into consideration the majority of cultural occurrences, which allows me to consider several factors that might be influencing the results I gathered from my study (Chapter 5) regarding my participant's cyber identity performances. 
Johnson's (1986-1987) four-point model looks like a circuit, each piece feeding into the other in a spiral effect:

$\leftrightarrow$ Production $\leftrightarrow$ Text $\leftrightarrow$ Readings $\leftrightarrow$ Lived Culture/Social Relations $\leftrightarrow$

These four points are also described as: (B) Production (producer), (C) Text (representation), and (D) Reading (will have conditional variance) and (A\&E) Everyday Life (consequences) (Johnson et al., 2004). Hoechsmann and Poyntz (2012) describe the circuit as "(1) production, (2) textual or material form, (3) audience, and (4) cultural influences on the media and media influences on culture" (p. 66). These four points are in a circuit and naturally feed into each other. When analysing a cultural form from a given point on this model, cultural researchers need to be aware that one point sometimes makes a person blind to the other moments that may be impacting the media site (Hoechsmann \& Low, 2008).

Johnson et al.'s (2014) methodological model of inquiry allows me to account for the subjective aspects of cultural production and consumption and how they connect to codes of behaviour and identity performance. It is an excellent way to achieve complexity in cultural production analysis. His model is a "holistic approach to understanding media culture, one that weaves together an analysis of media producers, texts, and audiences with the broader realities of culture and cultural change" (Hoechsmann \& Poyntz, 2012, p. 65). Most methods run against the grain of cultural studies, especially with regards to critique and codification (Johnson, 1986-1987), and narrowed critiques and systems of codification tend to ignore important aspects of cultural production.

Even though Johnson developed this model in the late 80s (Johnson, 1986-1987) before the internet and SNSs, it is an excellent heuristic for analysing SNSs which, like television, have a visual reading component to them. Yet, there is one large difference today- production includes producers and prosumers. When analysing television as a site of cultural production the four point model is looked at from one level of production: the production of the television producers, which is a reflection of cultural life and may affect cultural life through audience readings of its text. When analysing the cultural forms of SNSs like Facebook the audience members are also producers within the cultural site, making them prosumers. This makes the four point circuit of cultural production more complicated than with television because the production point needs to be analysed on three levels - from the production of the developers of Facebook, the production of the users of Facebook who produce cyber identities through it, and the interaction of these two cultural productions, which I discuss, in Chapter 6, as resulting in some co-production.

Johnson (1986-1987) developed his model around a theoretical and methodological divide within cultural studies that he felt was undermining comprehensive understandings of cultural forms. One side of the divide insisted that culture be studied as a whole, while the other side insisted on the specificity of situations or subjects. Johnson merged three distinct approaches to cultural studies theorizing and research 
to ensure that important cultural forms and processes are not neglected. The first approach he merged was the approach that critiques cultural production (Gramsci, 1971/1999; Willis, 1977). This approach is quite specific to capitalist production but neglects "attention to the dual nature of the circuit of cultural commodities" (Johnson, 1986-1987, p. 55). Johnson felt that too much emphasis is put on relating production to ideology in this approach while overlooking "textual forms and modes of its reception" (Johnson, 1986-1987, p. 56). An example of this is seen in statements that accurately describe the conditions of capitalist production and the fetishization of cultural commodities (Adorno, 1991; Benjamin, 1982/1999; Eco, 1986) but tend to make sweeping conclusions about the masses without considering individual motivations for the consumption of cultural products. A production "moment" should be just one stage in the analysis of cultural forms. Other aspects are not distinct from production, for example the end results of the text and how it is consumed by people. At the production point of analysis reflections are made on the various social and cultural constructs that may be shaping production.

The second approach Johnson (1986-1987) merges in his model is the textual approach. The reading of a text is as creative as its production. Some cultural analysts focus on production while others focus on the product or text. Textual analysis has a long linguistic and literary studies history. However, the text, it is argued, should not be the "ultimate object of cultural studies (...) [but rather] the social life of subjective forms at each moment of their circulation, including their textual embodiments" (p. 62). I consider the textual aspect of cyber identity performance on Facebook through the way the text of Facebook impacts production and the way that the text produced through cyber identity performance may be a reflection of dominant discourses while also impacting how people read each other.

The third approach Johnson (1986-1987) merges in his model is reader subjectivity and "lived culture". These make up the last two points of the model: readings/audience and cultural life. A distinction is made between "reader in the text [and] "reader in society" [which is the difference of] the most abstract moment (the analysis of forms) to the most concrete object (actual readers, as they are constituted, socially, historically, culturally)" (p. 66). The reader in the text comes from literary studies approaches and the reader in society comes from historical and sociological studies. It is hard to abstract one from another since subjectivity is always intertwined with the group; but there will be differences in peoples' readings occurring from "their social locations, their histories, their subjective interests, their private worlds" (p. 67). Thus, context is critical in cultural studies; both the immediate context and the broader socio-historical context.

In the point of readings/audience of Johnson's four point model, I also draw on three models that are used to theorize how people read media: the active audience model, media effects and cultivation models, and reception theories (Hoechsmann \& Poyntz, 2012). The active audience model contends that an author's original meaning intention is lost as soon as it is read by someone. This has serious repercussions when considering how people are reading each other's cyber performances on Facebook. 
In Chapter 6, I argue that the textual modalities of Facebook are infused with meaning coming from its structural code and basic format; and the reader cannot escape this. The meaning intentioned behind a person's cyber identity performance on Facebook will be skewed by the textual format of Facebook so the medium will affect the message (McLuhan, 1988; Turkle, 2011).

Drawing on media effects and cultivation models, which examine the effects media have on behavior (Hoechsmann \& Poyntz, 2012), I consider some of the negative consequences related to Facebook use and the negative readings some have of others and themselves. This has me question whether or not the medium of Facebook is responsible for all of the negative results associated with its use (discussed in Chapter 2) or if people's predispositions play a role in them. This enables me to look at the possible impact of dominant discourses from a different perspective by considering whether they arise from the self or from the surrounding culture.

Reception theories contend that audiences are capable of critical reflection when they read a medium. I consider whether or not my participants read Facebook critically when I assess how much agency is present by questioning if cyber identity performance on Facebook reflects dominant discourses related to consumerism and identity, if there is an awareness of Facebook's hyperreal nature, and how much selfsurveillance is present.

The last point on the model, cultural life, has me contemplate how Facebook as a medium impacts our everyday life and vice versa. I look at avatar attachment theory, identity discourse and age-related categorizations, and the possible effects of hyperreality as factors that may be driving people to go on Facebook and to stay there.

Johnson's (1986-1987) model deepens our understanding of culture and the forms it takes. Each approach that led to the development of a point on his model views the politics of culture differently. The production approach is concerned with the power of hegemonic cultural production and how to subvert it. The text-based approach is concerned with the creation of formative cultural practices. Lastly, the approaches that concern themselves with lived cultures have been most concerned with the politics of "representation" and marginalized people.

This model is not intended to be "a completed set of abstractions against which every partial approach can be judged" (Johnson, 1986-1987, p. 73). Its intention is to avoid reductionism and to use the other points to reconsider what has been analyzed, as they are not separable in the grand scheme of social reality.

\section{APPLYING JOHNSON'S FOUR-POINT MODEL TO MY STUDY RESULTS}

I analyse my study's finding (Chapter 5) and consider what they say from each point of Johnson's model (Chapter 6) as follows:

1. Production. A critical production analysis involves analyzing the origin of the 
cultural form, its capitalistic conditions, and how it has been influenced by dominant social values and discourses (Adorno, 1991; Althusser, 1965/2005 Gramsci, 1971/1999; Morrow \& Torres, 1995). Hoechsmann and Poyntz (2012) draw our attention to the "powerful relationship between business or economic life and media culture" (p. 68) and the production analysis point seeks to uncover the link between cultural production and social power in society. I consider the various factors that might be influencing cyber identity performance from the production point. This point concerns itself with all the social, political, and economic forces that work through media to reinforce power relations in society and come to impact how people shape media and how media shape people. This means production must be understood on two levels because there is the content produced by a corporation (Facebook) and the content produced by a prosumer through the corporation's content. Understanding production involves understanding how and why Facebook was produced and then understanding how cyber identity performance is produced through it. Based on my literature review and theoretical background, I consider the factors influencing these two levels of production to be:

- the socio-economic demographics of the corporation's producer(s) and the prosumer;

- consumer and identity discourses based on a broad ideology of consumerism;

- discourses related to age category conceptualizations;

- self-fetishization as a result of identity and consumer discourse and hyperreal considerations;

- constraints on agency reflected by homogeneity; and

- biological predispositions.

2. Text. This point has me deliberate how the textual modalities of Facebook (its basic format and structural codes) influence cyber identity performance. I then consider whether or not the texts or cyber identity performances produced by participants are reflections of dominant discourses and/or influenced by its textual modalities;

3. Readings. At this point I reflect on audience reception theories and I consider the Facebook profile analysis and viewpoints of my participants, as expressed in their surveys, through predisposition theories and considerations of emotional contagion.

4. Cultural Life. Here I take into account the interplay between cultural life and social life. People influence cultural production while simultaneously being affected by powers shaping cultural production. This point has me consider the influence of avatar attachment, dominant discourses, and considerations of hyperreality. Under this focal point I also employ McLuhan's tetrad. The tetrad shows the effects of new technology practices on society and culture in what is lost, gained, retrieved from the past, or enhanced. It also allows for a different perspective on the socio-cultural implications of Facebook use by considering 
these changes as changes in the way people communicate as opposed to changes stemming from the way technology makes people communicate. However, like Johnson, the tetrad also considers the social, cultural, and economic imperatives that have driven the technology practice.

McLuhan's tetrad (McLuhan, 1988) allows me to question how cyber identity performance on Facebook affects relationships and society by analyzing its effects through four points: what does Facebook enhance, reverse, retrieve, and make obsolete? These four points happen simultaneously, even if people only become aware of particular effects much later. Applied to my research focus of cyber identity performance on Facebook, the question becomes how does the medium of Facebook affect cyber identity performance and communication? I filter my study results through these four moments of the tetrad (Figure 2) to illuminate how Facebook "reverses" and "enhances" communication practices, and how Facebook is making certain forms of communication "obsolete", and "retrieving" others.

McLuhan was a Canadian communication theorist who argued in Understanding the Media (1964) and other key works that technology is an extension of the human being, so when something in the communication order changes, other changes will occur in cultural practices. He explains:

After three thousand years of explosion, by means of fragmentary and mechanical technologies, the Western world is imploding. During the mechanical age we had extended our bodies into space. Today, after more than a century of electric technology, we have extended our central nervous system itself in a global embrace, abolishing both space and time as far as our planet is concerned. Rapidly we approach the final phase of the extensions of man- the technological simulation of consciousness, when the creative process of knowing will be collectively and corporately extended to the whole of human society, much as we have already extended our senses and nerves by the various media. (p. 19)

I discuss this theory in relation to the tetrad because it is an important reminder of technological history; technology is not something separate from people but, rather, is an expression of social and cultural practices. McLuhan views the technological simulation of consciousness as the final phase of these expressions. Perhaps cyber identity performance on Facebook is a part of this final phase with people simulating their consciousness through its production modalities. It can be argued that cyber identity performance on Facebook is a hyperreal depiction of a person. However, in order to determine whether this extension, the technological simulation of consciousness, is positive or negative one should look at the history of human extensions because each extension has had a social and psychical effect. I use McLuhan's theory to consider from what human extension Facebook has arisen in order to have a more complete understanding of the socio-cultural implications of cyber identity performance on Facebook. 


\section{CHAPTER SUMMARY}

In this chapter I described my study, its rationale, design, my participants, and data collection process. This was followed by explaining how the study results are presented in Chapter 5 and critically examined in Chapter 6 by employing Johnson's four point model for analysing a media site/text and McLuhan's tetrad. 



\section{FACEBOOK STUDY RESULTS}

I'm friends with people who I wouldn't say hi to if I ran into them in person.

(Research participant)

Facebook use is filled with paradox. On the one hand, it is said to make people feel closer to each other and boost psychological well-being (Ellison et al., 2007; Grimes \& Fields, 2012; Turkle, 1995; Zhao et al., 2008); on the other hand, it is said to make people feel lonely and jealous of others (Philips \& Moberly, 2013; Turkle, 2011). Scholars contend that Facebook use is changing the nature of what friend and friendship means, how people socialize, relate to others, and think about themselves. It is also being used as a tool for increased social and political action (Kavador, 2012; Marichal, 2013; Davis III et al., 2012), yet, it is also cited as a source of personal exploitation (Grosser, 2011; van Dijck, 2013). More research needs to be conducted on whether or not Facebook use is leading to predominantly more negative or positive psychological, cultural, and social outcomes, especially since it is now being used by close to one billion people internationally of all ages (Brenner, 2013; International World Stats, 2014; Newsroom, 2013; Turkle, 2011). This study explores whether or not cyber identity on Facebook is performed by the Cusp Generation in similar ways and for the same reasons as by teens and young adults. If yes, this may have implications for what it means to be an adult. Additionally, if adults in the Cusp Generation are being affected by age-related identity discourses then younger people will most likely be affected by the same ones as they grow up. I also hope to reveal if there are differences between those who have grown up with SNSs as a natural part of their social lives (those born after the great digital divide and are members of Generation Z) and those who have not but still easily acquire new technology (members of the Cusp Generation and who are part digital native). I belong to the Cusp Generation and contend that if my peer group is having a hard time dealing with the hyperreal nature of Facebook through its effects on communication, relationships, and sense of self, then I contend these effects may be intensified with younger people who are considered to be more vulnerable (Attick, 2008; boyd, 2008) and less critical due to their technological immersion.

In this chapter, I relate the results of my study on Facebook. There are four parts involved in this study: a Facebook profile analysis (FPA), a survey, Facebook e-mail generated responses to why people had liked corporate brands, and an eight day home page analysis of advertising on my own Facebook profile. As mentioned, my 
study targets adults with an average age of 38. It is imperative to look at this age demographic because Facebook use has been increasing the most amongst 35 to 40 year olds (Turkle, 2011) and at the time of writing, little research had been published looking at why and how the Cusp Generation is using Facebook. This represents a serious gap in the scholarship, given that this demographic represents the first cohort of young people to grow up with the Internet, a group who were introduced to cyber identity performance on the threshold of becoming young adults (some early adopters would have been teenagers). To a great extent, this is the generation that straddles the divide between digital natives and immigrants (Prensky, 2001; Zur \& Zur, 2011) and many of these people were present on the ground floor for the new cyber industries, performing a variety of pioneer roles ranging from invention to coding to Web site design. As an age cohort, this group, the Cusp Generation, is the first of the cyber generations to have distinct memories of a previous era while being present for the profound changes that have taken place.

\section{FACEBOOK PROFILE ANALYSIS (FPA) AND SURVEY RESULTS}

The following FPA statistics were gathered from 99 of my own Facebook "friends". Many of these people I got to know through high school and, as I grew older, through the Anglophone community in the Montreal area. Some of my friends are also family members who reside in Finland. At the time of data collection, I had 397 friends on Facebook and I tried to include an equal number of males and females in the broadest age range possible in my 150 invitations. My hope was that by doing so I might come to be able to make general conclusions as well as deductions about whether or not gender discourse is playing a part in cyber identity performances. In the end, I analyzed 62 females ( $63 \%$ of respondents) and 37 males (36\% of respondents) with an average age of 37 . The average female age was 33 and the average male age was 38. I myself was 38 at the time of gathering this data in the summer of 2013 so it is not surprising that the mean ages are close to my own. The youngest female is 20 and the oldest is 68 , and the youngest male is 24 and the oldest is $68 .^{1}$ This sample was not meant to be representative of the distribution of males and females in my friends list, which had an almost even male to female representation with females at 50.9\%. However, it still provides insights into my research questions.

The survey (Appendix A) was sent out to 150 people and 18 people answered it. This included 14 females aged 33 to 67, with an average age of 39, and four males aged 31 to 50, with an average age of 38.5. The survey was broken into four sections. The first is "Other" and asked for general impressions about Facebook. These questions were designed to get some insight into how Facebook is affecting people's everyday lives. The second section is "Online Friends." These questions were meant to reveal what types of social capital were being created through Facebook and how relationships might be changing due to being online. The third section is "Profile and Usage." Here I wanted to hear from people directly about how they were performing their cyber identity. I also wanted to see whether advertising was having an impact. 
Lastly, the fourth section, "Other Comments", was for personal comments to see what the respondents wanted to express about their Facebook experience.

The four sections of the survey contained many open-ended questions and I generated two tables (Table 2, Table 3) using key words that reflected the descriptive items and phrases that were used by the respondents. Other questions of measure were charted accordingly. Table 2 reflects the data I gathered from questions one to four of "Other" and one to six of "Online Friends" of the Facebook survey (Appendix A). I did not chart the answers to question three in "Other" because the responses were reflected in either questions one or two of 'Other' or in the final section of the survey, "Other Comments". Table 3 represents survey questions one to 11 under "Profile and Usage". I charted the last section of the survey (Table 4) by selecting quotes that were of the most relevance for the study research generated by the final question on my survey: "Please tell me about anything that you feel is noteworthy regarding your experience with FB." I also separated males from females to see if there were any gender differences that would be indicative of the influence of gender discourse on cyber identity performance.

The Facebook profile statistics were generated through a content analysis of the production modalities of Facebook through the focal point of text on Johnson's fourpoint model. I wanted to see how meaning was being constructed by my participants. The survey questions were intended to generate findings on how participants viewed themselves and others on Facebook. By interrogating people's likes and dislikes about Facebook, I attempt to reveal how participants perceive the socio-cultural implications of cyber identity performance on Facebook. Readings of oneself and of others affect cyber identity performance, since I contend that people perform their identities for and against "others", discussed in Chapter 2. I relay the survey results through a coding frame I set up to detect trends or patterns (Table 2 and 3) as I did with the facebook profile analysis to show how people perceive their cyber identity performances on Facebook and how they feel these are impacting their lives. I simultaneously compare these findings to the Facebook profile analysis results. I do this so that I can have a more authentic understanding of the "production" and "reading" that occur. What follows is a synthesis of findings from these two parts of the study. I break them down into how cyber identity is performed, what function cyber identity performance serves, gender differences in cyber identity performance, and the positive claims and negative drawbacks associated with Facebook use by my participants and how these findings compare to the literature in Chapter 2.

\section{FACEBOOK STUDY FINDINGS: FPA AND SURVEY}

\section{How Cyber Identity Was Performed}

Cyber identity was performed around group or shared identity, consumer identity, socio-political identity, and narcissistic or self-absorbed identity. The importance of group and shared identity was evidenced through: 
1. The number of friends. The average number of friends was similar between males and females, at 322 and 358 respectively (Table 1). This demonstrates the importance of having a large group of friends.

2. Types of photos and albums. Almost everyone posted at least one album: $95 \%$ of men and $92 \%$ of females posted an album and these album types always contained pictures of events and family (Table 1). These albums are digital versions of physical photo albums where users upload pictures to a virtual album. One of the photos is chosen as the cover for the album and comments can be made for each photo or simply "liked".

3. Types of status updates. Types of status updates showed the importance of group identity. These included postings wishing people Happy Birthday and sociocultural and socio-political content (Table 1). Status update types were not discussed in previous studies. However, Joinson (2008) discusses them as one of the seven uses and gratifications associated with Facebook use.

4. Types of likes. Thirty-five $\%$ of women and $17 \%$ liked a grassroots organization or friend's business (Table 1), which show group connections. Likes were not discussed in previous studies.

5. Homogenous cyber identity depictions. Table 1 indicates consistencies among participants in the types of status updates, cover photos, profile pictures and types of albums posted. These may be an indication of cyber identity "mimicking" with my participants performing cyber identity through group identity, as was found by Zhao et al. (2008) and Ito et al. (2009). It may also be indicative of homogeneous performances of cyber identities or what Joinson (2008) refers to as shared identities. Grosser (2011) cites homogeneous cyber identity performances as resulting from the structure of Facebook and as limiting their identity performance.

6. The importance of social surveillance. When asked what people like about Facebook, ten out of 18 participants cited they like looking at friend's posts, nine out of 18 cited keeping in touch with old friends, and six out of 18 cited looking at photos (Table 2). When asked what they do most on Facebook, nine out of 18 said they check the newsfeed, five out of 18 said they check-up on people, and five out of 18 said they look at photos (Table 3). Excluding checking messages, these were the three most cited Facebook activities by my participants and they all revolve social surveillance. Zhao et al. (2008) found that social surveillance may signal the importance of group identity because people look at how others are performing their cyber identity for cues on how to perform their own in order to be a part of the group.

It seems that the members of the Cusp Generation are as just as concerned with articulating group identity through their cyber identity performance as are teens and young adults are. Having a large group of friends was discussed in terms of fierce competition and popularity by Zhao et al. (2008) and it makes me wonder if this finding represents an extension of adolescent behavior or is a reflection 
Table 2. Facebook survey: General impressions and "friends"

Females $14 \quad$ Males 4

Total

Other

1. What do you like about FB?

Networking

Looking at photos

Looking at friend's posts

Flirting

Events

Keeping in touch with old friends

Global community

Posting pictures

Sharing inspirational words

Getting updates with minimal contact

0

5

5

8

1

4

4

6

3

2

2

Spying on people/surveillance

Interaction with others

2. What do you dislike about FB?

Advertising

Over-posting/bragging posts/over-emoting

Privacy/security issues

Access to personal information

Addictive

Being tagged in photos

Game requests

Strange friend requests

Disturbing pictures

Full of junk

Feeling obligated to be on FB

4. Do you have more than one FB account?

If so, why?

For teaching, for a game

4

0

4

(Continued) 
Table 2. (Continued)

\begin{tabular}{|c|c|c|c|}
\hline & Females 14 & Males 4 & Total \\
\hline \multicolumn{4}{|c|}{ Online Friends } \\
\hline \multicolumn{4}{|c|}{$\begin{array}{l}\text { 1. Roughly what percentage of } F B \text { friends do } \\
\text { you interact with offline? }\end{array}$} \\
\hline $0-9 \%$ & 2 & 0 & 2 \\
\hline $10-20 \%$ & 2 & 4 & 6 \\
\hline $21-30 \%$ & 3 & 0 & 3 \\
\hline $31-40 \%$ & 3 & 0 & 3 \\
\hline $41-50 \%$ & 0 & 0 & 0 \\
\hline $51-60 \%$ & 1 & 0 & 1 \\
\hline $61-70 \%$ & 0 & 0 & 0 \\
\hline $71-80 \%$ & 0 & 0 & 0 \\
\hline $81-90 \%$ & 0 & 0 & 0 \\
\hline $91-100 \%$ & 1 & 0 & 1 \\
\hline \multicolumn{4}{|c|}{$\begin{array}{l}\text { 2. Roughly what percentage of FB friends do } \\
\text { you interact with only online? }\end{array}$} \\
\hline $0-9 \%$ & 5 & 1 & 6 \\
\hline $10-20 \%$ & 3 & 0 & 3 \\
\hline $21-30 \%$ & 3 & 1 & 4 \\
\hline $31-40 \%$ & 0 & 0 & 0 \\
\hline $41-50 \%$ & 2 & 2 & 4 \\
\hline $51-60 \%$ & 0 & 0 & 0 \\
\hline $61-70 \%$ & 0 & 0 & 0 \\
\hline $71-80 \%$ & 0 & 0 & 0 \\
\hline $81-90 \%$ & 1 & 0 & 1 \\
\hline $91-100 \%$ & 0 & 0 & 0 \\
\hline \multicolumn{4}{|c|}{$\begin{array}{l}\text { 3. Roughly what percentage of FB friends do } \\
\text { you have no contact with offline or online? }\end{array}$} \\
\hline $0-9 \%$ & 0 & 0 & 0 \\
\hline $10-20 \%$ & 1 & 1 & 2 \\
\hline $21-30 \%$ & 2 & 1 & 3 \\
\hline $31-40 \%$ & 1 & 0 & 1 \\
\hline $41-50 \%$ & 1 & 0 & 1 \\
\hline $51-60 \%$ & 2 & 2 & 4 \\
\hline $61-70 \%$ & 1 & 0 & 1 \\
\hline
\end{tabular}


Table 2. (Continued)

\begin{tabular}{|c|c|c|c|}
\hline & Females 14 & Males 4 & Total \\
\hline $71-80 \%$ & 2 & 0 & 2 \\
\hline $81-90 \%$ & 1 & 0 & 1 \\
\hline $91-100 \%$ & 0 & 0 & 0 \\
\hline \multicolumn{4}{|c|}{$\begin{array}{l}\text { And if there are such FB friends, why are you } \\
\text { friends with them? }\end{array}$} \\
\hline Potential networking & 0 & 1 & 1 \\
\hline Comfort & 0 & 1 & 1 \\
\hline Old high school friends & 3 & 0 & 3 \\
\hline Feel bad deleting & 1 & 0 & 1 \\
\hline Curiosity & 1 & 0 & 1 \\
\hline Live in a small town & 1 & 0 & 1 \\
\hline Met while travelling & 2 & 0 & 2 \\
\hline Alcohol inspired & 0 & 1 & 1 \\
\hline \multicolumn{4}{|c|}{$\begin{array}{l}\text { 5. Roughly what percentage of FB friends } \\
\text { would you consider as close friends? }\end{array}$} \\
\hline $0-9 \%$ & 6 & 2 & 8 \\
\hline $10-20 \%$ & 3 & 1 & 4 \\
\hline $21-30 \%$ & 2 & 1 & 3 \\
\hline $31-40 \%$ & 2 & 0 & 2 \\
\hline $41-50 \%$ & 0 & 0 & 0 \\
\hline $51-60 \%$ & 1 & 0 & 1 \\
\hline $61-70 \%$ & 0 & 0 & 0 \\
\hline $71-80 \%$ & 0 & 0 & 0 \\
\hline $81-90 \%$ & 0 & 0 & 0 \\
\hline $91-100 \%$ & 0 & 0 & 0 \\
\hline \multicolumn{4}{|c|}{$\begin{array}{l}\text { 4. For those you interact with offline, has the } \\
\text { nature of your relationship changed by being } \\
\text { on FB? }\end{array}$} \\
\hline YES & 9 & 1 & 10 \\
\hline \multicolumn{4}{|l|}{ If so, how? } \\
\hline More interaction & 0 & 1 & 1 \\
\hline Feel closer & 3 & 0 & 3 \\
\hline More transparency & 1 & 0 & 1 \\
\hline More informed & 5 & 0 & 5 \\
\hline
\end{tabular}


Table 2. (Continued)

\begin{tabular}{lccc}
\hline & Females 14 & Males 4 & Total \\
\hline $\begin{array}{l}\text { 6. Has Facebook changed your expectations } \\
\text { of your friends in any way? }\end{array}$ & 2 & & \\
YES & 0 & 1 & 3 \\
Less live nurturing required & 1 & 0 & 1 \\
Expect more interaction & 1 & 0 & 1 \\
May create false expectations & & & 1 \\
\hline
\end{tabular}

Table 3. Facebook survey: Profile and usage

\begin{tabular}{|c|c|c|c|}
\hline & $\begin{array}{c}14 \\
\text { Females }\end{array}$ & $\begin{array}{c}4 \\
\text { Males }\end{array}$ & $\begin{array}{c}18 \\
\text { Total }\end{array}$ \\
\hline \multicolumn{4}{|c|}{ 1. How do you choose your profile picture? } \\
\hline I look hot & 1 & 0 & 1 \\
\hline I look good & 6 & 2 & 8 \\
\hline Represents my mood/personality & 3 & 1 & 4 \\
\hline Not a close-up & 1 & 0 & 1 \\
\hline A close-up & 1 & 0 & 1 \\
\hline Any photo of myself & 2 & 1 & 3 \\
\hline \multicolumn{4}{|c|}{ 2. How do you choose your cover picture? } \\
\hline I relate to it & 5 & 1 & 6 \\
\hline It's a beautiful setting & 5 & 1 & 6 \\
\hline An interest of mine & 3 & 2 & 5 \\
\hline It should inspire & 2 & 1 & 3 \\
\hline A travel picture & 3 & 0 & 3 \\
\hline Has my kids in it & 1 & 0 & 1 \\
\hline Represents my values & 1 & 0 & 1 \\
\hline I don't have one & 1 & 0 & 1 \\
\hline \multicolumn{4}{|l|}{ (3) Do you share your full birth date? } \\
\hline YES & 5 & 2 & 7 \\
\hline $\begin{array}{l}\text { 3. If you do not share your birth d } \\
\text { have you chosen to hide it? }\end{array}$ & 9 & 2 & 11 \\
\hline Security concerns & 6 & 1 & 7 \\
\hline
\end{tabular}


Table 3. (Continued)

\begin{tabular}{|c|c|c|c|}
\hline & $\begin{array}{c}14 \\
\text { Females }\end{array}$ & $\begin{array}{c}4 \\
\text { Males }\end{array}$ & $\begin{array}{c}18 \\
\text { Total }\end{array}$ \\
\hline Age-related & 2 & 1 & 3 \\
\hline Hate birthday wishes & 1 & 0 & 1 \\
\hline \multicolumn{4}{|c|}{$\begin{array}{l}\text { 4. If you have "likes" how do you choose what } \\
\text { to like }\end{array}$} \\
\hline Friend's business & 4 & 1 & 5 \\
\hline Informative things & 2 & 1 & 3 \\
\hline Humorous & 4 & 1 & 5 \\
\hline Supporting a cause & 3 & 1 & 4 \\
\hline Creates an emotional response & 3 & 1 & 4 \\
\hline Friend's pictures & 2 & 2 & 4 \\
\hline \multicolumn{4}{|l|}{ 5. How often do you click on ads? } \\
\hline Never & 8 & 4 & 12 \\
\hline Rarely & 5 & 0 & 5 \\
\hline Sometimes & 1 & 0 & 1 \\
\hline Yes & 0 & 0 & 0 \\
\hline \multicolumn{4}{|c|}{$\begin{array}{l}\text { 6. How often do you find yourself looking at } \\
\text { them even without clicking on them? }\end{array}$} \\
\hline Never & 2 & 1 & 3 \\
\hline Rarely & 8 & 3 & 11 \\
\hline Sometimes & 3 & 0 & 3 \\
\hline Yes & 1 & 0 & 1 \\
\hline \multicolumn{4}{|l|}{ (7) Do ads affect you? } \\
\hline Yes & 8 & 1 & 9 \\
\hline \multicolumn{4}{|l|}{ 7. How do FB ads affect you? } \\
\hline Targeted ads & 3 & 0 & 3 \\
\hline Annoying & 4 & 0 & 4 \\
\hline Weight loss ads anger me & 1 & 0 & 1 \\
\hline Reminds me of capitalism & 0 & 1 & 1 \\
\hline \multicolumn{4}{|l|}{ 8. How often do you log onto FB? } \\
\hline Less than once/month & 0 & 1 & 1 \\
\hline
\end{tabular}


Table 3. (Continued)

\begin{tabular}{|c|c|c|c|}
\hline & $\begin{array}{c}14 \\
\text { Females }\end{array}$ & $\begin{array}{c}4 \\
\text { Males }\end{array}$ & $\begin{array}{c}18 \\
\text { Total }\end{array}$ \\
\hline 1/week & 1 & 0 & 1 \\
\hline 1/day & 2 & 2 & 4 \\
\hline $2-3 /$ day & 6 & 1 & 7 \\
\hline 4-5/day & 2 & 0 & 2 \\
\hline $6-7 /$ day & 1 & 0 & 1 \\
\hline 8-9/day & 0 & 0 & 0 \\
\hline 10+/day & 1 & 0 & 1 \\
\hline always on & 1 & 0 & 1 \\
\hline \multicolumn{4}{|c|}{ 9. How much time do you spend on FB/day? } \\
\hline Less than ten minutes & 0 & 1 & 1 \\
\hline 10 minutes & 3 & 0 & 3 \\
\hline 20 minutes & 3 & 2 & 5 \\
\hline 30 minutes & 3 & 1 & 4 \\
\hline 45 minutes & 0 & 0 & 0 \\
\hline 1 hour & 3 & 0 & 3 \\
\hline $1-2$ hours & 2 & 0 & 2 \\
\hline \multicolumn{4}{|l|}{ 10. What do you do most on FB? } \\
\hline Check newsfeed & 8 & 1 & 9 \\
\hline Messages & 5 & 1 & 6 \\
\hline Check notifications & 2 & 0 & 2 \\
\hline Add photos & 2 & 0 & 2 \\
\hline Check-up on people & 4 & 1 & 5 \\
\hline Share words of inspiration & 1 & 0 & 1 \\
\hline Be funny/look at funny things & 2 & 1 & 3 \\
\hline Entertain & 1 & 0 & 1 \\
\hline Look at photos & 4 & 1 & 5 \\
\hline Read articles & 1 & 1 & 2 \\
\hline Create event & 1 & 0 & 1 \\
\hline Share things & 1 & 0 & 1 \\
\hline \multicolumn{4}{|l|}{ 11. Do you play games on FB? } \\
\hline Yes & 4 & 0 & 4 \\
\hline
\end{tabular}


Table 4. Facebook survey: Other comments

Female Comments

I've been stalked

I've had emotional support

It has helped with loneliness

It's my main news source

I over share information which can put me at risk (home security)

I know how to work Facebook

Keeping far away connections are so important

I'm friends with people who I wouldn't say hi to if I ran into them in person

It can be negative and become a "show-off book" so it can create a lot of jealousy

Some people are inappropriate- young kids will learn hard lessons

There is pressure to be on Facebook

Sometimes I say "can we make this a Facebook free night?"

There is a danger of constantly being sucked in especially with a smart phone

Young kids don't know how to manage their identities

Cyber identity management is hard- I have so many identities

Sometimes I will just browse the newsfeed longer than usual and then I usually end up feeling bad about myself somehow

Male Comments

I don't say hi to people on street

'Defriending' is a tumultuous experience

It has changed way people communicate

It needs to be used moderately

It's a means of communication and networking

It has taken over my life but that's ok-I've met many like minded people

of the importance of a large social network for social capital purposes. Ensuring group belonging is also managed through cyber identity mimicking (Ito et al., 2009) and these results suggest that this may be happening with my participants through their rating of social surveillance as an important/frequent activity and the manifestation of homogenous cyber identity performances. Does this age group really care so much about what others are doing, how they look, and how they represent themselves or is the structure of Facebook just making it seem that way? 
Perhaps social surveillance is simply for the purpose of feeling connected. I take this issue up again in Chapter 6.

Cyber identity was also performed around consumer identity. This is not surprising since Facebook is not a neutral environment. It is run by a corporation with specific interests - those of making money. Therefore, encouraging the articulation of consumer identity is important because if people look to each other for cues on how to perform their identity - and consumer identity is one of these facets - then it can be assumed that people will have a higher tendency to perform their cyber identity around consumption. I saw patterns of consumer identity in the types of likes people had (Table 1). This category refers to things that are related to some type of advertising- products, campaigns, restaurants, events- or media-related hobby or interest, as also found by Zhao et al. (2008). Most people liked a mediarelated interest such as TV, Music, and Books. This is not surprising since media likes are prompted for during the account set-up through the basic format. However, other consumer identity likes included Shopping related items, Sports/Hobbies, and Fashion/Makeup (Table 1).

In order to see how my participants articulated liking media or corporate related items and how advertising on Facebook was impacting their consumer identity, I asked them questions about likes and advertising in questions four through seven in the survey section "Profile and Usage" (Table 3). The answers to the question about "what do you choose to like?" surprised me. In the FPA results (Table 1), $35 \%$ of females and $6 \%$ of males had liked a brand or logo linked to a corporation under the category of shopping. None of the participants had mentioned this in the survey. There were four mentions of friends' businesses, four about funny things, three about supporting a cause, and three about anything that causes an emotional reaction. These answers reflect loyalty, and being well-rounded. No one mentioned liking corporate brands related to media or shopping. Maybe they were somehow unaware that they were liking these brands? I created the corporate like follow-up email questions in order to better understand this discrepancy.

I felt the same tension when looking at the next question on advertising. This is one of the potential challenges of any such research - that is that participants are not always completely truthful, or that they respond in a manner that they expect the researcher to find helpful. Perhaps their answers are even truthful in the moment of filling out the survey and it reinforces the fact that these types of subjective survey responses must be taken with a sense of caution and that people's perceptions are forever changing. It must also be taken into consideration that many big brands ask people to like them in order to participate in some type of prize give away; in this scenario, it is possible that participants do not feel as though they have liked the corporate brand. What this finding suggests is an opportunity for further research to bring more insight into this issue, which I attempt later in the section on e-mail responses regarding corporate likes.

Regarding advertising, $57 \%$ of females and $100 \%$ of men said they never clicked on advertising through Facebook. Thirty-six percent of women said they "rarely" did 
and one woman said "sometimes". Next, I asked "do you find yourself looking at advertisements?" The majority of women, 57\%, said "rarely" as did the majority of men, $75 \%$. I then asked if they feel affected by advertising and if so how. Fifty-seven percent of women said yes. Most either felt "annoyed by them" in general and others felt "creeped-out" or "lured by targeted advertising". One woman said that "weight loss advertisements anger me" and one man said, "it reminds me of capitalism". These questions were designed to try to discern to what extent participants' cyber identity performances were being impacted by Facebook advertising. Their responses indicate that the commodified space of Facebook is creating a negative psychological response. Participants generally see advertising as an annoyance. However, these questions do not reveal the impact advertising has on consumer habits and the performance of cyber identity.

When a person likes a corporate brand it reinforces the brand's presence. This is because this liking of the brand is advertised on the right hand side of the home page beside the newsfeed page as well as on the newsfeed for everyone to see. These findings are significant given that Facebook makes its $85 \%$ of its money through advertising revenue generated on its site (Bohn, 2012). Facebook allows users to report back whether they find an add offensive so they can remove it from their user's feed - a gesture that shows how important it is to the makers of Facebook to keep users happy - and feed them what they want - while at the same time keeping their advertisers happy. Yet, the advertising never ends, and linking a person's "friends" to an advertisement through them having liked it reinforces the ads message. This shows the connection between economic imperatives and cultural forms (Eco, 1976, 1986; Kincheloe, 2005) and may be a sign of the link between power in the economy and the way cyber identities are performed on Facebook (Grosser, 2011; van Dijck, 2013). Later, I discuss the results of my eight day advertising analysis on my Facebook profile and explore targeted advertising, which these survey questions also did not elicit a response about. So even though my participant's performed some aspects of their cyber identity around consumer identity, no one ever talked about it.

Next, I found evidence of cyber identity being performed around socio-political identity. The FPA results (Table 1) showed that $22 \%$ of females and $15 \%$ of males had liked some type of social, political, or cultural event, cause or campaign. Thirtyfive percent of females and 17\% of males had liked either a friend's business or a grassroots organization. Through status updating, I saw that $21 \%$ of females and $18 \%$ of males had posted something involving a social or political cause or issue and $23 \%$ of females and $4 \%$ of males had posted something about society or culture. In the survey section under "Profile and Usage" I asked "If you have "likes" how do you choose what to like?" Three out of 14 females and one male responded that they like to support a cause (Table 3 ). These results suggest patterns of socio-political identity and Brenner's (2013) Pew report indicates that SNSs are becoming "an important arena for politics". Seeing this occurring with my peer group is exciting. However, I wonder if this articulation is a form of slacktivism (Morozov, 2011) with people not 
engaging in social and political issues offline and how it might be impacting readings of other people. On a side anecdote, I recall one of my "friends" promoting some extreme, right-wing political cause and instead of discussing his view points with him I removed him from my newsfeed. It has me question if the space of Facebook is conducive to political debate or if the hyperreal nature of communication destroys authentic communication, as Baudrillard would contend. I explore this issue further in Chapter 6.

Lastly, I found that cyber identity was also performed around narcissistic or selfabsorbed identity. I created this category based on profile picture and status update findings. The average person had dozens of profile pictures, reflecting a constant tinkering with one's Facebook profile avatar in relation to how one looks. One of my worst offenders had 178 profile pictures, the majority of which were of just her posing for the camera, looking fabulous. The odd thing is I know her quite well offline and I know that she has body image issues. Higher levels of offline low self-esteem and narcissism are correlated to greater online activity, according to Mehdizadeh (2010) and Nadkarni and Hofmann (2012). This may explain this particular participant's display of narcissism. In the survey, one participant stated that "[I] try to find a decent picture that I feel good and confident about" and another stated "I pick it [profile picture] if it's hot enough" (Table 3). I have noted that people I have just met offline and become friends with online often have a profile picture that I am quite surprised by, they always look better. It has me contemplating how much of these results can be attributed to narcissistic behavior, the emulation of celebrity culture, or a simple desire to be liked by others. It also has me thinking that if my peer group is prone to this type of cyber identity performance because of the mobilization of identity discourses related to beauty and celebrity culture, which encourages self-promotion, then it must be worse with teens who are considered more susceptible to these discourses (Attick, 2009). Additionally, if teens see their "friends" performing self-absorbed identity they may mimic this behaviour because their consciousness is even more defined through these hyperreal social network spaces. As Hoechsmann and Poyntz (2012) state, "Online social networks are in fact complementing and even displacing youth subcultures as vital nodes of youth identity. Digital media have thus become key modalities through which youth are exploring their [self]" (p. 153).

Anecdotally, I see further evidence of narcissistic behavior through people's self-absorbed status updates. Participants in my survey echo this sentiment with statements like "It can be negative and become a "show-off book" (Table 4) and nine out of 14 women complained about over-posting/bragging posts/over-emoting posts as a thing that they dislike about Facebook (Table 2). I wonder it younger adults and teens experience the same thing? Does my peer group not know proper Facebook etiquette (have they not developed the appropriate literacy to read and write their cyber identity performances as youth have? (see Ito et al., 2009)) or are some exhibiting narcissistic behavior? 


\section{Cyber Identity Performance Functions}

While cyber identity performance was articulated through group and consumer identity there were generally two functions this performance served: social desirability and social connectedness. Zhao et al. (2008) found that being socially desirable was one of the most important aspects of people's cyber identity performance and the primary motivator for joining was for social connection. These two functions overlap because being socially desirable helps to increase social connections. The importance of social desirability in my study was evidenced in looking good, wellrounded, and popular through:

1. A nice profile picture. Cyber identity is first revealed through a profile picture on Facebook. It is what everyone sees even before becoming Facebook "friends" with a person. It is also how most people show who they are, making identity and appearance closely intertwined (Hum et al., 2011; Morrison, 2010, 2011) which reflects consumer-related identity discourse. The majority of the immediate profiles pictures posted by males and females were of the self only (Table 1). I broke these into two categories- posed (intentioned for an audience) or natural (no audience intention). Posed indicates a picture when it was either taken professionally or was intentioned for an audience and may have undergone some type of retouching technology. A natural photo looked to be more spontaneous and not so retouched. Of the 62 females, 52\% had a posed photo and of the 37 males it was $65 \%$. Like Zhao et al. (2008), my participants were also concerned with social desirability. Zhao et al. found that profile pictures, whether choreographed or rough, were all an attempt to be socially desirable. I found the same to be true in the FPA results. Profile pictures, whether I designated them as natural or posed, were always a good photo of the person. In the survey, I asked how people chose their profile picture. Fifty percent of women said they had to "look good", with one woman going as far to say she has to "look hot", and $21 \%$ said the photo needs to reflect their mood or personality (Table 3). Fifty percent of men said they have to "look good". To have found a profile picture that was socially undesirable would have been positioned as a form of resistance in North American appearance-driven, commercial society. Before Facebook, offline social desirability would have been primarily carried out through being a part of the "in" group by wearing the "right" brands and knowing the "right" popular culture (Fiske, 2010). Facebook allows a user to generate the appearance of all of this and hopefully get the "right" people on one's friends list which will generate more social capital. There is a spill-over effect of trying to "fit in" offline that affects the online world (Morrison, 2011).

2. A cover photo that makes a person seem well-rounded. There was a common theme for cover photos in the FPA results: those who had one $(57 \%$ of men and $77 \%$ of women) usually had a nature photo with water and trees being the most popular (Table 1). When asked in the survey, "How do you choose your 
cover picture?" $50 \%$ of males and females responded that it should inspire or be beautiful (Table 3). This is consistent with the FPA results. "Relating" to the picture was another top answer among women and representing an interest was articulated by both men and women. This data, again, reflects the importance of seeming well-rounded, as identified by Zhao et al. (2008).

The cover photo lends itself to the feeling of a book cover and this might be also why these were the common choice for these photos. The dimensions of this photo (it spans the entire top of the profile page) are more conducive to panoramic photos, which are typically nature photos. Most males and females did not have more than one cover photo. This may indicate that it is not as important as the profile picture and is more like an album cover on a photo album with the profile picture being a picture inset on the album's cover indicating what is to be found inside. Unlike Dematteo's (2011) claim that the cover photo can be used as an "infographic resume", none of my participants used it for career-related purposes.

3. Types of albums. The types of albums were generally the same with baby, family, pets, travel, nature, and events being the most prevalent (Table 1). These categories not only depict people as a part of a group but they show well-roundedness, both of which are important aspects of being socially desirable, according to Zhao et al. (2008).

4. Humorous and words of inspiration status updates. Humorous postings were second in frequency for status update types for both men and women in the FPA (Table 1) and one woman in the survey stated that she likes to share words of inspiration (Table 3). These are both indications of well-roundedness.

For youth "who you know" is increasingly public and status can be attained be securing certain "friends" to your network (Hoechsmann \& Poyntz, 2012); this securing of friends is attained through being socially desirable just as it is for people offline because identity performance connects to the desire to be recognized (Butler, 2001). It was hard to tell whether social desirability is important for my peer group because of ego, or if it was related to increasing friends and social capital, but it was clearly also a conditioned response to the culture of Facebook where images of self are carefully selected. A lot of this depiction of social desirability was about looking well-rounded and projecting psychological well-being and may serve to make a person feel better about him or herself, especially if considering how the Facebook timeline serves the function of a scrapbook (O'Dell, 2011).

The importance of social connectedness was demonstrated through a person's "friends" list and being socially active. Social connectedness may serve to help increase a person's social network or it may serve to boost psychological well-being. It was evidenced through:

1. The number of friends. The number of friends also aids in socially desirability and the two categories often overlap with each other because appearing socially desirable also helps with getting more friends and increasing a person's social network. One male in my survey stated he has a large friends list for "potential 
networking" (Table 2). The importance of a large social network was also reflected in the survey question about the percentage of Facebook "friends" people are close to (Table 2). Forty-three percent of women declared $0 \%$ to $9 \%$ as did two of the four men surveyed. Even though my sample was statistically small, it reflects the results noted by Ellison et al. (2007) and Grimes and Fields (2012), which showed that most people's Facebook "friends" suggest the maintenance of weak ties. The number of friends also served to increase one male survey participant's psychological well-being. When asked why he was friends with people on Facebook he had no interaction with offline or online he said it was for "the comfort of having a large group of friends" (Table 2).

2. The activity of social surveillance. Browsing other people's profiles and checking the news feed are indicators of the importance of keeping informed about other people and I refer to this as social surveillance. The importance of social surveillance was elicited through the survey questions in Table 2. In the survey, when asked "What do you like about Facebook?" the predominant answer by women, stated by $57 \%$, and two of the four men was looking at friend's posts. Another way the importance of social investigation was brought forth was through the last three questions in the Profile and Usage section of the survey (Table 3) which asked about time and frequency of use, and activities. Ninetythree percent of women and $75 \%$ of men logged onto Facebook daily, and most women indicated they logged on two to three times per day. The time spent logged in varied for the majority of men and women between 20 and 30 minutes. Joinson's (2008) study found that frequent logins were done by those who ranked social investigation as a primary motivation for use and those who spent more time ranked content gratification as a primary motivation for use. Looking at the frequency and time break down (Table 3), women logged in more frequently than men and on average spent more time on Facebook. Therefore, within this small sample, women use Facebook more than men but these numbers do not indicate whether frequency relates to time spent on Facebook per session. A more nuanced set of questions or another research mechanism to time actual login lengths would need to be developed in future research to answer this question more fully. The lack of data showing how much time is spent per login has me question whether time spent on Facebook per day is a reflection of the number of logins for social investigation purposes or if content gratification represents one login while the rest are quick social investigations to see what people are up to; I admit that this is what I do.

3. Messaging. The same question as stated above "What do you like about Facebook?" also generated the response of keeping in touch with old friends by three out of four men and six out of 14 females.

4. Status updating. In the FPA (Table 1), $100 \%$ of women and $89 \%$ of men posted status updates. Stating Everyday Activities was the most common update, for example "I just had the most wonderful dinner" and it show the importance of keeping others informed about what is going on in a participant's life. This may 
help to increase social connectedness, especially if other people "like" your comment or comment on it.

5. Photos. Posting photos with friends and family is another way to show social connectedness and this was seen in the FPA results (Table 1).

Displaying social connectedness can be a strategy for gaining more "friends." Similar to offline social norms, appearing popular can increase popularity. However, networking was cited as a reason for having a large friend's lists by one male, as was the comfort of belonging to a broader group (Table 2). No one mentioned it serving the purpose of increasing popularity, but that would sound "juvenile" and no one would ever admit to that; perhaps not even a teen. It is also hard to discern whether or not social surveillance was done for feeling socially connected or for looking for clues on how to "belong" to increase social desirability. I found status updating about everyday mundane activities odd. Is it about maintaining a cyber presence, a manifestation of narcissism, looking for contact in hoping someone will respond, or not knowing Facebook etiquette, given that people get annoyed with over-posting? This annoyance seems to be an indicator there are Facebook social norms. I have felt the same annoyance with "friends" posting and I often do not how to "read" people; if a "friend" does this type of status updating frequently, I take it as a form of narcissism, SNS inexperience, or an awkwardness much like mixing up social cues in the offline environment. If it is infrequent, I am more likely to make a comment because I feel like they are looking for contact.

\section{Gender Differences and Evidence of the Mobilization of Gender Discourse}

Males and females performed their cyber identities differently, as was also noted by Ito et al. (2009), Joinson (2008), and Stern (2008). Ito et al. do not elaborate on these differences. Joinson contends that females see the social connection aspect as more important than males and it was evidenced by more frequent posting of pictures. Stern observes that teen boys join Facebook for flirting and dating purposes and young girls join because they are mimicking older girls. These are the gender differences I found in my participant's cyber identity performances:

1. Females are more socially proactive than males on Facebook. Even though social connection and social surveillance scored high for both males and females in my survey results, females were more proactive building social connections and this was seen through both the FPA and survey results. In the FPA results (Table 1), Women liked more Grassroots Organizations/Friend's Businesses (by $18 \%$ ) which may be indicative of rating social connection higher than males. They also far exceeded men in the number of albums posted with an average of 16.3 more albums per female user. When I asked my participants what they like about Facebook (Table 2), women indicated seven things they liked about Facebook that males did not cite, four of which link to social connectednessevents, posting pictures, global community, and interacting with others. The 
study results reinforce Joinson's findings that females score social connection and photographs higher than males and status updating as only slightly higher.

2. Males are less personal. Looking at the type of profile pictures the results were similar for both men and women. Each had mostly photos of themselves and then a small number were with a child or family member. However, men had more Art/Object as profile pictures than women, making them a little less personal. This might be indicative of females valuing social connection more than males (Joinson, 2008), therefore, they may try to make their profiles more personal, or it might indicate a lack of desire by men to personalize their profiles.

3. Females 'like' more things than males. On average women liked 105 things and males liked 54 things (Table 1). This category refers to things that are related to some type of advertising- products, campaigns, restaurants, events- and are not linked specifically to production modalities.

4. Females were more active with status updating. All women in the FPA (Table 1) had at least one status update as compared to $89 \%$ of men and they dominated in frequency in categories linked to looking well-rounded: posting pictures, giving birthday thanks, posting quotes, social and cultural issues, updating life events, and posting pictures of children.

5. Males mentioned networking as something they liked about Facebook, a category not articulated by women (Table 2). This reinforces male gender discourse where males are deemed to be more career oriented.

My study also found gender differences in cyber identity performance that might be connected to gender discourses along with indications of shifting gender discourse. First, female gender discourse being exhibited by female participants was evidenced through:

1. Only females liking Fashion/Make-Up (Table 1); and

2. in the survey section "Online Friends" (Table 2), I asked "And if there are such FB friends, why are you friends with them?" with regards to friends people have no contact with anywhere. Thirty-eight percent of the female respondents replied that they knew these people in high school, with the rest of the answers varying with comments such as: "I met them while traveling", "I am curious about their lives", "I feel bad deleing them", and "I live in a small town so I feel obliged." The female responses reflect female-related gender discourse where women often feel obligated to be nice and accepting.

Evidence of male's mobilization of male gender discourse was evidenced through:

1. Males liking two categories which women had no results for: Alcohol and Poker, which are typically viewed as "masculine" activities (Table 1).

2. Males leading in Career Related postings by $9 \%$, Sports Related content by $11 \%$ and Game Related by $9 \%$ (women had none for this category), reflecting, again, male gender discourse. 
3. In the "Other" section of the survey I asked what people like about Facebook. Males mentioned networking as a category they liked about Facebook, a category not articulated by women. This, again, reinforces gender discourse where males are deemed to be more career oriented.

I also found what I feel to be is evidence of shifts in gender discourse, specifically, beauty-related discourse that is more often connected to female identity performance. Men exhibited the internalization of female-related beauty discourse through:

1. Having more 'posed' profile pictures than females. Males had $13 \%$ more posed profile pictures (Table 1). This might indicate that dominant discourse related to beauty and typically associated with females has crept into the male psyche.

2. The non-disclosure of age. Men were almost as guarded about revealing their age as women were; only $41 \%$ of men indicted their age, as compared to $31 \%$ of women (Table 1). One male participant in my survey male alludes to beauty discourse stating “Also I don't like younger friends to know my age." Popular discourse would suggest that women often do not like to say their age for fear of seeming old; therefore, this discrepancy indicates that perhaps worry over looking or seeming old has crept into the male psyche. However, omitting age as an identifier may also suggest sensitivity to security issues, like fear of identity theft.

These results show that male gender discourse may be changing as a result of beauty-related consumer and identity discourse. Male cyber identity performances also reflect the importance of social connection more typically attributed to females (Geary \& Bjorklund, 2000). The structure and format of Facebook may be causing these changes (Mehdizadeh, 2010) as might shifts in the concept of adult, and new online social norms (Hum et al., 2011). These issues are explored in Chapter 6.

As with all identity performance, there will always be some anomalies. The anomalies I found in my study were for males: a religious symbols as a profile picture, a pair of high heels as a cover photo, an inspirational quote as a status update (more typical for females), an album centered on drinking alcohol, and another with fat booth photos. For females the irregularities were: self with a celebrity or brand as a profile picture, having only one profile picture in the history, a political protest as a cover photo, a breast feeding cover photo, an album with the participant drinking alcohol, an album with tattoo work, and three career related status updates.

\section{Hyperreal Enchantment and Disenchantment}

Facebook is hyperreal because it is a technological simulation of a person's identity and community. As discussed, hyperreality or simulation can cause confusion over what is authentic because appearances can substitute for the materially real; yet, many have come to prefer the hyperreal (Eco, 1986; Turkle, 2011). I feel that the positive and negative claims made by my participants about their Facebook use 
are connected to either knowing how to harness the hyperreal nature of Facebook (knowing how to read things in this space), or not being aware that the hyperreal, with all of its shiny promises, encourages overconsumption in a search for meaning. The comments generated in the survey in Tables 2, 3, and 4 demonstrate that Facebook is impacting people in both positive and negative ways. The positives include the role Facebook plays in:

- Maintaining distant connections. One woman stated, "Keeping far away connections are so important". This is similar to findings by Grimes and Fields (2012), Ellison et al. (2007), and Zhao et al. (2008). Here the hyperreal space of Facebook brings connection where there otherwise was none or a limited one.

- Being a source of emotional support and psychological well-being. "I've had emotional support" and "It has helped with loneliness" are sentiments expressed by some females and are similar to findings by boyd (2008), Turkle (1995), and Nadkarni and Hoffman (2012). Ellison et al. showed that the building of weak ties leading to more social capital held many positive outcomes for people. Grimes and Fields found one of these positive outcomes to be psychological well-being and this was articulated by a few of my respondents. One woman said, "when my mom was gravely ill we had so much support through our Facebook "friends" that I'm sure it had something to do with her miraculous recovery." The same affects can be seen offline when someone ill suddenly has even strangers rallying for him or her. But unlike offline, weak ties and even "friends of friends" can be rallied at a much faster rate. One man said that the reason he is friends with people on Facebook that he has zero contact with anywhere else is because "I get a feeling of comfort from them being there". The hyperreal is generating some of the positive psychological benefits of people's social networks on Facebook.

- Serving as a news source. One female stated, "It's my main news source". This was not discussed in the literature review. However, it signals the importance of Facebook being used as an information resource and many critical questions must be asked. Where does the news come from? What stories are displayed? Of course the same can be asked about the World Wide Web in general. However, what differs here is that people are reading what others in an affinity group have chosen to share with peers. It may be a form of democratic news sharing. However, it may lead to an over-proliferation of information and apathy if a person is seeing news postings from a particular "friend" too much; a concern also noted with the socio-political function of Facebook (Merrin, 2005; Morozov, 2011). When a person is bombarded by anything, over time, they tend to ignore it.

- Using Facebook for career and dating. One woman, when asked "what do you like about Facebook?", said "the publishing of stories or newsfeed things of my own, as an actor and a bachelorette- my own branding so to speak". She is clearly using Facebook to selectively present and market herself for dating and career purposes. She is branding herself and is aware of it and perhaps my peer group is aware that we all brand ourselves. This awareness impacts the way we read each 
other and this awareness should be cultivated in younger people who might take branding more seriously.

- The socio-political use of Facebook. The ability to use Facebook to generate awareness and support various causes and grass roots businesses was seen in the FPA and survey results. This shows that Facebook has moved beyond being simply a social networking tool and is now also becoming a marketing tool, a business necessity, and a tool for creating social and political awareness. This supports claims made by Kavador (2012), Marichal (2013), and Davis III et al. (2012). Cyber identity performances are becoming entwined with business and politics.

The negative drawbacks of Facebook use for were:

- Safety issues. One woman stated, "I've been stalked". A boyfriend at the time started posting excessively on her wall, making his presence felt, and commenting on old photos, making her feel watched. He would also make comments if he noticed her on the chat function about her use of time. She eventually ended the relationship and deleted and blocked him from her Facebook contacts. She felt violated; an indication of the "realness" of her cyber identity and its offline impact on her. Another woman said "I over share information which can put me at risk". Joinson (2008) states that women restrict their privacy more but the issue brought out in my survey was not solely about feeling like privacy and security was at risk. Some women stated: "I'm fed up about hearing about this issue", "I hate being warned about security constantly", and "I feel confused about privacy". Access to personal information was, however, a concern for three women and not cited by any men. The omission of a birthday was not about revealing age but rather of privacy and security concerns, yet the latter is a good excuse to not have to admit to not wanting to reveal one's age. However, one female respondent did outright say she omitted it because "I use Facebook for flirting and dating so I don't want the boys to know how old I am". One male also indicated that he hides his age because "I have a lot of young friends". Therefore, social desirableness does outright factor into this for some.

- Facebook being a waste of time or addictive. In the survey question "what do you dislike about Facebook?" three women, 21\%, said "it's addictive". Women articulated this as "Sometimes I say 'can we make this a Facebook free night?", "Sometimes I will just browse the newsfeed longer than usual and then I usually end up feeling bad about myself somehow", and "There is a danger of constantly being sucked in especially with a smart phone". Two males said, "It needs to be used moderately" and "It has taken over my life but that's ok-I've met many like minded people". These sentiments are echoed in the literature by Boon and Sinclair (2009) and Turkle (2011) and may be indications of overconsumption related to hyperreality. People are over-searching for connection and meaning.

- Feeling awkward with Facebook "friends" offline. One woman stated, "I'm friends with people who I wouldn't say hi to if I ran into them in person" and one 
male said, “I don't say hi to people on street". Ito et al. (2009) discuss changes in the term friend and friendship resulting from SNSs as both enabling and awkward. One male stated "Defriending' is a tumultuous experience". I think of this as the hyperreal disenchantment of Facebook. We get to "know" people online and then feel weird when we see them offline. It indicates that the Cusp Generation has a hard negotiating online and offline friendships and it may be even more difficult for younger generations. Will it make younger people more awkward offline if most of their socializing is done online? This has serious socio-cultural implications especially when considering that most people go online due to widespread community fragmentation. Perhaps there is a way to bridge the gap.

- Changes in friendships. Some participants felt closer or more informed about their friends' lives, one male even said his friendships required "less live nurturing to be maintained". However, others felt Facebook was creating negative outcomes. One female said "people might expect more interaction" and another said "it may create false expectations". These answers have socio-cultural implications: it makes some feel more connected and closer to other people, it generates hyperreal friendships where online interactions do not necessarily translate to offline interactions for some people, and it is distancing people from face to face contact. These are hyperreal concerns and are also brought up in the literature review by Boon \& Sinclair (2009), Turkle (1995), and Ito et al. (2009).

- Jealousy and narcissism. One woman said, "It can be negative and become a "show-off book" so it can create a lot of jealousy". This reflects theorizing that people may over-post due to narcissistic predispositions, some may be selfmarketing, and that Facebook use may lead to negative psychological outcomes. Interestingly, this same woman who made the above statement is someone I know offline, and she has always appeared to be very confident and she has a lot of friends; she is socially very busy. This indicates to me that Facebook affects even those I would deem to be "strong" people and has me worry about people with more obvious low self-esteems even though it has been shown to help users with low self-esteem. It may also indicate a pressure for people to appear to have it all going on, to be in control, to be happy and successful. Joinson (2008) states, "an increased awareness of others' actions has potentially important implications for how we relate to others, and understand ourselves" (p. 1035) and this sentiment is echoed in my survey. People either become annoyed with an increased awareness coming from people over-posting and/or feel closer and more informed.

- Social life lessons have more consequence and persistence due to technology traces. This is similar to Ito et al., Grimes and Fields, and Turkle's discussion of the spill-over effects or persistence of life lessons as a result of SNS use. Technology traces are the persistence of information on people's profiles. The similarity I found was more about technology traces than about social life lessons. Nine out of 14 women complained about over-posting/bragging posts/over-emoting. The consequences were that some respondents would remove these types of status updaters from their newsfeed or even delete them if they were always negative. 
The notion of technology traces comes from people's annoyance with overposting and bragging as well as with the changes in friendship expectations. Expecting more interaction and creating false expectations are also the result of people seeing, through technology traces, what others have been up to and expecting to be involved. Before Facebook, these situations would not have been so common but this has changed with access to profuse amounts of shared information. One participant did refer to social life lessons having more consequence stating, "Some people are inappropriate - young kids will learn hard lessons".

- A pressure to be on Facebook. One woman declared, "There is pressure to be on Facebook" and this is also discussed by Boon \& Sinclair (2009). One man expressed a sentiment repeated by others, "I feel obligated to be on it to maintain certain connections, for whom FB has become the predominant medium of communication". I also feel this way. I have established so many friendships online that I know would not exist offline that it is hard to imagine not being there. In my younger days, if you met someone and they moved away, maybe you wrote letters on occasion, but usually you never saw them again. Now you meet someone and you see them all the time on Facebook and it feels like you "know" them. Yet, you never see them offline. I know that my close friends are the ones I see offline because they are the ones I have a built a more intimate connection with, the ones who are worth more of my "real" time investment.

- Performance exhaustion. One female participant stated, "Even I find managing a 'cyber identity' too difficult. It's too uncomfortable because I have so many identities that are equally important to me. The only time I managed such a meta-identity management was on my wedding day!" It is interesting that she references her wedding day, one of the most contrived and highly performed days in most women's lives. There is a societal expectation to be perfect that day and a massive consumer industry that caters to it; it is all perpetuated through dominant discourses related to identity, gender, and beauty. This particular female participant equates the cyber identity performance to be as challenging as the performance she put on for her wedding day, indicating that she feels the pressure of societal expectations in cyber identity performance. This is also discussed by Turkle (2011). Another woman said she likes "getting updates with minimal contact". I found this odd since women rate social connectedness highly. It has me questioning what this is saying about Facebook. From a hyperreality perspective, are people becoming socially asphyxiated by too much contact as Merrin (2005) and Turkle (2011) contend? Sometimes too much stimulus makes people numb, and having to be constantly "on" in a hypersocial medium can become tiring and cause performance exhaustion.

One new finding the survey generated was by a female who stated, "I understand FB better than a lot of people do. I know what works and what doesn't. People 
wonder why I get so many comments". She has discovered how to manipulate the Facebook code (Weber, 2010) and is using it to generate social capital. It has me question what might happen if everyone knew how to do this? This is different than offline knowledge of knowing how to win popularity because it is about working a software code. However, just like offline popularity, there are always new ways of generating social capital and if everyone started receiving similar levels of attention due to the cracking of the Facebook Code, I am quite sure people would decide who to friend based on new criteria.

My participants cited many positive benefits to Facebook use including using it for networking, as a news source, for social and political activity, as a source of emotional and psychological well-being, and maintaining distant connections. However the negative drawbacks of a pressure to be on, wasting time, addiction, jealousy, awkward offline encounters, and performance anxiety indicate that it is difficult to balance the hyperreal nature of Facebook with its side benefits. The simulation of friendships on Facebook is hard to negotiate offline. For some, person-to-person contact may feel too intimate and maybe others feel that their own simulated self differs from their offline self; many of us do look better online. People's prosuming of themselves through Facebook, or self-fetishization, may be causing feelings of performance anxiety, and it may be causing people to be annoyed by others or feelings of jealousy. In order to harness the positive benefits of Facebook, the hyperreal nature of it must be constantly attended to emotionally (do not take it so seriously and learn to ignore some things) while focusing on using it for positive purposes.

\section{E-MAIL RESPONSES TO LIKES}

My FPA and survey did not generate results on why people were performing their cyber identities around consumer identity. In order to discern how my participants thought about their consumer identity, I emailed 11 of my study's participants who showed up on my newsfeed as having liked a corporate brand in April, 2014. This included nine females, aged 30 to 70, and two males, aged 40. I did this because even though the Facebook profile analysis showed that participants liked corporate brands, when I asked them about what they like on the survey, no one mentioned liking a corporate brand. Hence, this e-mail follow-up was designed to interrogate this discrepancy.

Of the 11 people I emailed, seven responded. Six females aged 33 to 70 with an average of 46 and one male aged 40. I asked them the following the question: "Hi, you popped on my news feed as having 'liked' $\mathrm{X}$. Could you tell me if this is because you participated in a survey or something?" I write X here because there were four brands that showed up as having been liked and I tailored each question to reflect the brand the participant had liked. The answers are listed in Table 5 below. 
Table 5. E-mail responses on likes

\begin{tabular}{|c|c|c|c|}
\hline Gender & Age & Brand & Response \\
\hline Female & 40 & Rogers & It must have been my kids. \\
\hline Male & 40 & Rogers & I saw it in my newsfeed - great marketing! \\
\hline Female & 50 & Target & $\begin{array}{l}\text { I don't recall having done that but truth be told I loved } \\
\text { Target in the US but not at all impressed with Target } \\
\text { Canada...lunch bag let down! It probable popped up } \\
\text { somewhere and I liked it cause I it did before it came here. }\end{array}$ \\
\hline Female & 70 & Target & $\begin{array}{l}\text { hmm! Can't ever remember liking Target - never been in } \\
\text { the store - sometimes I see on different things that I have } \\
\text { liked them, but don't know why }\end{array}$ \\
\hline Female & 42 & Target & $\begin{array}{l}\text { hm,. not sure. I actually haven't been to the store yet! it's possible } \\
\text { that I liked it? just not sure when or how. Sorry I don't remember!! }\end{array}$ \\
\hline Female & 33 & $\begin{array}{l}\text { Mott's } \\
\text { Fruit }\end{array}$ & $\begin{array}{l}\text { Hey! I am a big couponer so they were offering a coupon by } \\
\text { liking there page so that's why! }\end{array}$ \\
\hline Female & 42 & $\mathrm{CIBC}$ & It's my bank I think that is why. \\
\hline
\end{tabular}

Of the seven who replied to my e-mail, only two seem to recall having liked the brand. One blames her kids, three don't remember, and one assumes it's because it's her bank but does not offer a reason as to why it's showing up my newsfeed. This may be why no one mentioned liking corporate brands in my survey - they mostly don't remember or corporations are coming up with interesting ways of making it seem as though people have liked them. I know now not to trust that one of my Facebook friends has actually liked a corporate brand that pops up on my newsfeed. Biddle (2013) discusses the phenomenon of corporations recycling people's likes from years ago. This may well be what is occurring here with my friends.

These results indicate that cyber identity performed around consumer identity may be the result of co-production with Facebook. Facebook overtly controls the production modalities of cyber identity performance through its basic format, and it seems it also has some control over consumer identity on a more subtle level. Hoechsmann and Poyntz (2012) remind us that "new media environments (...) are dominated by private enterprise" (p. 161) and Biddle (2013) shows that corporations are sneaky in using information to reflect an ongoing corporate relationship and consumer identity. More studies should be conducted to track likes as I have done and also get people's reactions to how it makes them feel. It could be seen as a form of personal exploitation.

\section{EIGHT DAY SCREEN SHOT ANALYSIS OF HOME PAGE ADVERTISING (APPENDIX C)}

In order to evaluate the effects of Facebook advertising on consciousness and articulations of consumer identity, I conducted an analysis of my home page 
over an eight day period. In the survey, my participants discussed their general annoyance over advertising but did not discuss the possible effects of Facebook advertising on their consciousness or cyber identity performance. In this part of the study, I try to be as candid as possible about the effects of advertising on my consciousness.

The advertising shows up on the home page in a column on the right-hand side of the page. The screen shots are shown in Appendix $\mathrm{C}$ and are cropped from the rest of my home page.

Table 6. Home page advertising for 8 days

\begin{tabular}{|c|c|c|c|}
\hline Day & & Advertising heading & Advertising caption \\
\hline \multirow[t]{5}{*}{ Day 1} & $\begin{array}{l}\text { Clothes/ } \\
\text { Accessories }\end{array}$ & $\begin{array}{l}\text { \$24 Wrap Bracelet } \\
\text { Sale } \\
\text { Victoriaemerson. } \\
\text { com }\end{array}$ & $\begin{array}{l}\text { \$199 Wrap bracelet Bracelets on } \\
\text { sale starting at } \$ 24\end{array}$ \\
\hline & $\begin{array}{l}\text { Health/ } \\
\text { Diet }\end{array}$ & $\begin{array}{l}\text { Redeem Your } \\
\text { Coupon Today! } \\
\text { altitude-sports.com } \\
\text { coupon }\end{array}$ & $\begin{array}{l}\text { Save big on outdoor apparel \& } \\
\text { gear with weekly altitude-sports. } \\
\text { com discount codes }\end{array}$ \\
\hline & $\begin{array}{l}\text { Health/ } \\
\text { Diet }\end{array}$ & $\begin{array}{l}\text { Sum-Sum- } \\
\text { Summertime! } \\
\text { zumba.com }\end{array}$ & $\begin{array}{l}\text { Summer is here, Trade that parka } \\
\text { for a polka-dot bikini! }\end{array}$ \\
\hline & Decor & $\begin{array}{l}\text { Rustic Chic Decor } \\
\text { Jossandmain.com }\end{array}$ & $\begin{array}{l}\text { Add a rustic touch to your home } \\
\text { with weathered furniture finds! } \\
\text { We ship to Canada! }\end{array}$ \\
\hline & $\begin{array}{l}\text { Health/ } \\
\text { Diet }\end{array}$ & $\begin{array}{l}\text { Suffer from cold } \\
\text { sores? } \\
\text { Gsk.ca }\end{array}$ & $\begin{array}{l}\text { Use abreva at the } 1 \text { st sign of a } \\
\text { cold sore. It's clinically proven to } \\
\text { speed healing. }\end{array}$ \\
\hline Day 2 & $\begin{array}{l}\text { Clothes/ } \\
\text { Accessories }\end{array}$ & $\begin{array}{l}\text { Wedding Party } \\
\text { Dress Deals } \\
\text { Lightinthebox.com }\end{array}$ & $\begin{array}{l}\text { Wide Range of Choice of } \\
\text { Wedding Party Dresses, } 75 \% \\
\text { Off, Free Shipping }\end{array}$ \\
\hline $\begin{array}{l}\text { Liked by } 1 \\
\text { friend }\end{array}$ & Insurance & $\begin{array}{l}\text { Obtenez une } \\
\text { soumission } \\
\text { Tdassurance.com }\end{array}$ & $\begin{array}{l}\text { Obtenez une soumission de TD } \\
\text { Assurance et tirez le maximum } \\
\text { de votre assurance habitaton }\end{array}$ \\
\hline \multirow[t]{2}{*}{$\begin{array}{l}\text { Liked by } 1 \\
\text { friend }\end{array}$} & $\begin{array}{l}\text { Health/ } \\
\text { Diet }\end{array}$ & $\begin{array}{l}\text { Yoga for Cyclists } \\
\text { Yogaglo.com }\end{array}$ & $\begin{array}{l}\text { Improve your performance on } \\
\text { and off the bike with YogaGlo's } \\
\text { tailored cycling classes }\end{array}$ \\
\hline & $\begin{array}{l}\text { Clothes/ } \\
\text { Accessories }\end{array}$ & $\begin{array}{l}\text { Maxi Dresses } \\
\text { Around } \$ 10 \\
\text { Rosewholesale.com }\end{array}$ & $\begin{array}{l}\text { Women's Maxi Dresses All } \\
\text { Around } \$ 10 \text {, Best Price \& Great } \\
\text { Look, Order } \$ 70+\text { Get } 10 \% \text { Off }\end{array}$ \\
\hline
\end{tabular}


Table 6. (Continued)

\begin{tabular}{|c|c|c|c|}
\hline Day & & Advertising heading & Advertising caption \\
\hline \multirow{6}{*}{$\begin{array}{l}\text { Day } 3 \\
1,580,401 \\
\text { people like } \\
\text { this }\end{array}$} & Clothes/ & Maxi Dresses & Women's Maxi Dresses All \\
\hline & Accessories & Around $\$ 10$ & Around $\$ 10$, Best Price \& Great \\
\hline & & Rosewholesale.com & Look, Order $\$ 70+$ Get $10 \%$ Off \\
\hline & Decor & $\begin{array}{l}\text { Joss \& Main } \\
\text { Furniture! } \\
\text { Jossandmain.com }\end{array}$ & $\begin{array}{l}\text { Add a pop of color to your decor } \\
\text { with patterned accent chairs. We } \\
\text { ship to Canada! }\end{array}$ \\
\hline & Technology & $\begin{array}{l}\text { PCMAG Best } 2014 \\
\text { Antivirus } \\
\text { Bitdefender.com }\end{array}$ & $\begin{array}{l}50 \% \text { off now! Trust Bitdefender, } \\
500 \text { million users already do! }\end{array}$ \\
\hline & Credit Card & $\begin{array}{l}\text { The first year is on } \\
\text { us. } \\
\text { Americanexpress. } \\
\text { com }\end{array}$ & $\begin{array}{l}\text { Earn 25,000 Welcome Bonus } \\
\text { points with the American } \\
\text { Express Gold Rewards Card. } \\
\text { Learn More. }\end{array}$ \\
\hline $\begin{array}{l}\text { Day } 4 \\
\text { Liked by } 1 \\
\text { friend }\end{array}$ & Insurance & $\begin{array}{l}\text { Obtenez une } \\
\text { soumission } \\
\text { Tdassurance.com }\end{array}$ & $\begin{array}{l}\text { Obtenez une soumission de TD } \\
\text { Assurance et tirez le maximum } \\
\text { de votre assurance habitaton }\end{array}$ \\
\hline $\begin{array}{l}\text { Liked by } 1 \\
\text { friend }\end{array}$ & $\begin{array}{l}\text { Health/ } \\
\text { Diet }\end{array}$ & $\begin{array}{l}\text { Secret to Good } \\
\text { Health? } \\
\text { Youtube.com }\end{array}$ & $\begin{array}{l}\text { Can NutriBullet and } 10 \mathrm{~K} \text { pounds } \\
\text { of produce transform the health } \\
\text { of } 46 \text { high school students? }\end{array}$ \\
\hline $\begin{array}{l}\text { Liked by } 1 \\
\text { friend }\end{array}$ & Contest & $\begin{array}{l}\text { Win } 10,000 \$ \text { in } \\
\text { cash }\end{array}$ & $\begin{array}{l}\text { Visit our Facebook page for your } \\
\text { chance to win }\end{array}$ \\
\hline $\begin{array}{l}\text { Liked by } 1 \\
\text { friend }\end{array}$ & Food & $\begin{array}{l}\text { Catelli } \\
\text { Feed the Hope }\end{array}$ & $\begin{array}{l}\text { Catelli will donate pasta servings } \\
\text { to families in need when you like } \\
\text { \& share! }\end{array}$ \\
\hline \multirow[t]{3}{*}{ Day 5} & Travel & $\begin{array}{l}\text { Choicehotels.ca } \\
\text { Two Stays Pays }\end{array}$ & $\begin{array}{l}\text { Take two separate trips at any } \\
\text { Choice hotel, earn } \$ 50 \text { gift card. } \\
\text { Conditions apply. }\end{array}$ \\
\hline & Travel & $\begin{array}{l}\text { Ramada Worldwide } \\
\text { Ramada.com }\end{array}$ & $\begin{array}{l}\text { Book } 3 \text { nights or more and } \\
\text { receive } 20 \% \text { off your stay. Visit } \\
\text { our official site. }\end{array}$ \\
\hline & Books & $\begin{array}{l}\text { CDN\$14.43at } \\
\text { Amazon } \\
\text { Amazon.ca }\end{array}$ & $\begin{array}{l}\text { Alone Together: Why We Expect } \\
\text { More from Technology and Less } \\
\text { from Each Other.CDN\$ } 14.43\end{array}$ \\
\hline $\begin{array}{l}46 \text { people } \\
\text { going }\end{array}$ & Make-up & $\begin{array}{l}\text { ÉVÉNEMENT } \\
\text { BENEFIT } \\
\text { SEPHORA }\end{array}$ & $\begin{array}{l}\text { La plus GRANDE innovation } \\
\text { monde de la beauté } \\
\text { est ici! }\end{array}$ \\
\hline Day 6 & Cars & Mazda.com & $\begin{array}{l}\text { La Mazda3 a remporté } \\
\text { les deux prix décernés aux } \\
\text { petites voitures par l'AJAC }\end{array}$ \\
\hline
\end{tabular}


Table 6. (Continued)

\begin{tabular}{|c|c|c|c|}
\hline Day & & Advertising heading & Advertising caption \\
\hline $\begin{array}{l}\text { Liked by } 1 \\
\text { friend }\end{array}$ & Insurance & $\begin{array}{l}\text { Obtenez une } \\
\text { soumission } \\
\text { Tdassurance.com }\end{array}$ & $\begin{array}{l}\text { Obtenez une soumission de TD } \\
\text { Assurance et tirez le maximum } \\
\text { de votre assurance habitaton }\end{array}$ \\
\hline $\begin{array}{l}\text { Liked by } 1 \\
\text { friend }\end{array}$ & $\begin{array}{l}\text { Health/ } \\
\text { Diet }\end{array}$ & $\begin{array}{l}\text { Yoga for Women } \\
\text { Yogaglo.com }\end{array}$ & $\begin{array}{l}\text { Classes for fertility, menopause, } \\
\text { PMS, anti-aging and more in the } \\
\text { comfort of your home. }\end{array}$ \\
\hline \multirow[t]{2}{*}{$\begin{array}{l}\text { Liked by } 1 \\
\text { friend }\end{array}$} & $\begin{array}{l}\text { Clothes/ } \\
\text { Accessories }\end{array}$ & $\begin{array}{l}\text { Cheap Dresses } \$ 9 \\
\text { Rosewholesale.com }\end{array}$ & $\begin{array}{l}\text { Must-Have Cheap Casual } \\
\text { Dresses } \$ 9 \text {, Free Shipping } \\
\text { Selected Items, Order } \$ 70+\text { Get } \\
10 \% \text { Off }\end{array}$ \\
\hline & Contest & Until July 6! & $\begin{array}{l}\text { Get a chance to win a collection } \\
\text { of } 50 \text { blues CDs with a value of } \\
\$ 1000 \text { ! }\end{array}$ \\
\hline \multirow[t]{3}{*}{ Day 7} & Eye Wear & $\begin{array}{l}\text { Shipping is Free! } \\
\text { Clearlycontacts.ca }\end{array}$ & $\begin{array}{l}\text { Enjoy free shipping right to your } \\
\text { door at ClearlyContacts.ca }\end{array}$ \\
\hline & Technology & $\begin{array}{l}\text { PCMAG Best } 2014 \\
\text { Antivirus } \\
\text { Bitdefender.com }\end{array}$ & $\begin{array}{l}50 \% \text { off now! Trust Bitdefender, } \\
500 \text { million users already do! }\end{array}$ \\
\hline & $\begin{array}{l}\text { Clothes/ } \\
\text { Accessories }\end{array}$ & $\begin{array}{l}\text { Designer Shoes: } \\
60 \% \text { OFF! } \\
\text { Gilt.com }\end{array}$ & $\begin{array}{l}\text { Get insider access to today's top } \\
\text { brands. Join gilt.com today for } \\
\text { FREE SHIPPING TO CANADA }\end{array}$ \\
\hline \multirow[t]{2}{*}{$\begin{array}{l}79,637 \\
\text { people like } \\
\text { this }\end{array}$} & Cars & $\begin{array}{l}\text { THE INSPIRED } \\
\text { PERFORMANCE } \\
\text { Infiniti.ca }\end{array}$ & $\begin{array}{l}2014 \text { Infiniti Q60 Coupe Up to } \\
\$ 7,250 \text { in savings for a limited } \\
\text { time. Learn more. }\end{array}$ \\
\hline & Insurance & $\begin{array}{l}\text { Obtenez une } \\
\text { soumission } \\
\text { Tdassurance.com }\end{array}$ & $\begin{array}{l}\text { Obtenez une soumission } \\
\text { de TD Assurance et tirez le } \\
\text { maximum de votre assurance } \\
\text { habitaton }\end{array}$ \\
\hline $\begin{array}{l}\text { Day } 8 \\
\text { Liked by } 1 \\
\text { friend }\end{array}$ & Contest & $\begin{array}{l}\text { Win } 10,000 \$ \text { in } \\
\text { cash }\end{array}$ & $\begin{array}{l}\text { Visit our Facebook page for your } \\
\text { chance to win }\end{array}$ \\
\hline \multirow[t]{2}{*}{$\begin{array}{l}\text { Liked by } 1 \\
\text { friend }\end{array}$} & $\begin{array}{l}\text { Clothes/ } \\
\text { Accessories }\end{array}$ & $\begin{array}{l}\text { Maxi Dresses } \\
\text { Around } \$ 10 \\
\text { Rosewholesale.com }\end{array}$ & $\begin{array}{l}\text { Women's Maxi Dresses All } \\
\text { Around } \$ 10 \text {, Best Price \& Great } \\
\text { Look, Order } \$ 70+\text { Get } 10 \% \text { Off }\end{array}$ \\
\hline & $\begin{array}{l}\text { Clothes/ } \\
\text { Accessories }\end{array}$ & $\begin{array}{l}\text { Designer Handbags } \\
\text { on Gilt } \\
\text { Gilt.com }\end{array}$ & $\begin{array}{l}\text { Find Vintage Handbags at } \\
\text { Insider Prices. Join GIlt Today } \\
\text { for FREE SHIPPING TO } \\
\text { CANADA! }\end{array}$ \\
\hline
\end{tabular}


Table 6 shows that in eight days I was targeted at least 34 times (I say at least because some of my screen shots cut off some information): by a Credit Card company once, three times by the same contest, a food related company once, clothing or accessory companies eight times by four different companies, twice by the same technology related company, a make-up company once, by five different health and dieting related companies, a book dealership once, twice by the same decor company, eyewear once, twice by two different cars companies, and twice by two different travel related companies.

I am a 39 year-old, married woman with one child. Facebook knows that I am married and a woman. Through my photos it might know that I have a baby. It also knows that I was born in December and by looking at my "friends" list it may see that I am friends with a lot of older adults. These may be the reasons that I am mostly being targeted by clothing, accessory, health, and dieting related companies. There are two instances of retargeted advertising: Gilt.com and Turkle's book Alone Together. I once clicked on Gilt.com through Facebook and it may be why it showed up twice that week; however, Maxi dresses (rosewholesale.com) showed up four times and I have never been to their website. The only verifiable retargeted advertising is Turkle's book. I went to Amazon.com to look inside the book and then it showed up on my Facebook home page about a week later and I thought to myself "How creepy!". My Facebook home page does not reflect a lot of retargeted advertising maybe because I do not shop online very much. I have become annoyed by the constant gilt.com and Maxi dress advertising because I am not interested in them. They do change their photos each time they advertise, so I look at the fashion choice of the day and, along with the influence of dieting and health related companies, I find myself longing for an amazing body and wardrobe, especially now that I am in my third trimester of pregnancy with a very limited wardrobe. I wonder how this might be impacting my sense of self. I feel like going shopping.

Every time a friend had liked a particular company, and that company showed up as advertising on another day, his or her like was recycled; just as it had been done within my newsfeed in the previous analysis. This shows that likes are being recycled in two areas of Facebook advertising. I have started to think about particular friends as product representatives.

If advertising has to be present on Facebook I wish I could have a say in what type shows up on my home page, perhaps even weekly. I do not want to be shown things I have already shopped for myself online, such as Turkle's book. I also do not want them selling me what they feel I should want based on my age and gender. This week, for example, I would love to see advertising on perennial flower discounts, outdoor barrel saunas, and baby slings. Then I might consider Facebook advertising as less of an annoyance and less creepy knowing that I was controlling them.

I contend that even though people may articulate parts of their cyber identity performance around consumption practices, consumer identity may not be a conscious part of my participants' cyber identity performance. First, consumer identity is prompted by Facebook's format that encourages people to list 
media-related hobbies and interests as a base line measure of self-identity and cultural affinities. Participants may not even think about these categories as being consumerrelated but more of as pop-culture related. The more overtly corporate consumer identity is associated with brands and none of my participants discussed them as a part of their Facebook experience; it only surfaced slightly when I asked them about why they had liked a particular brand. Second, corporations take advantage of people who at some point like them by recycling their likes and getting people to like them through product-related incentives; it seems that these likes are a by-product of coupons and so forth with most participants questioned not being sure when they had even liked a particular brand. But having tracked advertising on my own home page has made me realize that I am influenced by seeing people I know like a brand. It makes me think about the brand more since it is being "valued" by a friend. Even though I know likes are being recycled, the brand was still liked at some point.

Facebook profits from data mining and advertisers are a major driving force in the economic structure of Facebook; it is apparent as soon as a person starts using Facebook that it is a highly sophisticated consumption and marketing environment. Advertising is subtly tailored to reflect one's interests, and differs from person to person, making access to personal information one of the economic outputs of Facebook. Additionally, data mining allows corporations to retarget advertising, making them even more personal. On a technical level, data mining is enabled by cookies (bits of information that are sent from a website to a person's computer that are then accessed by the same website when the person returns so that the website can tailor content to the visitor (What are cookies?, 2012)). An explanation of tracking devices is hidden in plain sight in Facebook's privacy settings. Here is some information posted in the Help Center under Privacy (Facebook, 2013):

We and our affiliates, third parties, and other partners (partners) use these technologies [cookies, pixels, local storage] for security purposes and to deliver products, services and advertisements, as well as to understand how these products, services and advertisements are used. (para. 2)

According to AdRoll (2013), the number one partner on FBX, advertisers can "use your first-party data to retarget your site visitors on the largest inventory source on the web, with over one Billion active users and $28 \%$ of U.S. ad impressions" (para. 1). Their average client has a 16 time return on advertisement spending through this new system. The idea is that if someone looks at someone's website but does not purchase anything, AdRoll will later show that advertising to that person on Facebook. This is the current business model of Facebook. Advertisements show up in a person's news feed alongside their news feed, and in a side bar on the profile page. They are an integral part of the Facebook experience.

Facebook exacerbates the "group" that identity is performed for and against in modern consumer culture through the commodification of its cyberspace. Its users are bombarded by consumer discourse, which impacts cyber identity performance. Neo-liberal discourse encourages the need to articulate individuality through 
"choices" that are structured by a discourse of consumerism. Likes and Hobbies and Interests are reflections of consumer identity, even though online advertising seems to annoy Facebook users (Table 3). My participants willingly discussed their annoyance in the survey over advertising but never discussed liking any corporate brands, even though they had done so, according to my Facebook Profile analysis results (Table 1). It has me question whether cyber identity performance through consumer identity has become so normalized that it is hardly talked about, and that it is a form of a panoptic backdrop to Facebook. Facebook users can also see when someone has liked a corporate brand because it is advertised; given that cyber identity on Facebook is performed mainly around group and consumer identity (Table 1), this invariably has some impact on how people read others and, potentially, how they perform their cyber identities.

\section{CHAPTER SUMMARY}

In this chapter I presented the results generated by the Facebook profile analysis, survey, e-mail responses on likes, and eight days of advertising on my home page. I discussed these results in how they compared with the previous literature and studies explored in Chapter 2. I started making conjectures at how identity and consumer-related discourses, the structure of Facebook, and the hyperreal nature of Facebook might be behind some of these findings. I also discussed the possibility that consumer identity may be a result of Facebook co-producing identity and that it could be form of personal exploitation. Lastly, I concluded that the hyperreal nature of Facebook had both negative and positive potential but was dependent upon having an awareness of it. In the next chapter, I filter these results through Johnson's four-point model for analysing a media site and McLuhan's tetrad in order to answer the research questions formulated in Chapter 1 and to, ultimately, explore the sociocultural implications of Facebook use for the Cusp Generation, in Chapter 7.

\section{NOTE}

1 When I began the data collection, my intention was not to solely focus on those belonging to the Cusp Generation, which explains why three of my participants were aged over 48 (one male and two females). I also refer to my peer group as representing the fastest growing demographic on Facebook, those in their 30s, yet I defined the Cusp Generation as including those in their 20s, 30s, and $40 \mathrm{~s}$. However, the average age of my participants was 38 for all parts of the study and the survey only included two people over 48, therefore, my study still speaks to understanding this age group's increasing SNS presence. 


\section{A CRITICAL ANALYSIS OF FACEBOOK STUDY FINDINGS}

The Almost Real arises only as a neurotic reaction to the vacuum of memories; the Absolute Fake is offspring of the unhappy awareness of a present without depth.

(Eco, 1986, pp. 30-31)

The hyperreal space of Facebook is intimately connected to identity performance, and because it is all about the self, it encourages overproduction through the constant attention to one's self in pursuit of perfected meaning and authenticity. Facebook's scrapbooking style timeline format in particular (O'Dell, 2011) tugs at people's memories and emotions, making them want to divulge even more of themselves. To develop the timeline, Facebook developers did "entire studies on scrapbooks" (O'Dell, 2011, para. 3) and harnessed the power of memory and emotion. Facebook's product chief describes his reaction to his first time using timeline:

Years-old memories flashed before me - old friends, old places, things I hadn't thought about in ages. I got sucked back into the past the same way I would have in front of my mothers old cedar chest, a trunk packed full of childhood tchotckes and pictures that holds our familys history. (O'Dell, 2011, para. 8)

Avatar attachment, discussed later under "cultural life", may be another factor leading to overproduction or "addiction". As such, there are multiple dynamics that influence people to keep logging on to Facebook and to think about how they are depicting themselves to others through it, even while they are offline.

In this chapter, I employ Johnson's four-point model for analysing a media site and McLuhan's tetrad to better understand the Cusp Generation's use of Facebook and its socio-cultural implications. Johnson's four-point model allows for a deeper analysis of how and why my participants are performing their cyber identity because this model explores "how economic, political, and cultural forces work through the media to shape the exercise of social power in society" (Hoechsmann \& Poyntz, 2012, p. 72). Participants' "production" of cyber identity may reflect social and cultural constructs arising from their own experiences or from the producers of Facebook. Examining the "text" of Facebook may reveal embedded dominant values that are produced by the individual or are encouraged by its modalities (the basic format and structural code). Production and text overlap with each other because to analyse production that is not in the moment with someone one must look at the 
textual result. How people "read" other people's cyber identity performances, or the text embodied by the production modalities (status updates, uploaded photos and so forth), may be a reflection of their own psychological predispositions, coproduction identity performances, or hyperreal distortions. Lastly, "lived culture" has me consider how participant's Facebook cyber identity performances are influenced by socio-cultural factors arising from everyday life and how their performances are affecting cultural life. It is at this point that I also draw on McLuhan's tetrad to deepen my exploration of the socio-cultural implications of cyber identity performance on Facebook because it looks at why we are drawn to this form of communication, what it is replacing, what it is making obsolete, and what it is "endangering".

\section{PRODUCTION: REFLECTIONS OF CONSUMER AND IDENTITY DISCOURSE}

A critical production analysis draws our attention to political economy and involves analysing the influence of social and economic power, as wielded, on the one hand, by the corporations who control the mainstream media, and, on the other, as expressed through the everyday prosumers of the participatory, social media. Hoechsmann and Poyntz (2012) draw our attention to the "powerful relationship between business or economic life and media culture" (p. 68) and the production analysis point seeks to uncover the link between cultural production and social power in society. This perspective illuminates the link between capitalism and the processes of social reproduction that ensure its success. These processes of social reproduction are rooted in a broad ideology of consumerism (Sandlin \& McLaren, 2010), disseminated by the media through identity and consumer related discourses (Hoechsmann, 2010; Kincheloe \& Steinberg, 2004; King, 2004). At times, production analysis involves analyzing text, readings, and lived culture as they all feed into each other. When analyzing production, we are also analyzing how "culture shapes the production of media" (Hoechsmann \& Poyntz, 2012, p. 75). All cultural production holds residues of past experiences and they are entrenched in "social and cultural constructs related to race, gender, class, age, and (...) inform the representations of individuals and groups in society" (Hoechsmann \& Poyntz, 2012, p. 74). Production on Facebook must be understood on two levels: the content produced by a corporation (Facebook) and the content produced by a prosumer. Both levels of production are impacted by our socio-economic reality, while prosuming is additionally affected by the explicit governance stemming from the structure, rules and regulations of Facebook. All of this will affect people's cyber identity as the "media concentration and economic power can shape what media is produced and how this media effects processes of socialization and acculturation" (Hoechsmann \& Poyntz, 2012, p. 72).

\section{Corporate Production}

As mentioned in Chapters 1 and 5, Facebook was first launched in 2004 by Mark Zuckerberg for the purpose of social networking at Harvard University. It became 
open to the general public and anyone over 13 in 2006 (Facebook, 2013). It now has more than one billion international users (Newsroom, 2013) whose information it has a right to share with service providers according to its data use policy (Data Use Policy, 2014). This is important because Facebook makes $85 \%$ of its profits through advertising (12\% comes from the gaming company Zynga) (Bohn, 2012). Access to user information attracts advertisers because they can tailor their ads around the user's demographics; moreover, through "cookies, pixels, [and] local storage" (Facebook, 2013) they can track their internet activity and retarget advertising (AdRoll, 2013). Facebook's basic format (discussed under text) and its timeline structure encourage people to communicate their personal information, which Facebook then shares with other corporations for economic profit. This results in the coproduction of cyber identity performances through consumer practices, whether consciously or not and may be considered a form of exploitation in two ways:

1. Facebook sells personal information back to its users through targeted advertising and also sells users' personal information to corporations who then sell it back to users through retargeted advertising, both of which may impact people's consumer habits and articulation of a consumer identity. This can impact both how people present themselves and the way we perceive or read other people. Advertising is a major driving force in the economic structure of Facebook and it exacerbates the new 'group' that identity is performed for and against in modern consumer culture through the commodification of its cyberspace. Its users are constantly bombarded by consumer discourse which impacts cyber identity performance. The consumer discourse inherent in the business model may become internalized and exhibited through production with cyber identity being performed through consumer practices. This internalization may also occur through people "reading" the co-produced consumer identities of others (discussed under "production" through the recycling of likes) and, wanting to "belong", they may mimic this performance. The internalization of consumer discourse may also stem from a broader ideology of consumption.

2. Corporations reinforce consumer identity through the recycling of likes (Biddle, 2013) which makes it seem like users are constantly endorsing particular brands. I showed evidence of this in Chapter 5 when I demonstrated that most of my research participant's could not remember when they had liked a particular brand (Table 5), and through the effects it was having on me seeing that people were attached to particular brands over the course of an eight day analysis of advertising on my home page (Table 6).

The coproduction of consumer identity is exploitative on many levels: it uses people as instruments of capital (Grosser, 2011), it may encourage others to articulate consumer identity since so much of identity performance involves looking at others for cues (Butler, 2001), and it may result in the internalization of consumer discourse (Fiske, 2010; Sandlin \& McLaren, 2010). 
In regards to its authorship, Facebook was largely produced by a homogenous group of white males. It is contended that "Facebook's current popularity originates from its exclusionary framework; the site's genesis as a boutique Ivy League network has led it to enable segregation along racial lines and to its domination of use by upper class educated whites" (Grosser, 2011, p. 6). All ethnic backgrounds now use Facebook; however, given that one social group is producing a communication vehicle for global consumption, it is inevitable that the ethics and ideals of that social group will be embedded in the software design. Facebook's software development may reflect the internalized codes of behavior and discourses related to identity performance for this homogenous group of white males and it surfaces in the design of Facebook. This may be why Grosser refers to the majority of cyber identity performances on Facebook as representing a "gated community." In Chapter 5, I showed that there were homogenous tendencies in cyber identity performances (Table 1), which Grosser cites as stemming from the limits imposed by Facebook's structure. Therefore, while the prosumer of Facebook may be mobilizing his or her identity related discourses in their cyber identity performance, they are also doing it through the producer(s) of Facebook's world view.

Facebook is a business and the developers of Facebook will be tasked to ensure that the content of Facebook encourages the consumption of Facebook and the content within it. Reflections of consumer encouragement can be seen through my peer group's cyber identity performances through the types of likes they had (Table 1). Some of these likes are prompted by its basic format and are media-related likes. However, the business model of Facebook is also coproducing participant's cyber identity performances by getting people to like brands (whether consciously or not) and recycling these likes and attaching people's identities to particular brands.

\section{Participants' Production}

Participants' production on Facebook may be impacted by five factors: the structure and business of model of Facebook (discussed above), the mobilization of consumer-related discourses, the hyperreal nature of Facebook, gender dynamics, and psychological predispositions. The first three are relevant for considering the relationship between economic, political, and cultural forces (Hoechsmann \& Poyntz, 2012) in cultural production and the other two factors raise the possibility that there may be some remnants of behavior from our social history behind gender differences and personal, psychological factors behind self-absorbed identity performances.

The mobilization of consumer-related discourses in production on Facebook will influence how cyber identity is performed/produced. I evidenced discourse mobilization through the importance of being socially desirable and self-promotion (which I discussed as self-absorbed identity in Chapter 5). Being socially desirable may be related to gendered beauty discourse as most participants had "good-looking" profile photos (Table 1). However, gendered beauty discourse traditionally targets females and the fact the males had more overtly posed photos shows that they too 
have become targets of beauty discourse, and scholarly work on the inversion of the male gaze (Patterson \& Elliott, 2002) and metrosexuality (Lertwannawit \& Gulid, 2010) speak to this phenomenon. However, the results still leave me questioning if having a nice profile picture is about social desirability connected to "group" belonging, the mobilization of gender discourse, or a broader consumerist longing to belong inside the product frame.

The tendency to self-promote is linked by scholars to neo-liberal discourse, which encourages individual articulation through consumer choices, and to celebrity worship culture, which encourages the value of self-promotion. The mobilization of either or both consumer-related discourses would lead to high levels of selfpromotion on Facebook. My peer group was prone to self-promotion through their profile pictures and status updating (Table 1). However, there are other factors to consider that might be behind self-promotion. Self-promotion may also be related to psychological predispositions, where a high level of offline depression and narcissism lead to higher levels of self-promotion online in an attempt to feel better about one's self. Table 4 shows that my participants were annoyed by people overposting, bragging and emoting but the question remains, why were people overproducing their cyber identities and doing so in self-promotional ways?

Simulation can be very exciting and Boon and Sinclair (2009) note,

One of the most novel - and to some most attractive - aspects of Facebook is that it allows its users, within predefined limits, to create a digital self that is at once fluid, protean, amorphous, and temporary. Users alter their profiles daily, hourly, even minute by minute. Almost every piece of information on a profile is open to manipulation. (p. 102)

This quote hints at the attraction of the hyperreal which Turkle (2011) cites as being a lure of SNSs and a cause of people's discontentment with these. As discussed in Chapter 3, the ability to identify with one's avatar leads to immersion or focused attention and intense engagement where the content produced influences a person's subjectivity. Becoming wrapped up in one's avatar may lead to overproduction (spending a lot of time on Facebook tinkering with one's avatar or on the social surveillance of others for cues on how to perform a homogenous, socially desirable cyber identity) and, possibly, self-fetishization; because the self has become a simulation, it may be more desirable than a person's physical self and fetishized with qualities of the ideal self. Being on Facebook frequently naturally leads to simultaneously over-consuming the content of Facebook - the profiles of others and its advertising.

Lastly, gender dynamics may impact how cyber identity is performed. My Facebook profile analysis and survey results showed that while females and males valued social connection highly, females were more socially proactive and males showed more production around career and social networking (Table 1, Table 2). This is not a surprise, given that from a developmental psychology perspective, females' social activities are generally more communal than those of males and the 
self is defined more commonly through relationships (Gilligan, 1982/1993). This is because social history has resulted in "developmental sex differences in social goals, behaviors, and motivations" (Geary \& Bjorklund, 2000, p. 60). According to these theories, females are more concentrated on developing and maintaining relationships with other females that will provide stability and social support in adulthood. Males are more associated with aggressive behavior; however, there is still competition between females that seems to stem from the attempt to disrupt the social networks of their competition for mates and various resources. In teenagers this takes the form of gossip and shunning. This perspective may explain why females are more proactive with the social connection aspect of Facebook than males, which was also cited in earlier studies by Joinson and Stern. It may also explain why females tended to complain more about posts where peers appeared to be bragging and over-emoting - perhaps they were signs of attempts to disrupt social networks.

When we think of the excesses of identity-related consumer discourse, mobilizing of gendered beauty discourse (social desirability through beauty), and celebrity worship culture (self-promotion), there is an association with teens and young adults who are characterized as vulnerable to marketing. Given that these phenomena are so prevalent among the Cusp Generation appears to be evidence of adultescent behavior associated with the social, cultural and psychological demands that are thrust upon, and absorbed within, the mediated social networking self of the typical Facebook user.

Production on Facebook is of necessity co-production, where the business needs of this media corporation merge with the social, cultural and psychological needs and desires of its prosuming users. This makes today's "prosumer" different than the one conceptualized by Jenkins (2006) because Facebook users serve Facebook corporate interests through their production. In Chapter 1, I argued that Jenkin's conceptualization of "prosumers", where individuals consume media then remix and join different media to produce something new, differs in the contemporary space of Facebook. This is because individuals have become workers more than fans through their production on Facebook; they work on behalf of the corporation of Facebook by granting them access to their personal information and by liking brands that then use them as product representatives. Participants' productions are also a reflection of the structural format of Facebook, which results in the creation of homogeneous cyber identities and furthers Facebook's co-production of consumer identities. People might not even realize how homogenous their cyber identities are or that they are being exploited through co-production. Foucault would contend it becomes internalized as a form of self-surveillance or panopticism, with general surveillance becoming a way to ensure homogeneity.

\section{TEXT: STRUCTURAL IMPACTS ON PRODUCTION AND READINGS}

The text of any given cultural form is a reflection of dominant societal values within a historical moment. When analyzing a text we are asking: what does the 
text communicate and what how does it impact people's subjectivity? To read into the "cultural myths" being reproduced by Facebook as text I am essentially doing a critical analysis of its textual modalities - the basic format and its structural code. A traditional text reading would involve simply analysing what people have written and posted on their pages, both print and visual, which I did in the Facebook profile analysis content analysis in Chapter 5. However, in a post-HTML Web 2.0 environment, a deeper analysis of textual representation requires a careful examination of how the productions of "meanings" is an interplay between what users hope to state within the constraints of the coding and framing of Facebook's programmers. Thus, my innovative approach to textual reading analyses the meanings that arise from the intersection of its format, code, and user intervention.

The basic format of Facebook governs how people produce their cyber identities. It structures how a person performs that identity on Facebook and is seen filtered through preset production modalities. There are many production modalities on Facebook, so I will only discuss those that impact how meaning is articulated. The first is through photos and includes profile pictures, cover photos, and albums. Profile pictures are the first things other users see and, whether intentional or not, Facebook reinforces the importance of self-promotion and beauty and reproduces the link between social power and looks. As Fiske (2010) states, "the meanings of health are social and not physical, the meanings of beauty are political and not aesthetic: health and beauty are equally socio-political and therefore discourses for the exercise of social power" (p. 74). The perfect way to display social power is through a picture which captures a moment in time when a person feels that he or she embodied, as best as possible, their ideal self. This replicates how still advertising works: a picture is a perfected representation of a commodity that can bring social power through its consumption; it fetishizes the product and, similarly, the Facebook profile picture fetishizes the user where the user is "selling" an idea of him or herself.

The second production modality that impacts how meaning is articulated is "likes". Media-related likes are one of the first bits of profile information people are prompted to enter when registering. There are no suggestions as to what those should be at that point. However, when this is accessed through the profile page, each section is filled with suggestions. Most likely these suggestions are based on popularity and include the categories of media related things such as TV shows, movies, books, inspirational people, sports/sports teams, athletes, and games. These "likes" are a part of a new way to ensure that a person is displaying the correct popular culture and sub-cultural expressions of belonging. Hoechsmann and Poyntz (2012) state, "digital media enable a form of symbolic articulation (...) they provide spaces where the relationship between our socio-cultural selves and our individuated selves becomes apparent" (p. 154). Even though they are referring to the use of digital media for exploring "the me that is me" (p. 153), I contend that this new form of symbolic articulation can be stretched to include the use of media as symbols in a digital media environment to display "the me that is me". 
The third production modality of interest here is the "friends" list. It is a display of popularity and group belonging. If a user has nice pictures and interesting "likes" it may lead to acquiring more friends. This is because most people draw on the same consumer-related discourses to confirm social desirability, and attracting new "friends" may be a sign of successful self- branding. These three production modalities connect consumer-related discourses, such as gendered beauty and selfpromotion, to displaying consumer identity through "likes" to social desirability, popularity, and group belonging; all of which link to Facebook's business model that revolves around the coproduction of consumer identity.

The news feed is a part of Facebook's basic format but it is not a production modality, rather it is here that many users "read" their "friends"" "productions". It showcases top stories or most recent stories from "friends" along with advertisements for various products including Facebook apps. However, when a person has hundreds of "friends" what will he or she actually see? And when a person is new to Facebook who will see that person in their news feed? There is some measure of control in the "friend" settings. People can decide what updates they see from particular "friends" and who they get notifications from. Users can also remove "friends" from their news feed which usually generates someone new appearing on it. I link the way the news feed functions to some of the socio-cultural implications that were raised by my survey questions: annoyance regarding over-posting and bragging, jealousy of others, feelings of loneliness and isolation, addiction, annoyance with targeted advertising, and knowing how to 'work' Facebook or its structural code.

The structural code may govern how people feel about their experience with Facebook; it may impact their psychological well-being because it determines how much interaction people have with each other. Together the basic format and structural code constitute the governance of Facebook and they have important ramifications for cyber identity performance on this social network site.

An article published by Weber (2010) on The Daily Beast entitled Cracking the Facebook Code discusses the code behind Facebook's news feed. His investigation of how the newsfeed functions was spurred by the question "Why does this guy that I barely know from the 10th grade keep showing up in my Facebook feed?" (para. 2). He conducted an experiment to "crack the Facebook code" for what shows up in a person's newsfeed. They had a new person, Phil, join Facebook and had him friend over two dozen volunteers with previous accounts that would go through their news feed and record any sightings of him. They came up with ten key findings:

1. There is a bias against newcomers. No matter how much Phil posted no one noticed his postings on the news feed.

2. Once the volunteers started interacting with him it led to the second insight which they labeled a catch-22: to get exposure your friends need to interact with you in particular ways. But how will this happen if you aren't being noticed by them to begin with? 
3. The third insight was particular types of interactions between friends lead to getting on people's News Feeds. It wasn't a guarantee for being in the Top News, which is the one most people get their Facebook information from according to this article. Top News may show you older posts from friends but filter out more recent news. Getting into Top News was dependent on the type of interactions you have.

4. The fourth insight was that most Recent News is also censored. Most would assume that Recent News is unbiased; however, there is a setting in the News Feed that caps the number of friends that get shown there.

Looking into Weber's fourth insight I noticed that it had changed since then. You can block people from appearing on your news feed but I did not see any edit setting for deciding how many people can appear on my news feed. You can also block people from your newsfeed.

5. The fifth insight is that if you 'stalk' your friends you won't get noticed more by them. It is important to note here that stalking and following are two different things. Stalking is when you go on people's profiles and observe them without them knowing, whereas when you "follow" someone you have notified them through your "friend" options. In the edit privacy section of your "friends" list it says that "the people you follow can see that you're following them" (Facebook, 2013). It is not just about visiting their profile page or trolling through someone's photos.

6. The sixth insight was that if you get stalked regularly and people click on your links and look at your postings you will show up on their news feed more often.

7. The seventh insight was that if you post links these will more likely show up on someone's feed than a regular status update.

8. The eighth insight was that photo and video postings show up more than links.

9. The ninth insight was that the more people that comment on your postings the more you will start showing up on people's news feed.

10. The last insight was that "Facebook Really is Like High School" (para. 24). This is because the "popular kids" (para. 24), or those who have more than 600 friends, still had not seen Phil in their newsfeed. Those who first saw Phil's postings were those with less than 200 friends. So the key to Facebook success is to build a relationship with people who aren't so popular first to improve your own visibility. But you will never know who actually sees your posting.

This "code" impacts people unknowingly if they are not aware of it. Feelings of isolation and loneliness, as cited in my survey and in findings by Turkle and by Marche, may be a result of not knowing how to work the "code". If a person is not posting the right kind of stuff, like videos and photos, and are not generating comments on their postings, they will not be noticed. Grimes and Fields (2012) claim that Facebook can help with low self-esteem in young adults because they can stay "in the loop" 
of the popular kids. However, this depends on a few variables. First this implies that a popular kid will 'friend' you. Secondly, it implies that self-esteem is just about an awareness of others. Being in the loop might generate an initial good feeling but will eventually lead to loneliness and isolation again when no one pays attention to you. However, there is hope to remedy the situation if a person knows how to work the code. One female in my survey stated "I know how to work Facebook". Her friends ask her why she gets so many comments and it's because she knows how to show up in News Feeds. The key to success is: increase visibility first with people who have a similar number of "friends"; post videos and pictures; come off as socially desirable by posting pictures of yourself with friends and come-off as well-rounded by posting funny and inspirational things. Do not brag, do not over-post, do not over-emote or people will remove you from their News Feeds. To be popular and increase your social capital you need to have balance and you should comment on other people's postings. This should result in people clicking on you more, becoming more visible on News Feeds, and slowly building up your social capital. It will lead to fewer feelings of isolation and loneliness. As Ellison et al. (2008) contend, positive psychological outcomes also come out of building weak ties, so the initial foray into building up your popularity may come from connecting with close friends and acquaintances.

The addictive nature of Facebook, cited in my survey results, may also stem from working the code. Popularity is linked to working Facebook and if a user is not commenting or generating comments, they may lose their edge. This might be the reason for comments related to the pressure to perform (Table 4). Annoyances with over-posting and over-bragging may be occurring as result of people not knowing what they should be posting and perhaps taking any attention as positive attention, which may ultimately lead to decreased popularity. Lastly, feelings of jealousy may stem from a person not knowing how to work the code and seeing other people getting lots of attention on the news feed while he or she is getting minimal attention or none at all. One last consideration is that just because you post something it does not mean that everyone will see it for the reasons stated above, but also because the news feed changes rapidly. I once posted a video that I had tagged about ten friends in and only two commented. I thought it was strange and asked the others if they had seen it and they had not. So even with explicit tagging, some people do not see news feed items. One cannot assume that others understand how to work Facebook and this may also lead to some of the negative psychological outcomes associated with Facebook use.

A textual analysis of Facebook reveals that format and code impact the articulation of meaning. Particular production modalities of its basic format encourage identity performance around consumer-related discourses through links to appearance, media likes, and well-roundedness which enhance social desirability and increased popularity. This reflects the business model of Facebook which coproduces consumer identity and encourages it. The structural code also impacts people's "production" and "readings" of others. I do not relate the structural code to dominant discourse, but rather it is a by-product of the system that needs to be understood in order to have a more fulfilling cyber identity performance. 


\section{READINGS: HOW DOES THE MEDIUM AFFECT THE READING?}

I want to know how people "read" others on Facebook and whether it stems solely from its governance and communication styles. This question allows me to explore the socio-cultural implications of cyber identity performance on Facebook. The textual analysis and production point demonstrated that its basic format, structural code, and business model influence how people perform their cyber identities and they may also influence how people read other. My study results showed that nine out of 18 participants surveyed made sure they have a nice picture (Table 3 ), the activity they do most is check the newsfeed (Table 3), the newsfeed generated annoyances about over-posting, bragging, over-emoting, and advertising (Table 2), and that Facebook was being used as a "show-off book" and made one participant feel "badly about myself" (Table 4). Previous studies do not delve into how the textual modalities impact people's readings of each other.

It is not far-fetched to conceive that what a person intends to be the reading of their cyber identity may not be how it is read by others. Facebook will shape the message, and we cannot get away from this. No matter what we intend our message to be, the medium affects how it is presented and how it will be read. It is not only the structure of Facebook that shapes the message, but also the hyperreality of the communication. In the introduction, I gave a personal example of what put this research into motion for me, my Facebook friendship with my mother. Her lack of interaction on my postings and her comments on other people's postings impacted me negatively by making me feel neglected, but this was not her intention. Her intention was not to boast about her children yet the nature of the medium of Facebook had me read it differently. I cannot say that these issues have not occurred offline on occasion, but on Facebook it becomes intensified through its hyperreal and public nature. The hyperreal nature distorts communication and its public nature makes the effects feel more pronounced.

Another point to consider in how people "read" each other is individual subjectivity. Though some readings will be predictable, and may stem from the structure of Facebook, people will also have random readings coming from their own personal view points. Previous studies have also cited psychological predispositions as a factor related to how people "read" each other on Facebook. People with low self-esteem may become jealous of others and their ensuing tendency to overproduce in a search for meaning and belonging may cause others to read them as simply selfabsorbed, without knowing the root cause behind their "annoying" cyber identity performance. A study conducted by Kramer et al. (2014) also shows that emotional contagion, resulting from the reading of others, affects people's psychological wellbeing. Their experiment indicates that some of the negative drawbacks associated with Facebook use, such as unhappiness, may be due to other people's status update types. So "readings" of others on Facebook are impacted by several factors: its structure and code, its business model (which I cite as influencing me to "read" others as product representatives in Chapter 5), personal subjectivity, hyperreal communication and its public nature, and psychological predispositions. 


\section{Cultural Life: The Back and Forth Play between Cultural Production and Everyday Life}

Examining cultural life allows me to look at my central research question of what are the socio-cultural implications of cyber identity performance on Facebook for my target population. In essence, it involves the study of how the media impacts everyday life and how everyday life influences cultural production. Here we are speaking of the classic feedback loop between cultural life and media representations. Speaking about media-based advertising, Willis (1990) states that "commerce keeps returning to the streets and common culture to find its next commodities" (p. 94). The corporate media utilizes our consciousness but do not manufacture it; our consciousness is in part a reflection of dominant cultural values that are propagated by media and other large institutions such as church, education, and family (Buckingham, 2008; Giroux, 2001).

Facebook use is impacting society and culture life in the way people socialize and communicate with each other, read each other, see themselves, and present themselves to others. It is changing the meaning of friend and friendship, age category definitions, and news sources, and it is also improving people's social capital leading to positive psychological benefit, affecting socio-political action, while causing addictive behavior, and feelings of pressure to be on. Among the multiple practices and ways of doing and being that we can see transformed through our online lives, the most salient is the bifurcation of self into material being and avatar. To some extent, I am now we, and you are you (plural). Our connection to a hyperreal version of our selves is an instance of avatar attachment.

The bifurcation of the self into an avatar is leading to confusion over feelings about the self. Turkle (2011), for example, had a respondent state that if Facebook were deleted she would be deleted and this came up with one my female survey respondents. After finishing the survey she deleted her account. I asked her what she meant by this. She said "I deactivated it". I asked what she would have to do to reactivate it. She said "wait 30 days and answer some security questions." I asked her why she did not just delete it and she responded "I'm not comfortable doing that, all my pictures are there and interactions with other people. It would feel weird to delete all my memories." Even though she was tired of Facebook, she could not delete her account. This struggle with Facebook profile deletion signals a struggle that is occurring for some users about where aspects of themselves reside.

The Facebook profile has become a physical extension of its users; the commodified space of Facebook and how people view their interaction with others impacts their offline lives. Drawing on avatar attachment theory, I argue that the immersion that occurs on Facebook due to identification and interactivity leads to a greater chance that its users will internalize its narrative. The narrative may be one that the user develops him or herself around his or her "readings" of their own cyber identity performance and those of others, or it could be the "reading" of the consumer discourses that are inherent part of Facebook's structure. As Hoechsmann 
and Poyntz (2012) say "it is not a stretch to see media viewing habits and practices as a concomitant variable in actions, practices, and behaviors" (p. 92).

\section{McLuhan's Tetrad: Facebook as an Extension of Everyday Life}

McLuhan's (1964) perspective is that media are extension of humans and that the nature of the medium reflects something of them. Facebook has been influenced by everyday life, is an extension of it, and also impacts it. As he famously said, "the medium is the message" (p. 23), which means that the medium becomes a part of the message and influences how it is "read" by others. We need to also remember that any consequence, personal or social, that is felt as a result of Facebook use is a result of how it changes a pre-existing pattern. People tend to focus on content instead of on the nature of the medium to determine meaning and consequence. McLuhan's tetrad (1988) maps out and analyses the effects of media and technologies through four points asking: what does the media enhance, reverse, retrieve, and make obsolete. These four points happen simultaneously, even if we only become aware of particular effects much later. Applied to my research focus of cyber identity performance on Facebook, the questions become how does the medium of Facebook affect identity and communication, and what are the socio-cultural implications? I map out Facebook effects through these four points below.

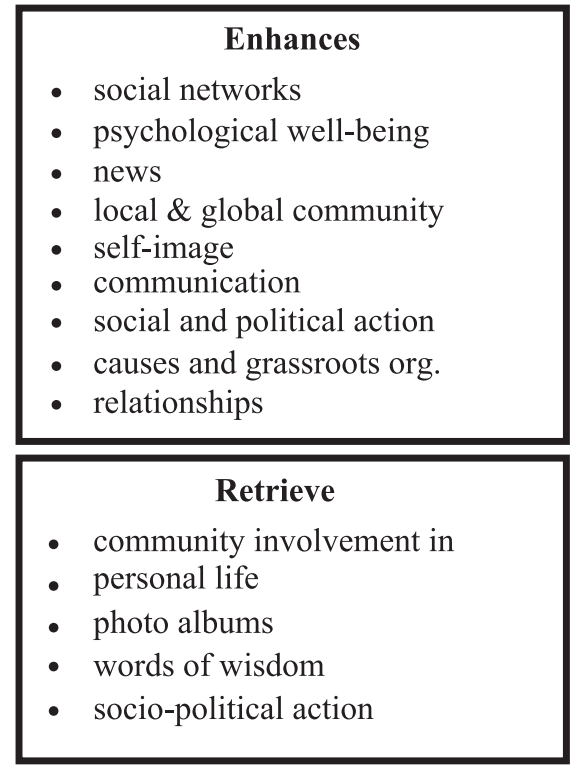

\begin{tabular}{|c|}
\hline \begin{tabular}{ll} 
& \multicolumn{1}{c}{ Reverse } \\
- & loneliness/ jealousy/annoyance \\
- & socio-political "slactivism" \\
- & exploitation \\
- & personal and identity insecurity \\
- & addiction/waste of time \\
- & targeted advertising \\
- & miscoling pressured \\
- & performance exhaustion
\end{tabular} \\
\hline $\begin{array}{l}\quad \text { Obsolete } \\
\text { - } \quad \text { privacy } \\
\text { - } \text { snail mail/telephone } \\
\text { - newspaper } \\
\text { - "cause" unawareness } \\
\text { - offline community? }\end{array}$ \\
\hline
\end{tabular}

Figure 1. Tetrad of Facebook effects 
The things that are "enhanced" or "reversed" by Facebook use relate to the positive and negative claims associated with its use for individuals, the community, and the larger society and culture. What is "retrieved" involves things that the new technology re-enables that may have been lost with previous technologies or media. In the case of Facebook, it "retrieves" community involvement in personal lives as many contend that offline community has become fragmented making people wary of each other. It also "retrieves" photo albums in digital form, words of wisdom in that people share inspirational thoughts with each other which is something that may have more likely occurred in church settings, and socio-political action because it is encouraging people to share information and join causes which is expanding democracy and revitalizing politics. However, Facebook is also superseding or making "obsolete" other technologies and elements of society and culture. Privacy is threatened due to the waiving of rights through Facebook's data use policy as Philips and Moberly (2013) state:

At the same time, Facebook sells the users data to the hordes of bidders whose interest in her marches in blocks down the right panel of the screen and pursues her even when she is not using Facebook. The very relations that sustain her Facebook presence become threatening: privacy broached, the limitless self falls prey to its own exposure, sustained by its friendships with carefully tailored projections and then made unhappy by them, targeted by marketing efforts that bind friendships to layered forms of commodification, profoundly confirmed as it is profoundly threatened. (para. 28)

Facebook is also making snail mail and telephone "obsolete", although I contend that this is an ongoing process stemming also from other technology use such as cell phones and e-mail. However, I feel that Facebook is accelerating their disappearance because of its fast and constant forms of communication through postings and messages and smart phone access. Newspapers are similarly further threatened through the sharing of electronic news through news feeds, which may grab people's attention and result in them no longer seeking out paper news or even other forms of electronic news. The state of social "cause" unawareness is changing through the dissemination of information on Facebook. Facebook may also be making offline communities "obsolete" and this can be looked at from a negative or positive perspective. From a negative perspective, communities, which are already considered fragmented, may become further threatened through the creation of superficial friendships and community and from a positive perspective, online communities are fulfilling the psychological and emotional needs of its users making offline communities dispensable.

The tetrad helps us to map out how this new medium changes what we do on an everyday level in the concourse of our lives. Thus far, I have focused on the effects that dominant discourse, co-production around consumer identity, psychological predispositions, biological predispositions, and avatar attachment have on cyber identity performance and I related them mostly to the negative outcomes of enhanced 
consumer identity, constricted production, addiction, jealousy, and depression. The tetrad asks us to examine the positive and negative outcomes associated with Facebook use along with constancy and change. In doing so, I question how the positive outcomes are possible within such a constrained context of dominant discourses and hyperreal considerations of inauthentic technology communication; are these positive outcomes sustainable or fleeting, and are these cyber identities performances on Facebook resulting in the recovery of community and selfexploration? Personally, it has made me closer to my family in Finland and I have gotten to know them in ways I may never have otherwise. Occasional quick trips to Finland would never reveal as much as albums and status updates do on a daily basis. But again I am troubled in my reading. Am I reading people as they would intend me to? Something is always lost in translation and the medium shapes the message.

Has the artificial become more real than the original? Are online communities and relationships artificial because they have been manufactured through a technologically produced medium? For many, Facebook use is based on a hyperreal notion that it will bring them the authenticity they are missing in their everyday lives while distancing them even further from it. The fact that most people do not question the paradox resulting from a simultaneous increase in communication with a reduction of human relations shows how deeply technologies have infiltrated their lives.

\section{A CRITICAL PERSPECTIVE ON AGENCY IN FACEBOOK USE}

Even though some technology "advances" us, a lot of is also connected to making an economic profit, not maximizing human potential. Foucault contends that our agency is reduced by two factors: a dominant discourse that encourages overconsumption and impacts our subjectivity, and a form of self-regulation or policing of oneself in the context of panoptic surveillance (Agger, 2004; Foucault, 1980, 1982).

In Chapter 1 I discussed why agency is an area of concern when exploring the socio-cultural implications of cyber identity performance on Facebook for my peer group, members of the Cusp Generation. I define agency in connection to personal empowerment and consciousness, and, without it, identity and subjectivity are confined by power and economy. I question whether Facebook is a form of social reproduction that reinforces dominant ideologies connected to the maintenance of power and economy. Agency involves overcoming dominant discourse in one's identity or cyber identity performance; to overcome it or not be affected by it involves being conscientious of it. I consider whether I see critical awareness of dominant discourse through my study results that would be indicative of agency. Agency also involves exposing hyperreality's connection to economy and power. This means that agency in cyber identity on Facebook will come with an understanding of the limitations that hyperreality imposes on relationships. Uncovering how much agency is present also involves revealing whether or not there is a form of self- 
surveillance occurring through the cyber identity performance on Facebook with my peer group, as Foucault would contend (Sim \& Van Loon, 2001). Conversely, uncovering a burgeoning critical awareness of constraints on agency may suggest that there is a resurgent agency referred to as critical conscientization by Freire (Freire \& Shor, 2003; McLaren, 2003). I saw evidence of some critical awareness of the hyperreal nature of Facebook in my study when survey respondents cited feelings of awkwardness occurring offline when running into people they are friends with on Facebook, wanting to have Facebook free nights, and the need for it to be used moderately.

Just because agency seems on the surface to be constricted by the textual modalities of Facebook it does not mean that our subjectivity is as impacted. The social and political expressions brought forth by my research participants present a different aspect to the question of agency. It is, perhaps, indicative of a critical consciousness. For example, four out of 14 participants in my survey cited that they chose to like or support a cause (Table 3) and the Facebook profile analysis of 99 people showed that $22 \%$ of females and $17 \%$ of males liked something of socio-cultural or political significance and $21 \%$ of females and $18 \%$ of males had a socially or politically-related status update (Table 1). Some are radical, some are progressive, some are concerned citizens, but almost all have adopted Facebook as a place where a social and political vision is appropriate and welcome. At worst, this resurgent activist sentiment is a reflection of the minor resistance that capitalism needs to thrive (McLaren \& Scatamburlo-D'annibale, 2004) that will be asphyxiated through oversaturation (Merrin, 2005), but there is some interesting ground to cover here and time will tell how much Facebook matures as a town hall space for social and political discourse.

Facebook as a medium reflects dominant ideologies and particular discourses related to identity and consumerism. There is no escaping this since its textual modalities reflect them and determine how we perform our cyber identity. Thus, we can see the feedback loop of cultural life at work in the reasons for using Facebook: on the one hand, it is a mass response to a powerful commercial push for the consumption of technology and associated products and services, and, on the other hand, a reflection of the desire by everyday people to connect to others and to recover community. Facebook allows for the maintenance of social capital which has been connected to many positive social outcomes like lower crime rates and better health care. Social capital maintenance is connected to being socially desirable and this is achieved by seeming well-rounded and a strong group identity. It is also dependent upon working the 'code' to generate feedback and increase one's presence and extend one's social network. Knowing how to work the code or not work the code is connected to both positive and negative outcomes, like feeling supported, on the one hand, or isolated and lonely, on the other.

Facebook also feeds off people's psychological predispositions. If you are depressed then you will more likely see the negative aspects of Facebook and spend more time using it to try to make yourself feel better. It most likely will not help this 
type of individual, especially if there is no awareness of how the code works, on top of it all. Avatar attachment theory contends that Facebook's structure promotes an attachment to our hyperreal selves. This is further exacerbated by our cultural love of iconic forms, making Facebook the perfect breeding ground for the fetishization of ourselves.

If the user is critically aware and empowered, Facebook has the potential to be a positive socio-cultural phenomenon. Grassroots businesses and socio-political causes, both of which chip away and try to subvert dominant forces, as discussed by Fiske, are often promoted, making Facebook a possible avenue for democratic, social organization. What needs to be determined is whether Facebook users in their 30s and 40s are largely adultescents who fetishize cyber identity or critically, conscientized cyber identity performers. As McLuhan says, the nature of the medium reflects something of the nature of people. We are social beings and I hope that Facebook will lead to more positive societal changes rather than an acceleration of hyperreal consumptions of the self. At this moment both are happening and there are positive and negative socio-cultural implications that arise from them both. 



\section{CONCLUSION}

I belong to a lost generation and am comfortable only in the company of others who are lost and lonely.

(Eco, 1986, p. 67)

This chapter is an opportunity to reflect critically on my own Facebook use. I then discuss future research directions stemming from this research, the study's theoretical and educational implications, and limitations incurred in this study. When I began this study I found myself questioning if my agency was constricted on Facebook, if my subjectivity was a victim of a self-imposed surveillance that seeks to conform as a result of consuming dominant discourses related to identity, whether I am an adultescent, and if the prosuming of my "self" on Facebook is a form of selffetishization. After all, I could not deny that I try to look good in my pictures and to come off as well-rounded in my cyber identity performance. I also wondered about my attachment to Facebook as I often find myself thinking about what I should post on Facebook and occasionally find myself thinking "status update thoughts" and screening them for appropriateness. I questioned if my Facebook use and striving for social desirability were an extension of commodity fetishism and panopticism that feed capitalist interests or if they were "natural" and simply an extension of my desires. Yet, even the basis of my desires needed to be questioned. Steinberg (2010) contends that desire can be used by "power wielders for destructive and oppressive outcomes" (p. 144) and, like Fiske, she sees these desires as being innate, but as ultimately exploited by the market economy. In the end, I find myself teetering between acting like an adultescent, fetishizing myself, falling victim to marketrelated discourses, struggling with the hyperreal and enjoying more contact with friends and family far away, getting involved more in social and political causes, and trying to think more about how I perform my cyber identity.

Being socially desirable helps with group belonging but there needs to be a balance, especially in the hyperreal space of Facebook because hyperreality can erode relationships and promote overconsumption. I still experience break-downs in communication with my friends on occasion and feelings of awkwardness when seeing Facebook "friends" offline. Recently, I was out for dinner at a hotel, when I noticed a familiar looking woman sitting not far from me. I realized that she was a Facebook "friend" and I did not know what to say, knowing quite well how the hyperreal nature of Facebook was impacting me. It felt odd to say "hi" just because of our online relationship. We do not interact on Facebook; she is a "friend" of a 
"friend" with whom I do interact with online and offline. I decided to wait and see if she would say something, but she didn't. I almost ran into her the next morning and I found myself dodging her presence around the breakfast buffet tables. It was extremely uncomfortable. The funny thing is I am very social person and do not shy away from interactions. However, this experience showed me that the awkwardness stemmed from us really not "knowing" each other at all, which points to the hyperrealness of my "friends" list, and as much as I am aware of the workings of hyperreality on my subjectivity, it is still hard to not have it affect me.

There is no doubt that I am even more aware now of the hyperreal nature of Facebook. More recently, I joined a community group for stay-at-home mothers and, after getting to know some of them, I have become friends with them on Facebook. I find it interesting how my off line impression of them has changed by a reading of their cyber identity performance. I read the self they want to project and get an idea of their idealized representation of reality. Some of them even look quite different in their profile pictures, dare I even say prettier and slimmer? Had I gotten to know them first through Facebook and then met them offline, maybe I would not have known how to read their offline presence. I admit I have a hard time negotiating the two worlds. The same continues to be true of my relationship with my mother; I do not know how to read her cyber identity performance at times and, as I mentioned earlier, I feel that the public nature of our relationship makes me react more strongly towards what may be misreadings of her coming from generational differences towards technology use, cultural and linguistic differences, and communication break-downs caused by the hyperreal nature of communication technology. Even though I know not take readings at face value, it is difficult to always follow my own advice.

I try to balance out the narcissistic side of my cyber identity performance on Facebook and to feel like I have some social and political agency by using it to spread information related to the environment and social and political causes. I especially love avaaz.org, which gives me updates on the outcomes of particular petitions and campaigns; I feel like I am making a difference. However, I have to constantly ask myself if this activity is just a form of symbolic resistance that helps me justify and feel happy about the simultaneous commodification of myself in order to keep myself in check and ensure some measure of agency.

Philips and Moberly (2013) contend that people's tendency to equate the purpose of Facebook use with the generating of happiness is why so many studies revolve around looking at the negative psychological effects of its use, which "preempt[s], if not deflect[s], a more sustained examination of the underlying social, economic, and political conditions" (para. 10) of happiness as symptomatic of a larger ideological strategy "to mask the material realities of socioeconomic and cultural production" (para. 11). Facebook is a commercial enterprise and it resells our personal information to advertisers; its impetus is not to serve my socio-political or communal needs. In fact, the authors contend that "Facebook and its games erect fantasies of the good life we would like others to imagine that we live as our lives both within and outside 
Facebook" (para. 40). In a world of continuously increasing environmental, social, and political concerns that are largely related to overconsumption, concentrating on an idealized version of one's self seems absurd. It leaves me wondering if the ego can ever really be overcome and how to balance it with true agency on Facebook.

Am I living a hyperreal life on Facebook and how much of my cyber identity performance on Facebook can be translated to my everyday life? Actually, I think a lot of it does reflect the 'real' me, and Facebook enables me to be more politically and socially involved through the dissemination of information. I just never know who my social and political information is impacting. I try to make an effort to bring up issues more in person now to ensure that Facebook does not become too hyperreal. Yet, I am guilty of making sure that my appearance on Facebook is always great. I do not post pictures of myself where I look fat or old, sad or angry. I also think about what types of things I post so that I don't seem weird or annoying. Therefore, Facebook is changing the way I think and it is impacting my behavior.

\section{FUTURE RESEARCH DIRECTIONS}

Throughout this book, I have brought up points of interest in need of further research. They are:

1. Based on Larose et al.'s (2011) study conclusions, it is worth exploring if all those who use Facebook for help in overcoming depression and low self-esteem always end up self-criticizing, wasting more time on Facebook, and eventually self- regulating themselves.

2. Stemming from my relationship with my mother, further research could consider how generational, cultural, and linguistic differences impact cyber identity performances and, consequently, readings of each other on SNSs like Facebook.

3. How much more hyperreal is Facebook for those who have grown up with it? I remember how friendships functioned without the use of Facebook and this has me question if those who do not have this reference use it differently with different impacts on their friendships.

4. Many studies have been conducted on how Facebook is used for socio-political purposes and to connect with like-minded people (Bohler-Muller \& van der Merwe, 2011; Kavador, 2012; Marichal, 2013; Smeltzer \& Keddy, 2010; Stieglitz \& Dang-Xuan, 2013). However, studies have not been conducted on whether or not this type of Facebook activity influences those "friends" not so politically inclined to become more active and the general effects on them.

5. In order to assess the impacts of Facebook's coproduction of a person's consumer identity, surveys should ask how participants view their "friends" liking brands. I, for example, associate brands with particular "friends" and consequently view them as product representatives. It also makes me think about the brand more. I also wonder if I am being used by a corporation and future research could be conducted around monitoring for this and making people aware of how far the 
corporate exploitation goes. This awareness might change the way people interact with advertising on Facebook.

\section{THEORETICAL IMPLICATIONS}

This research breathes new life into previous theories on dominant discourse, hyperreality, and agency by showing how they link to each other in the particular domain of cyber identity performance on the social network site Facebook. My study results show that cultural industries, as described by Adorno (1991), are alive and well in the Web 2.0 atmosphere of SNSs with cultural production on Facebook serving capitalist interests through the reinforcement of consumer discourse and the coproduction of consumer identity. The legitimization of capitalism through ideological manipulation, as witnessed by Adorno and Horkheimer, has continued on Facebook through its connection to a broad ideology of consumerism in both the corporate production of Facebook and the production that occurs through its software by users. The business model of Facebook reinforces these discourses through the commodification of this cyber space and through the coproduction of participant's consumer identity.

Next, I have extended Baudrillard's and Eco's conceptualization of hyperreality to Facebook and argued that it is the ultimate form of commodity fetishism because the object that is being fetishized is the self. Baudrillard argued that any form of communication that is not face-to-face is inauthentic and meaningless because it does not require much effort and Eco, drawing on Benjamin, argued that North Americans prefer simulated copies over originals because they embody ideal versions, if only for a moment. This makes communication on Facebook problematic because authentic communication will not be easily found and copies of one's self will lead to the overproduction of ideal versions of the self for the user and for others to consume. Avatar attachment may also lead to heightened hyperreal drawbacks such as loneliness, wasting time, and performance exhaustion that arise from equating the simulated self and relationships with authenticity.

Lastly, I extended the conversation on agency to cyber identity performance on Facebook. I showed that agency is constrained on Facebook due to its reinforcement of dominant discourses and hyperreal nature. These agency constraints will have socio-cultural implications because so many people are joining Facebook and using it as a site of communication and identity performance. Therefore, Facebook use is impacting the way people think about themselves and relate to others.

\section{EDUCATIONAL IMPLICATIONS}

My investigation of the socio-cultural implications of cyber identity performance has revolved around showing that Facebook is linked to dominant discourses related to identity and consumerism that may be constricting a user's agency. In order to ensure that this does not happen, people need to be, at the very least, made aware 
of how the medium of Facebook can affect identity and relationships through its textual modalities (business model, basic format, structural code) and its hyperreal seduction of happiness and community. I hope this work can contribute to critical pedagogy (Freire, 1998; Freire \& Shor, 2003) because I have attempted to illuminate that agency on Facebook is problematic and that the medium of Facebook serves processes of social reproduction, if a person is not aware.

Many of my research participants struggled with the effects of the hyperreal nature of Facebook and also performed cyber identities that leaned towards potential self-fetishization because of the prosuming of the self. Since many of today's parents and teachers are members of the Cusp Generation it is essential that they understand their own SNS use and the various factors that may be impacting their cyber identity performances in order to begin to understand its influence on children and teens. Therefore, the insights generated by my findings can be used in the teaching of critical media literacy in teacher education; it will help teachers who are members of the Cusp Generation gain a better understanding of their own SNS practices, and how these might be similar to as well as different from students, making them more thoughtful teachers of youth. My findings can also be used in critical media literacy aimed at students in both secondary and post-secondary school settings. Hoechsmann and Poyntz (2012) point out that most media literacy initiatives "have generally focused on addressing what are perceived to be the negative effects of media on youth aggression and crime, materialism, sexuality and alcohol and drug use" (p. 11). In areas of media literacy specifically dealing with "the participatory potentials of the new communication technologies and the platforms of Web 2.0" (p. 39), educators tend to focus on "youth transgressions and victimization" through cyber bullying, "stranger danger", violent behavior, cognitive effects, and "buying into consumer culture". However, there is little awareness of how mega-corporations are framing and constraining youth self-perceptions and communication with their peers, elders, and the broader community and world through SNSs like Facebook, and how they are perpetuating consumer-related discourses; corporations are cultivating social and political identities.

Hoechsmann and Poyntz's view is similar to the one expounded by Buckingham (2000) who feels that education should prepare children for the marketplace with economic literacy, not protect them. He promotes a form of consumer empowerment for children and feels that they have "a right to accurate information and advice [and] a right not to be exploited" (p. 167). Additionally, it should also involve a "rigorous examination of what is assumed about children's cultural needs, and of the ways in which the media is said to fulfil them" (p. 167). I extend this thinking to the way the market functions on the Web 2.0. Children, teens, and young adults are being exploited on Facebook and yet Facebook fulfils many of their socio-cultural needs. Therefore, instead of discouraging Facebook use, they should be empowered with the correct literacy so that they are not exploited.

Drawing on Freire, my promotion of an empowering critical media literacy centered on Facebook use and its links to market exploitation empowers students 
even more through its recognition of the importance of SNSs in their everyday lives. Any education that enters into a critical dialogue with students about the significance of their experiences in the world is empowering for them. Furthermore, this approach entails that educator's need to be aware that Facebook use is not inconsequential; as our material beings and our hyperreal selves continue to overlap, we need to ask ourselves: who is sitting in the classroom? Is it the material person, the hyperreal, or some blend of both?

Drawing on Johnson's four-point model, educators can show students how Facebook serves processes of social reproduction and how subjectivities and relationships are influenced by dominant discourses and hyperreality; this illumination may lead to increasing agency on Facebook, empowering youth to shape their own identities, and create more meaningful relationships with others. I also hope that this research lends itself to further discussions on how the medium of Facebook can be used critically in educational settings. Facebook is being used a news source and for raising awareness about social and political causes. To ensure that it is a critical form of information sharing, more research needs to be conducted on how information is shared and from where information is retrieved. This may become another component of critical media literacy. It is imperative to ensure that the positive social and political aspects of Facebook use, which are indications of agency, are not a hyperreal form of politicization, and misinformation. Facebook could be harnessed as cyberspace for positive socio-cultural purposes if there is agency or a critical conscientization of the workings of dominant discourses and the effects of hyperreality.

Lastly, I hope that the research in this book is used to inform further studies and discussions on these implications in like populations and that they also situate the cultural product of Facebook within broader socio-economic considerations. Insights gathered from the unique perspective of the Cusp Generation should be used to consider younger generation's cyber identity performances on Facebook.

\section{LIMITATIONS INCURRED IN THIS STUDY}

My study became more limited than intentioned because of the length of my survey and my sample size. When I later asked people why they had chosen not to participate, they stated the burdensome length of the survey as the reason. This study cannot fully answer the socio-cultural implications of cyber identity performance due to my limited sample. However, Bhutta (2012) states:

As others have shown, biased samples drawn from the web often preserve measures of statistical relationships quite well. For example, Best et al. (2001: 143). separately analyzed a random telephone sample and an Internet sample and found that the same factors influence political attitudes in both. Consequently, the authors believe they would have reached the same conclusions about the determinants of particular political attitudes by relying 
on a diverse convenience sample of Internet users as [they] would have by using a more expensive, time-consuming, probabilistic telephone sample. (p. 70)

So, even though my sample may have been biased (participants were from my Facebook "friends") and small in number (99 in the Facebook profile analysis, 18 in the survey, and seven e-mail responses on likes), my results reflected many of the same findings of previous studies. Yet, I cannot dismiss the fact that I remain questioning whether those who participated in my research did so because they fall into an extreme of either loving or hating Facebook. As such, like a bricoleur I am always left questioning. Kincheloe (2004d) states:

Bricoleurs are comfortable with the unfinished, unresolved nature of the multi- dimensional, ever-changing constructions of reality they produce. When faced with such complexity many researchers from the monological tradition become paralysed, as the single predetermined path to knowledge production closes down. (pp. 89-90)

I began this concluding chapter with a quote from Eco, who discussed his comfort in finding company with people who are "lost and lonely" like him. I chose this quote because it resonates so perfectly with my study, yet, comes from a time before SNSs or the Internet even existed. It shows that social and personal fragmentation precedes Facebook use and will likely continue to evolve in unsuspecting ways. So like bricoleurs, academics and scholars must be open to the "ever-changing" nature of our social realities and have their research reflect that. 



\section{APPENDIX A}

\section{SURVEY}

\section{FACEBOOK (FB) SURVEY}

\section{Other}

1. What do you like about FB?

2. What do you dislike about FB?

3. How has FB impacted your life?

4. Do you have more than one FB account? If so, why?

\section{Online Friends}

1. Roughly what percentage of FB friends do you interact with offline?

2. Roughly what percentage of FB friends do you interact with only online?

3. Roughly what percentage of FB friends do you have no contact with offline or online? And if there are such FB friends, why are you friends with them?

4. For those you interact with offline, has the nature of your relationship changed by being on FB? If so, how?

5. Roughly what percentage of FB friends would you consider as close friends?

6. Has Facebook changed your expectations of your friends in any way?

\section{Profile and Usage}

1. How do you choose your profile picture?

2. How do you choose your cover picture?

3. If you do not share your birth date, why have you chosen to hide it?

4. If you have "likes" how do you choose what to like?

5. How often do you click on ads?

6. How often do you find yourself looking at them even without clicking on them?

7. How do FB ads affect you?

8. How often do you log onto FB?

9. How much time do you spend on FB/day?

10. What do you do most on FB?

11. Do you play games on FB? 
APPENDIX A

Other Comments

Please tell me about anything that you feel is noteworthy regarding your experience with FB. 


\section{SAMPLE FACEBOOK PROFILE}

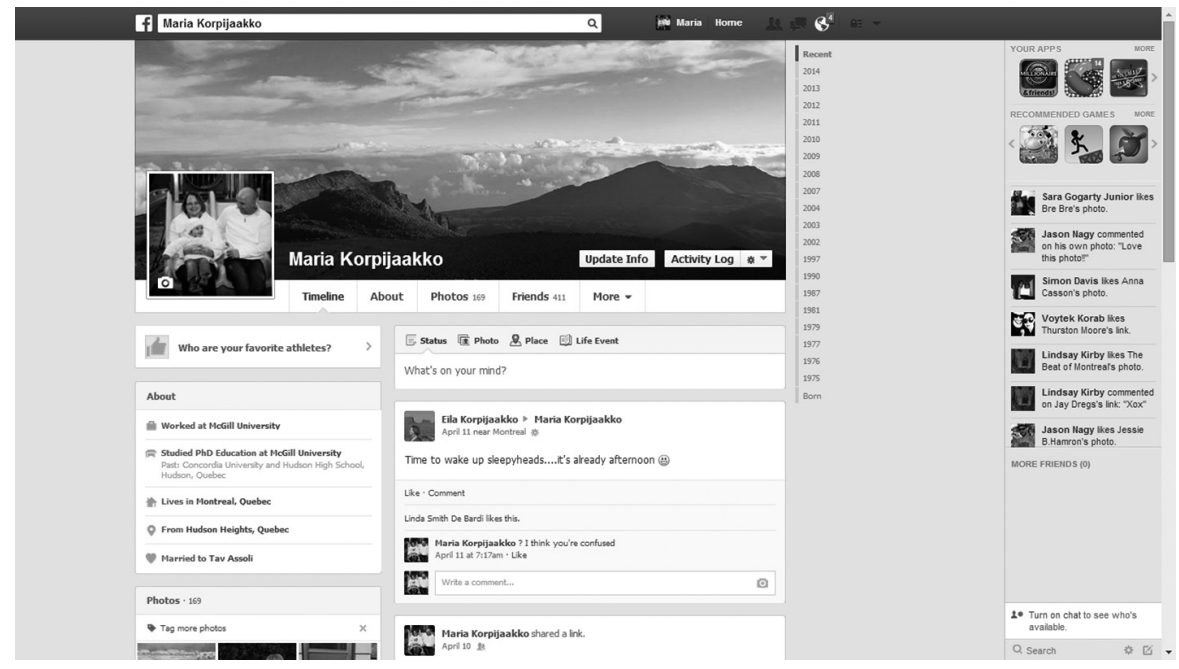





\section{HOME PAGE ADVERTISING SCREEN SHOTS FOR 8 DAYS}

Day 1

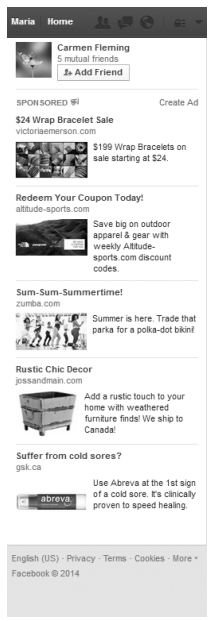

Day 2

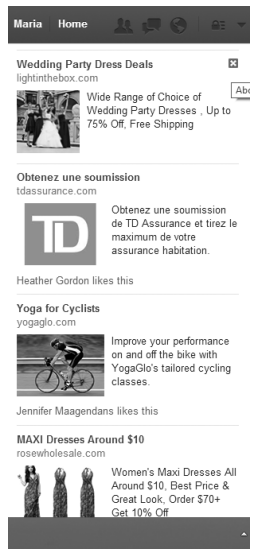


APPENDIX C

Day 3

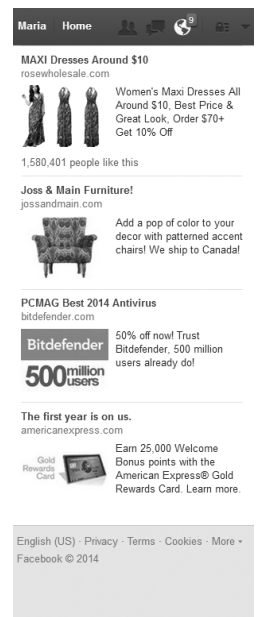

Day 4

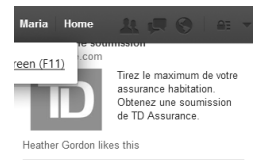

Secret to Good Health?

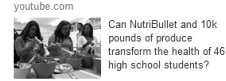

Donnamarie Levin likes this

Win $10,000 \mathrm{~s}$ in cash

CIIIISY Visit our Fac abook page for

BUNIEST

Heather Gordon likes this

Catelli
Feed the Hope

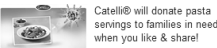

Like Page - Tifany Giancola likes this page

English (US) - Privacy - Terms - Cookies - Mare Facebook $\Theta 2014$ 


\section{Day 5}

Day 6
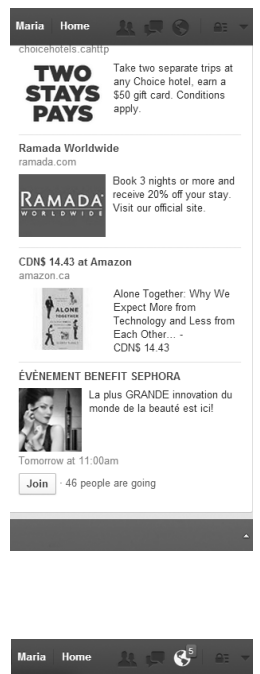

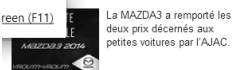

Obtenez une soumission

Tirez le maximum de votre

Obtenez une soumission

Heather Gordon likes this

Yoga For Women

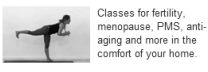

tennifer Magagndans likes this

Cheap Dresses 59

(17x

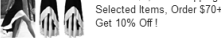

Alex Bourgeois likes this

Until July $6 !$

CONIEST 
APPENDIX C

Day 7

Day 8
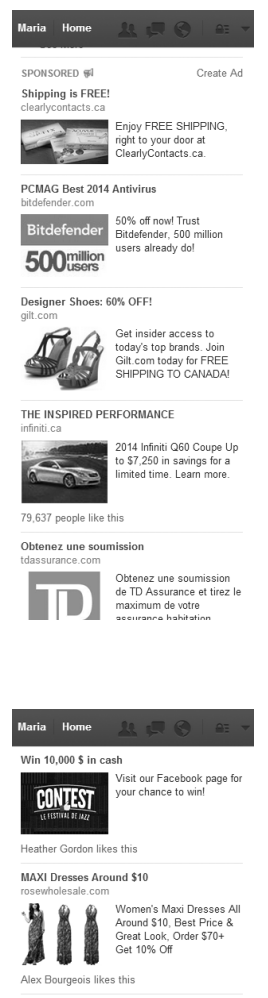
Designer Handhags on Gilt Find Vintage Handbags at
insider Prices Join Git
Today for FREE SHIPPING
TO CANADAI English (US) - Privacy- Torms Cookios : More -
Facebook Q 2014 


\section{BIBLIOGRAPHY}

\#Occupy. (n.d.). About \#occupy. Retrieved from http://www.occupytogether.org/aboutoccupy/\#background Adorno, T. W. (1991). In J. M. Berstein (Ed.), The culture industry: Selected essays on mass culture. London, UK: Routledge.

AdRoll. (2013). Retrieved from http://www.adroll.com/Facebook_exchange

Adult. (2014, June 29). Wikipedia. Retrieved from http://en.wikipedia.org/wiki/Adult

Agger, B. (2004). The virtual self. Oxford, UK: Blackwell Publishing.

Althusser, L. (2005). For Marx (F. Maspero, Trans.). London, UK: Verso. (Original work published 1965)

Anwar, J. (2014, July 2). Facebook COO Sheryl Sandberg says psychology experiments on users were just product testing. The Times of India. Retrieved from http://timesofindia.indiatimes.com/tech/social/ Facebook-COO-Sheryl-Sandberg-says-psychology-experiments-on-users-were-just-product-testing/ articleshow/37634680.cms

Attick, D. (2008). Consumption is the message. In D. Boyles (Ed.) The corporate assault on youth (pp. 51-68). New York, NY: Peter Lang.

Avaaz. (2014, July 27). Wikipedia. Retrieved from http://en.wikipedia.org/wiki/Avaaz

Back, M. D., Stopfer, J. M., Vazire, S., Gaddis, S., Schmukle, S. C., Egloff, B., \& Gosling, S. D. (2010, January 29). Facebook profiles reflect actual personality, not self-idealization. Psychology Science (Online First), 1-3. doi:10.1177/0956797609360756

Barber, B. R. (2007). Consumed: How markets corrupt children, infantilize adults, and swallow citizens whole. New York, NY: W.W. Norton and Company.

Baudrillard, J. (1993). Symbolic exchange and death (I. H. Grant, Trans.). London, UK: Sage.

Baudrillard, J. (1995). Simulacra and simulation (S. F. Glaser, Trans.). Ann Arbor, MI: University of Michigan Press.

Baudrillard, J. (1996). The system of objects (J. Benedict, Trans.). London, UK: Versa.

Benitz, G. (2014, March 28). School district pays $\$ 70 \mathrm{~K}$ to settle lawsuit over girl's Facebook posts. $A B C$ News. Retrieved from http://abcnews.go.com/US/school-district-pays-70k-settle-lawsuit-online-posts/ story? id $=23094873$

Benjamin, W. (1999). The Arcades project (H. Eiland \& K. McLaughlin, Trans.). Cambridge, MA: MIT Press. (Original work published 1982)

Biddle, S. (2013, January 23). Don't "like" companies of Facebook or you'll embarrass yourself. Gizmodo. Retrieved from http://gizmodo.com/5978342/dont-like-companies-on-facebook-or-youllembarrass-yourself

Bohler-Muller, N., \& van der Merwe, C. (2011, March). The potential of social media to influence socio-political change on the African Continent. Policy Brief: Africa Institute of South Africa, 46, 1-8. Retrieved from http://www.ai.org.za/media/publications/Policy\%20Brief/AISA\%20Policy\%20 Brief\%2046.pdf

Bohn, D. (2012, February 1). How Facebook makes money: 85 percent from ads, 12 percent from Zynga. The Verge. Retrieved from http://www.theverge.com/2012/2/1/2764825/Facebook-revenue-ads-12percent-zynga

Boon, S., \& Sinclair, C. (2009). A world I don't inhabit: Disquiet and identity in second life and Facebook. Educational Media International, 46(2), 99-110.

Bourdieu, P. (1986). The forms of capital. In J. Richardson (Ed.), Handbook of theory and research for the sociology of education (pp. 241-258). New York, NY: Greenwood Press.

Bourdieu, P., \& Wacquant, L. J. D. (1992). The purpose of reflexive sociology (Chicago workshop). In P. Bourdieu \& L. J. D. Wacquant (Eds.), An invitation to reflexive sociology (pp. 61-216). Chicago, IL: The University of Chicago Press.

Bowles, S., \& Gintis, H. (1976). Schooling in capitalist America. New York, NY: Basic Books.

boyd, d. (2008). Why youth (heart) social network sites: The role of networked publics in teenage social life. In D. Buckingham (Ed.), Foundation series on digital learning - Youth, identity, and digital media volume (pp. 119-142). Cambridge, MA: MIT Press. 


\section{BIBLIOGRAPHY}

Brenner, J. (2013, February 14). Pew Internet: Social networking (Full detail). Pew Internet. Retrieved from http://pewinternet.org/Commentary/2012/March/Pew-Internet-Social-Networking-full-detail.aspx

Buckingham, D. (2000). After the death of childhood. Malden, MA: Blackwell Publishers Inc.

Buckingham, D. (2008). Introducing identity. In D. Buckingham (Ed.), MacArthur foundation series on digital learning - Youth, identity, and digital media volume (pp. 1-24). Cambridge, MA: MIT Press.

Butler, J. (2001, Winter). Giving an account of oneself. Diacritics, 31(4), 22-40.

Cannella, G. S. (2002). Global perspectives, cultural studies, and the construction of a postmodern childhood studies. In G. S. Cannella \& J. L. Kincheloe (Eds.), Kidworld: Childhood studies, global Perspectives, and education (pp. 3-20). New York, NY: Peter Lang.

Chang-Kredl, S. (2007). The toughest chick in the alien world. In D. Macedo \& S. Steinberg (Eds.), Media literacy: A reader (pp. 395-404). New York, NY: Peter Lang.

Cooper, R. (2007). Alter ego: Avatars and their creators. London, UK: Chris Boot Publishing.

Crawford, K. (2012). Reanimating adulthood. In K. H. Robinson \& C. Davies (Eds.), Queer and subjugated knowledges: Generating subversive imaginaries (pp. 140-167). Sharjah, United Arab Emirates: Bentham Science Publishers.

Croft, J. (2011). "It's just a game" - Ethical reasoning within virtual worlds. In H. Gardner (Ed.), Good work project report series, 73. Retrieved from http://www.thegoodproject.org/pdf/73-Its-Just-a-Game.pdf

Data Use Policy. (2014). Facebook. Retrieved from https://www.facebook.com/about/privacy/ your-info\#facebookcontent

Davis III, C. F., Deil-Amen, R., Rios-Aguilar, C., \& Gonzalez Canche, M. S. (2012, January). Social media in higher education: A literature review and research directions. Tucson, AZ: The Center for the Study of Higher Education at the University of Arizona.

Delwiche, A. (2007). From the green berets to America's army: Video-games as a vehicle for political propaganda. In J. P. Williams \& J. H. Smith (Eds.), The player's realm: Studies on the culture of video games and gaming (pp. 91-109). London, UK: McFarland and Company.

Dematteo, R. (2011, September 28). New Facebook cover photo provides creative options for job seekers. Corn on the Job. Retrieved from http://www.cornonthejob.com/social-media/new-Facebook-coverphoto-provides-creative-options-for-job-seekers/

Device Ownership. (2014). Pew Research Center. Retrieved from http://www.pewresearch.org/data-trend/ media-and-technology/device-ownership/

Eco, U. (1976). A theory of semiotics. Bloomington, IL: Indiana University Press.

Eco, U. (1986). Travels in hyperreality: Essays (W. Weaver, Trans.). New York, NY: Harcourt Brace.

Ellison, N. B., Steinfield, C., \& Lampe, C. (2007). The benefits of Facebook "friends": Social capital and college students' use of online social network sites. Journal of Computer-Mediated Communication, $12,1143-1168$.

Erikson, E. (1968). Youth in crisis. New York, NY: W.W. Norton \& Company.

Facebook. (2013, March 28). Wikipedia. Retrieved from http://www.en.wikipedia.org/Facebook\#cite_note-8

Fiske, J. (1996). Opening the hallway: Some remarks on the fertility of Stuart Hall's contribution to critical theory. In D. Morley \& K.-H. Chen (Eds.), Stuart Hall: Critical dialogues in cultural studies (pp. 212-220). New York, NY: Routledge.

Fiske, J. (2010). Understanding popular culture (2nd ed.). New York, NY: Routledge.

Foucault, M. (1980). In C. Gordon (Ed.), Power/knowledge: Selected interviews and other writings. New York, NY: Pantheon.

Foucault, M. (1982). The subject and power. Critical Inquiry, 18(4), 777-795.

Foucault, M. (1991). The ethic of care for the self as a practice of freedom: An interview. In J. Bernauer \& D. Rassmussen (Eds.), The final Foucault (J. D. Gauthier, Trans.). Cambridge, MA: The MIT Press.

Freire, P. (1972). Pedagogy of the oppressed. Harmondsworth, England: Penguin.

Freire, P. (1998). The process of political literacy. In The politics of education (pp. 99-108). New York, NY: Bergin and Garvey.

Freire, P., \& Shor, I. (2003). What are the fears and risks of transformation? In M. Baltodano, A. Darder, \& R. D. Torres (Eds.), The critical pedagogy reader (pp. 479-496). New York, NY: RoutledgeFalmer.

Geary, D. C., \& Bjorklund, D. F. (2000, January/February). Evolutionary developmental psychology. Child Development, 71(1), 57-65. Retrieved from http://onlinelibrary.wiley.com.proxy2.library.mcgill.ca/ doi/10.1111/1467-8624.00118/pdf 
Gee, J. P. (2003). What do video games have to teach us about learning and literacy? New York, NY: Palgrave Macmillan.

Gee, J. P. (2007). Good video games and good learning. In C. Lankshear \& M. Knobel (Eds.), New literacies and digital epistemologies (Vol. 27). New York, NY: Peter Lang.

Gerbner, G., \& Grossberg, L. (1974). A system of cultural indicators. Public Opinion Quarterly, 38(3), 460-461.

Giddens, A. (1991). Modernity and self-identity: Self and society in the late modern age. Stanford, CA: Stanford University Press.

Gilligan, C. (1993). In her own voice. Cambridge, MA: Harvard University Press. (Original work published 1982)

Giroux, H. (1999). The mouse that roared: Disney and the end of innocence. Lanham, MD: Rowman \& Littlefield Publishers, Inc.

Giroux, H. (2001). Stealing innocence: Corporate culture's war on children. New York, NY: Palgrave Macmillan.

Gladwell, M. (2010, October 4). Small change: Why the revolution will not be retweeted. The New Yorker. Retrieved from http://www.newyorker.com/magazine/2010/10/04/small-change-3

Globe Staff. (2014, June 29). Facebook psychology experiment raises ire. The Globe and Mail. Retrieved from http://www.theglobeandmail.com/technology/tech-news/facebook-psychology-experimentraisesire/article19386909/?cmpid=rss1\&click=sf_globefb\#dashboard/follows/

Gramsci, A. (1999). Selections from the prison notebooks (Q. Hoare \& G. N. Smith, Eds., \& Trans.). London, UK: Electric Book Company. (Original work published 1971)

Grimes, S. M., \& Fields, D. A. (2012, Fall). Kids online: A new research agenda for understanding social networking forum. The Joan Ganz Cooney Center at Sesame workshop. Retrieved from http://www.joanganzcooneycenter.org/wpcontent/uploads/2012/11/jgcc_kidsonline.pdf

Grossberg, L. (1996). On postmodernism and articulation: An interview with Stuart Hall. In D. Morley \& K.-H. Chen (Eds.), Stuart Hall: Critical dialogues in cultural studies (pp. 131-150). New York, NY: Routledge.

Grossberg, L. (2009). Cultural studies: What's in a name (One more time)? In R. Hammer \& D. Kellner (Eds.), Media/cultural studies critical approaches (pp. 25-48). New York, NY: Peter Lang.

Grosser, B. (2011). How the technological design of Facebook homogenizes identity and limits personal representation. Retrieved from http://bengrosser.com/wp-content/themes/grosser/files/ GROSSER-facebook-identity.pdf

Hoechsmann, M. (2010). Rootlessness, reenchantment and educating desire: A brief history of the pedagogy of consumption. Critical pedagogies of consumption (pp. 23-35). New York, NY: Routledge.

Hoechsmann, M., \& Low, B. E. (2008). Reading youth writing: "New" literacies, cultural studies \& education. New York, NY: Peter Lang.

Hoechsmann, M., \& Poyntz, S. R. (2012). Media literacies: A critical introduction. Malden, MA: Blackwell Publishing.

Howe, N., \& Strauss, W. (2000). Millennials rising: The next great generation. New York, NY: Vintage Books.

Hum, N. J., Chamberlin, P. E., Hambright, B. L., Portwood, A. C., Schat, A. C., \& Bevan, J. L. (2011). A picture is worth a thousand words: A content analysis of Facebook profile photographs. Computers in Human Behaviour, 27, 1828-1833.

Hunsinger Benbow, D. (2014, February 20). Facebook bullying case disturbs school officials. USA Today. Retrieved from http:/www.usatoday.com/story/news/nation/2014/02/20/facebook-bullying-casedisturbs-school-officials/5666481/

Internet. (2014). Wikipedia. Retrieved from http://en.wikipedia.org/wiki/Internet

Ito, M., Horst, H., Bittanti, M., boyd, d., Herr-Stephenson, B., Lange, P. G., .. Robinson, L. (2009). Living and learning with new media: Summary of findings from the digital youth project. In The John D. and Catherine T. MacArthur foundation reports on digital media and learning (pp. 4-52). Cambridge, MA: The MIT Press.

Jacobs, G. E. (2006). Fast times and digital literacy: Participation roles and portfolio construction with instant messaging. Journal of Literacy Research, 38(2), 171-196. 


\section{BIBLIOGRAPHY}

Jenkins, H. (1998). Introduction: Childhood innocence and other modern myths. In H. Jenkins (Ed.), The children's culture reader (pp. 1-40). New York, NY: New York University Press.

Jenkins, H. (2006). Convergence culture. New York, NY: New York University Press.

Johnson, R. (1986-1987, Winter). What is cultural studies anyway? Social Text, 16, 38-80.

Johnson, R., Chambers, D., Raghuram, P., \& Tincknell, E. (2004). The practice of cultural studies. London, UK: Sage Publications.

Joinson, A. N. (2008). 'Looking at', 'looking up' or 'keeping up with' people? Motives and uses of Facebook. Paper presented at CHI 2008, Florence, Italy, April 5-10.

Jordon, T. (1999). Cyberpower. London, UK: Routledge.

Kasturi, S. (2002). Constructing childhood in a corporate world: Cultural studies, childhood, and Disney. In G. S. Cannella \& J. L. Kincheloe (Eds.), Kidworld: Childhood studies, global perspectives, and education. New York, NY: Peter Lang.

Kavador, A. (2012). Engagement, bonding, and identity across multiple platforms: Avaaz on Facebook, YouTube, and MySpace. MedieKultur: Journal of Media and Communication Research, 28(52), 28-48.

Kelle, H. (2001). The discourse of development: How 9- to 12-year-old children construct 'childish' and 'further developed' identities within their peer culture. Childhood, 8(95), 95-114.

Kellner, D. (2002). The Frankfurt school and British cultural studies: The missed articulation. In J. Nealon \& C. Irr (Eds.), Rethinking the Frankfurt school: Alternative legacies of cultural critique (pp. 31-58). Albany, NY: State University of New York Press.

Kelly, D., Pomerantz, S., \& Currie, D. (2005). Skater girlhood and emphasized femininity: You can't land an ollie properly in heels. Gender and Education, 17(3), 129-148.

Kincheloe, J. L. (2004a). Introduction: The power of bricolage: Expanding research methods. In J. L. Kincheloe \& K. S. Berry (Eds.), Rigour and complexity in educational research (pp. 1-22). Maidenhead, England: Open University Press.

Kincheloe, J. L. (2004b). Redefining rigour and complexity in research. In J. L. Kincheloe \& K. S. Berry (Eds.), Rigour and complexity in educational research (pp. 23-49). Maidenhead, England: Open University Press.

Kincheloe, J. L. (2004c). Questions of disciplinarity/interdisciplinarity in a changing world. In J. L. Kincheloe \& K. S. Berry (Eds.), Rigour and complexity in educational research (pp. 50-81). Maidenhead, England: Open University Press.

Kincheloe, J. L. (2004d). Redefining and interpreting the object of study. In J. L. Kincheloe \& K. S. Berry (Eds.), Rigour and complexity in educational research (pp. 82-102). Maidenhead, England: Open University Press.

Kincheloe, J. L. (2005). Critical pedagogy primer. New York, NY: Peter Lang.

Kincheloe, J. L. (2011). The complex politics of McDonald's. International Critical Childhood Policy Studies, 4(1), 1-46.

Kincheloe, J. L., \& Berry, K. (2004). Rigour and complexity in educational research. Bodmin, England: MPG Books Ltd.

Kincheloe, J. L., \& Steinberg, S. (Eds.). (2004). Kinderculture: The corporate construction of childhood. Boulder, CO: Westview press.

King, B. (2004). Mass media. In G. Taylor \& S. Spencer (Eds.), Social identities: Multidisciplinary approaches (pp. 182-198). New York, NY: Routledge.

Koslow, S. (2012). Slouching toward adulthood: Observations from the not-so-empty nest. London, UK: Penguin Books.

Kramer, A. D. I., Guillory, J. E., \& Hancock, J. T. (2014). Experimental evidence of massive-scale emotional contagion through social networks. PNAS, 111(24), 8788-8790. Retrieved from www.pnas.org/cgi/doi/10.1073/pnas.1320040111

Lahti, M.. (2003). As we become machines: Corporealized pleasures in video games. In M. J. P. Wolf \& B. Perron (Eds.), The video game theory reader (pp. 157-170). New York, NY: Routledge.

Lankshear, C., \& Knobel, M. (2003). New literacies, changing knowledge and classroom learning. Buckingham, England: Open University Press. 
Lankshear, C., \& Knobel, M. (2006). New literacies, everyday practices \& classroom learning (2nd ed.). New York, NY: McGraw Hill.

Larkin-Leiffers, P. A. (2010, July 19). Images of childhood and the implied reader in young children's information books. Literacy, 44(2), 76-82.

Larose, R., Kim, J., \& Peng, W. (2011). Social networking: Addictive, compulsive, problematic, or just another media habit? In Z. Papacharissi (Ed.), A networked self: Identity, community, and culture on social network sites (pp. 59-81). New York, NY: Routledge.

Lertwannawit, A., \& Gulid, N. (2010, November). Metrosexual identification: Gender identity and beauty-related behaviors. International Business \& Economics Research Journal, 9(11), 85-91.

Levin, D., \& Kilbourne, J. (2008). So sexy so soon: The new sexualized childhood and what parents can do. New York, NY: Balantine Books.

Lule, J. (2012). Mass media and popular culture. Understanding media and culture: An introduction to mass communication. Retrieved from http://2012books.lardbucket.org/books/mass-communicationmedia-and-culture/s04-06-mass-media-and-popular-culture.html

Marche, S. (2012, April 2). Is Facebook making us lonely? The Atlantic. Retrieved from http://www.theatlantic.com/magazine/archive/2012/05/is-Facebook-making-us-lonely/308930/

Marichal, J. (2013, December). Political Facebook groups: Micro-activism and the digital front stage. First Monday, 18(12). Retrieved from http://ojphi.org/ojs/index.php/fm/article/view/4653

McDonald, P. (2011, December 15). Timeline: Now available worldwide. Facebook. Retrieved from https://www.Facebook.com/notes/Facebook/timeline-now-available-worldwide/10150408488962131

McLaren, P. (2003). Critical pedagogy: A look at the major concepts. In A. Darder, M. Baltodano, \& R. D. Torres (Eds.), The critical pedagogy reader (pp. 69-96). New York, NY: RoutledgeFalmer.

McLaren, P., \& Scatamburlo- D’annibale, V. (2004). Paul Willis, class consciousness, and critical pedagogy: Toward a socialist future. In N. Dolby \& G. Dimitriadis (Eds.), Learning to labour in new times (pp. 41-60). New York, NY: Routledge Falmer.

McLuhan, E. (1988). Laws of media. Retrieved from http://www.collectionscanada.gc.ca/ innis-mcluhan/030003-2030-e.html\#al

McLuhan, M. (1964). Understanding media: The extensions of man. Toronto, Ontario, Canada: Signet Books.

Mehdizadeh, S. (2010). Self-presentation 2.0: Narcissism and self-esteem on Facebook. CyberPsychology, Behaviour, and Social Networking, 13(4), 357-364.

Merrin, W. (2005). Baudrillard and the media. Cambridge, UK: Polity Press.

Montague, D. (2014, June 10). UPDATE: Sheshatshiu Innu school closed after Facebook post. $N L$ News Now. Retrieved from http://www.nlnewsnow.com/News/Local/2014-06-10/article-3758127/ UPDATE\%3A-Sheshatshiu-Innu-School-closed-after-Facebook-post/1

Morozov, E. (2011). The net delusion: The dark side of Internet freedom. New York, NY: Public Affairs.

Morrison, C. (2010). Who do they think they are? Teenaged girls and their avatars in spaces of online social communication. New York, NY: Peter Lang.

Morrison, C. (2011). Avatars and the cultural politics of representation: Girlhood identity in social networking spaces (Doctoral Dissertation). Retrieved from Memorial University libraries. (5652.cpd)

Morrow, R. A., \& Torres, A. C. (1995). Social theory and education: A critique of theories of social and cultural reproduction. Albany, NY: State University of New York Press.

Mulligan, J., \& Patrovsky, B. (2003). Developing online games: An insider's guide. San Francisco, CA: New Riders Publishing.

Nadkarni, A., \& Hofmann, S. G. (2012). Why do people use Facebook? Personality and Individual Differences, 52, 243-249.

Newsroom. (2013). Facebook. Retrieved from http://www.newsroom.fb.com/Key-Facts

O'Dell, J. O. (2011, October 6). Once Facebook launches timeline, you'll never want to leave. Venture Beat. Retrieved from http://venturebeat.com/2011/10/06/facebook-timeline-lessin/

Patterson, M., \& Elliott, R. (2002). Negotiating masculinities: Advertising and the inversion of the male gaze. Consumption Markets \& Culture, 5(3), 231-249.

Philips, D., \& Moberly, K. (2013). Spectacular unhappiness: Social life, narcissistic commodification, and Facebook. Reconstruction: Studies in Contemporary Culture, 13(3/4). Retrieved from http://reconstruction.eserver.org/133/133_Phillips_Moberly.shtml 


\section{BIBLIOGRAPHY}

Prensky, M. (2001). Digital natives, digital immigrants, part I. On the Horizon, 9(5), 1-6.

Reed, B. (2014, July 1). Facebook's creepy psychology experiment is even worse than we thought. In $B G R$. Retrieved from http://bgr.com/2014/07/01/facebook-psychology-experiment-controversyupdate/

Rochman, B. (2011, August 8). Kids who use Facebook do worse in schools. Time. Retrieved from http://healthland.time.com/2011/08/08/kids-who-hang-out-on-facebook-do-worse-in-school/

Rose, N. (1999). Governing the soul: The shaping of the private self (2nd ed.). London, UK: Free Association Books.

Sandifer, P. (2009). Avatari: Disruption and imago in video games. Digital Humanities Quarterly, 3(3). Retrieved from http://digitalhumanities.org/dhq/vol/3/3/000066/000066.html

Sandlin, J. A., \& McLaren, P. (2010). Introduction: Exploring consumption's pedagogy and envisioning a critical pedagogy of consumption- living and learning in the shadow of the "shopocalypse". Critical pedagogies of consumption (pp. 1-20). New York, NY: Routledge.

Schonfeld, Z. (2014, July 1). Facebook performed a psychology experiment on thousands of users without telling them. Newsweek. Retrieved from http://www.newsweek.com/facebook-performedpsychology-experiment-thousands-users-without-telling-them-256914

Schroer, W. J. (n.d.). Generations X, Y, Z and the others. The social librarian. Retrieved from http://www.socialmarketing.org/newsletter/features/generation3.htm

Schulman, N. (1993). Conditions of their own making: An intellectual history of the centre for contemporary cultural studies at the University of Birmingham. Canadian Journal of Communication, 18(1). Retrieved from http://www.cjc-online.ca/index.php/journal/article/view/717/623

Sim, S., \& Van Loom, B. (2001). Introducing critical theory. Singapore, Malaysia: Icon Books.

Simon, D. (2014, June 5). Cops: Facebook threat against Massapequa high school lands former students in trouble. Newsday. Retrieved from http://www.newsday.com/long-island/nassau/richard-delpesceand-corinne-terris-made-facebook-threats-toward-massapequa-high-school-police-say-1.8344438

Smeltzer, S., \& Keddy, D. (2010). Won't you be my (political) friend? The changing Face (book) of socio-political contestation in Malaysia. Canadian Journal of Development Studies, 30(3), 421-440.

Social networking factsheet. (2014). Pew Research Center. Retrieved from http://www.pewinternet.org/ fact-sheets/social-networking-fact-sheet/

Stald, G. (2008). Mobile identity: Youth, identity, and mobile communication media. In D. Buckingham (Ed.), MacArthur foundation series on digital learning - Youth, identity, and digital media volume (pp. 143-164). Cambridge, MA: MIT Press.

Steinberg, S. (2010). Power, emancipation, and complexity: Employing critical theory. Power and Education, 2(2), 140-151.

Stephenson, N. (1992). Snow crash. New York, NY: Bantam.

Stern, S. (2008). Producing sites, exploring identities: Youth online authorship. In D. Buckingham (Ed.), MacArthur foundation series on digital learning - Youth, identity, and digital media volume (pp. 95-117). Cambridge, MA: MIT Press.

Stieglitz, S., \& Dang-Xuan, L. (2013, December). Social media and political communication: A social media analytics framework. Social Network Analysis and Mining, 3(4), 1277-1291.

Subrahmanyam, K., \& Greenfield, P. (2008). Online communication and adolescent relationships. The Future of Children, 18(1), 119-146.

Tancer, B. (2008). Click: What millions of people are doing online and why it matters? New York, NY: Hyperion Press.

Taylor, G., \& Spencer, S. (2004). Introduction. In G. Taylor \& S. Spencer (Eds.), Social identities: Multidisciplinary approaches (pp. 1-13). New York, NY: Routledge.

Thomas, A. (2004). Digital literacies and the cybergirl. E-learning, 1(3), 358-382.

Thomas, A. (2007). Youth online: Identity and literacy in the digital age. New York, NY: Peter Lang.

Tierney, J. (2004, December 26). 2004: In a word: Adultescent. New York Times. Retrieved from http://query.nytimes.com/gst/fullpage.html?res=9D04EEDD1E30F935A15751C1A9629C8B63

Turkle, S. (1995). Life on the screen: Identity in the age of the Internet. New York, NY: Simon and Schuster. 
Turkle, S. (1996, Winter). Virtuality and its discontents. The American Prospect, 24, 50-57. Retrieved from http://web.mit.edu/sturkle/www/pdfsforstwebpage/ST_Virtuality\%20and\%20its\%20discontents.pdf

Turkle, S. (2005). The second self: Computers and the human spirit (20th Anniversary ed.). Cambridge, MA: MIT Press.

Turkle, S. (2011). Alone together: Why we expect more from technology and less from each other. New York, NY: Basic Books.

Usage and Population Statistics. (2014). Internet world stats. Retrieved from http://www.internetworldstats.com/stats.htm

van Dijck, J. (2013). You have one identity: Performing the self on Facebook and LinkedIn. Media, Culture \& Society, 35(2), 199-215.

Walker, L. (2014). Facebook cover photo guide. About.com social media. Retrieved from http://personalweb.about.com/od/Facebook-photos/a/Facebook-Cover-Photos.htm

Walkerdine, V. (1993, July). Post-modernity and feminist research. Paper presented at Psychology of Women Conference. Brighton, England: University of Sussex.

Weber, S., \& Mitchell, C. (2008). Imaging, keyboarding, and posting identities: Young people and new media technologies. In D. Buckingham (Ed.), MacArthur foundation series on digital learning Youth, identity, and digital media volume (pp. 25-47). Cambridge, MA: MIT Press.

Weber, T. (2010, October 18). Cracking the Facebook code. The Daily Beast. Retrieved from http:/www.thedailybeast.com/articles/2010/10/18/the-Facebook-news-feed-how-it-works-the-10biggest-secrets.html

Willett, R. (2008). Consumer citizens online: Structure, agency, and gender in online participation. In D. Buckingham (Ed.), MacArthur foundation series on digital learning - Youth, identity, and digital media volume (pp. 119-142). Cambridge, MA: MIT Press.

Williams, R. (1961). The long revolution. London, UK: Chatto \& Winders Ltd.

Willis, P. (1977). Learning to labour. New York, NY: Columbia University Press.

What Are Cookies? (2012, October 10). WebWise. Retrieved from http://www.bbc.co.uk/webwise/guides/ about-cookies

Wolfendale, S. (2007). My avatar, myself: Virtual harm and attachment. Ethics and Information Technology, 9(2), 111-119.

Yaftali, A. (2011, December 8). School children should not have access to Facebook: Argumentative essay. Digitizeme. Retrieved from http:/digitizeme.ca/2011/12/08/school-children-should-not-haveaccess-to-facebook-argumentative-essay-2/

Zhao, S., Grasmuck, S., \& Martin, J. (2008). Identity construction on Facebook: Digital empowerment in anchored relationships. Computers in Human Behavior, 24, 1816-1836.

Zur, O., \& Zur, A. (2011). On digital immigrants and digital natives: How the digital divide affects families, educational institutions, and the workplace. Zur Institute - Online Publication. Retrieved from http://www.zurinstitute.com/digital_divide.html 



\section{INDEX}

\section{A}

active audience model, 67

addiction, 27, 29, 30, 33, 38, 41, 51, 56, $97,105,112,119$

Adorno, Theodor, 44, 67, 69, 126

adult, 13-15, 17-19, 23, 31, 35-41, 56

adult education, 13

adultescent, 8, 12, 14, 37-39, 41, 44, 110,123

advertising, 3, 4, 11-14, 40, 46, 57,

$64,73,74,77,84,85,91,98,99$, 102-104, 107, 109, 111, 112, 115, $116,126,135$,

age, $1,3,5,7,8,10,15,16,18-20,23$, 33-39, 41, 44, 46, 51, 53, 56, 58, $60,61,64,65,68-70,73,74,81$,

$83,92,94,98,102,104,106,116$

age-related categories, 7, 8, 33

agency, 2, 3, 7, 9-14,16, 19, 24, 33,

36-38, 41, 45, 46, 48-53, 55-58,

$65,68,69,119,120,123-128$

alienation, 6, 45, 49

annoyance, 5, 85, 90, 96, 99, 102, 104,

112

anxiety, 2, 27, 56, 97

Arab Spring, 25

Arcades Project, 45

audience, 3, 11, 17, 26, 58, 61, 66, 67, 69,87

authentic communication, 5, 46, 86, 126

Avaaz, 6, 25, 29, 124

avatar, 41-44, 51, 53, 59, 86, 109, 116

avatar attachment, 12, 14, 33, 41-44,

51, 53, 55, 56, 68, 69, 105, 116,

$118,121,126$

awkwardness, 28, 90, 120, 123, 124
B

Baudrillard, Jean, 5, 9, 13, 14, 33, 44, 46-50, 86, 126

beauty, 19, 39-41, 60, 86, 92, 96, 108-112

Benjamin, 7, 9, 14, 44, 45, 67, 126

biological predisposition, 69, 118

brand, 29, 60, 61, 64, 84, 85, 92, 93, 97, $98,103,104,107,125$

bricolage, 12, 55

bullying, 1, 2, 127

C

campaigns, 25, 84, 91, 124

capitalism, 4, 5, 44, 46, 49, 52, 65, 81, $85,106,120,126$

capitalist production, 6, 9, 45, 46, 67

career, 60, 61, 63, 88, 91-93, 109

celebrity worship culture, 19, 109, 110

child, 5, 8, 34-38, 61, 91

childhood, 2, 34-38, 40, 41, 105

codes of behavior, 108

coding frame, 11, 60, 64, 75

commodification, 13, 27, 40, 103, 107 , $118,124,126$

commodified space, 13, 85, 116

commodity consumption, 6,9

commodity fetishization, 7, 47

communication, 2, 5, 6, 10, 11, 16,

18, 22-24, 44, 46, 47, 55, 57,

$70,73,83,86,96,106,108$,

$115,117-119,123,124$,

126,127

authentic, 5, 7, 11, 26, 45, 46, 75, 86, 92,126

practices, 10, 13, 16, 17, 33, 34, 46,

68-70, 102, 107, 116, 117, 127 
INDEX

technology, 1-3, 5, 9-11, 16, 17, $23,24,26,30,43,44,46,47,49$, $51,52,57,69,70,73,87,95,96$, $100-102,118-120,124$

community, 5, 6, 18, 20-22, 24, 25, 28, $30,31,35,38,45,47,51-53,74$, $77,90,92,95,108,118-120,124$, 127

confusion, 7, 23, 35, 36, 45, 92, 116

consumer discourse, 10, 12, 13, 36, $37,46,64,69,103,107$, 110,126

consumerism, $3,7,9,12,13,36-41$, $45,46,51-53,57,59,60,68,69$, $104,106,120,126$

contextualization, 10, 57, 65

cookies, 103, 107

corporate brands, 11, 64, 73, 84, 97, 98, 104

habits, 30, 51, 85, 107, 117

identity, 1-4, 7-17, 19-26, 29, 31, 33-37, 39-45, 47, 48, 51-53, 55-60, 64-70, 73-76, 83-88, 90-92, 94, 96-99, 102-112,

114-121, 123-128

production, 106, 126

cover photo, 24, 56, 59, 60, 87, 88, 92

critical conscientization, 9, 120, 128

critical literacy, 53

critical media literacy, 13, 14, 52, 127 , 128

critical research, 52

cultural codes, 8

differences, 3, 19, 21, 22, 34, 41, 67, $73,75,90,91,108,110,124,125$

life, $2,5,6,9,11,12,16,19,21$, $23,26,30,34,35,38,44,46,47$, $55,58,61,63,66-69,83,89,91$, 94-96, 105, 106, 116, 117, 120, $124-126,131$

meaning, 5, 7, 20, 24, 35, 45-47, $51,67,68,75,93,94,105,111$, 114-117 production, $6,9,11-14,17,27$, 44-46, 48-50, 52, 55, 59, 60, 64-70, 75, 91, 98, 105-112, 114-116, 118, 119, 124, 126, 129 reproduction, $65,106,119,127,128$ studies, 2, 4, 7, 11-17, 19-24, 26, $31,34,52,56,58,65-67,76$, $98,104,105,110,115,124,125$, 128,129

symbols, 8, 17, 22, 34, 37, 59, 92, 111

curriculum, 2

Cusp Generation, 3, 8, 10, 12, 13, 15, $20,23,31,33,73,74,76,95$,

$104,105,110,119,127,128$

cyber identity performance, 2, 3, 7-11, $13,14,33,41-44,47,48,51-53$, $55,56,58-60,65,67-70,74-76$, $86,87,91,96,98,99,102-104$, 106-108, 112, 114-120, 123-126, 128

cyberspace, 7-10, 53, 103, 107, 128

D

data collection, 12, 55, 57, 59, 60, 64, $71,74,104$

dating, 18, 20, 56, 90, 93, 94

delinquent, 18, 35

democracy, 25, 29, 118

depression, 2, 16, 30, 51, 56, 109, 119, 125

desires, 4, 38, 45, 48, 52, 110, 123

developmental stages, 34, 35, 41

digital immigrant, 2

digital natives, 2, 3, 74

discontentment, 5, 109

discourses, 7, 9, 10, 12, 13, 18, 19, 33, 34, 36-41, 46, 48, 50-53, 55, 57, 59, 60, 64, 67-69, 73, 86, 91, 96, 104, 106, 108, 109, 111, 112, 114, $116,119,120,123,126-128$

distant connections, 93, 97

diverse backgrounds, 19, 36 
dominant classes, 50

dominant discourses, 7, 9, 10, 12, 13, $37,39,50-52,57,67-69,96,119$, $123,126,128$

dominant culture, 9, 16, 48

$\mathbf{E}$

Eco, Umberto, 6, 7, 9, 10, 14, 33, 44-46, 48, 67, 85, 92, 105, 123, 126,129

economy, 9, 46, 52, 65, 85, 106, 119 , 123

education, $13,50,116,127,128$

educational research, 56

educators, 13, 127, 128

emotional contagion, 27, 30, 55, 69, 115

environment, $6,8,17,18,20,84,90$, $103,111,124$

evolution, 49

evolutionary developmental psychology, 34

exhaustion, 27, 96, 126

exploitation, 13, 27, 30, 36, 51, 56, 73, $98,104,107,126,127$

F

Facebook code, 97, 112

homepage, 12

newsfeed, 10, 11, 14, 29, 64, 76, 82, $83,85,86,93-95,97,98,102$,

$112,113,115$

profile, 4, 10-12, 14, 20, 21, 24, 27, $42,43,51,56-61,64,69,73-76$, 80, 84-89, 91, 92, 97, 103, 104, $108,109,111,113,116,120,124$, $129,131,133$

Profile Analysis, 11, 14, 57-59, 64, 69, 73-75, 97, 104, 109, 111, 120, 129

scientists, 27

statistics, 1, 11, 17, 19, 23, 31, 39, $60,64,74,75$ structure, 5, 13, 15, 29, 30, 43, 44, $56,58,59,76,83,92,103,104$, $106-108,115,116,121$

family, 6, 34, 55, 58, 60-62, 74, 76, 88, $90,91,116,119,123$

fashion, 3, 33, 60, 63, 84, 91, 102

fetishizing, 9, 10, 13, 123

Fiske, 9, 40, 45, 47, 48, 50, 52, 87, 107, $111,121,123$

flirting, 18, 56, 90, 77, 94

Foucault, Michel, 14, 33, 48-50, 52, $110,119,120$

four-point model, 11, 12, 14, 55, 58, $64-68,71,75,105,128$

friends, $1,5,6,9,10,12,13,17,18,20-23$, 27-29, 55-60, 62, 73-80, 83-98, $102,105,112-114,120,123-125$, 129,131

G

gender, 8-10, 19, 21, 24, 34, 41, 60, 64, $65,74,75,90-92,96,98,102$, $106,108,109$

gender differences, 21, 34, 41, 75, 90, 91, 108

gender discourse, 10, 41, 60, 74, 75, 90-92, 109

gendered commodification, 40

Generation Y, 3

$\mathrm{X}, 2$

$\mathrm{Z}, 2,3,56,73$

Giroux, 18, 36, 38, 116

GLBT, 18

gossip, 18, 39, 110

government, 45

grassroots, 23, 60, 62, 76, 85, 90, 121 great digital divide, 2,73

group, 2-5, 7-10, 12, 13, 16, 18-23, 29, $31,34,38,39,41,45,51,52,56$, 58, 60, 65, 67, 73-76, 83, 85-90, 93, 103, 104, 107-109, 112, 119, $120,123,124$ 
H

habitus, 9

happiness, 7, 46, 124, 127

hermeneutics, 57

Hoechsmann, Michael, 4, 9, 11-13, 45, $52,55,58,59,64,66-69,86,88$, $98,105,106,108,111,116,127$

Hollywood, 36

homogeneity, 58, 69, 110

homosexuality, 16

human rights, 6,25

hypersocial, 17, 96

hyper-connectivity, 26,27

hyperreal, 2, 3, 5, 7-9, 33, 44-47,

$51-53,55,68-70,73,86,92,93$,

95, 97, 104-106, 108, 109, 115, $116,119-121,123-128$

hyperreality, 3, 7, 9-12, 14, 33, 44, 46, $48,50,52,53,56,57,65,68,69$, $92,94,96,115,119,123,124$, 126,128

I iconic realism, 45

identity, 1-4, 7-17, 19-26, 29, 31, 33$37,39-45,47,48,51-53,55-60$, 64-70, 73-76, 83-88, 90-92, 94, 96-99, 102-104, 105-112, 114-121, 123-128

construction, 1, 16, 18, 33, 35, 36, 53

discourse, $8,10,12,13,26,36-41$, $45,46,48-53,56,57,60,64,65$, $68,69,74,75,87,90-92,103$, 104, 106-110, 114, 118-120, 126 experimentation, 16, 19, 35 exploration, 13, 16, 19, 22, 56, 106, 119 fixed, 34

fragmented, 24, 36, 38, 39, 51, 118 group, 2-5, 7-10, 12, 13, 16, 18-23, $29,31,34,38,39,41,45,51$, $52,56,58,60,65,67,73-76,83$, 85-90, 93, 103, 104, 107-109, $112,119,120,123,124$ narcissistic, 75, 86

self-absorbed, 75, 86, 108

performance, 1-4, 7-14, 22, 25, 27, $29,33-35,37,40-45,47,48$, $51-53,55,56,58-60,65-70$, 74-76, 85-88, 91, 92, 96-99, 101-108, 112, 114-120, 123-126, 128

political, 4, 7, 9, 14, 25, 26, 29, 35, $36,46,50,51,56,65,73,75,76$, $85,86,92-94,97,106,111,116$, $118,120,121,123-125,127,128$ practices, 10, 13, 16, 17, 33, 34, 46, 68-70, 102, 107, 116, 117, 127 socio-political, 7, 14, 26, 61-63, 75, $76,85,93,94,111,116,118,121$, 124,125

ideology of consumerism, 45, 51, 53, $59,69,106,126$

idols, 39

informal learning, 16

instruments of capital, 4, 27, 107

internet, 2-4, 6, 16, 19, 23, 24, 26, $27,29,30,39,44,66,74,107$, 128,129

intimacy, 21, 23, 24, 29

Iranian Green Revolution, 25

isolation, $6,112-114$

$\mathbf{J}$

jealousy, 5, 56, 83, 95, 97, 112, 114,119

Jenkins, Henry, 4, 7, 51, 110

Johnson, Richard, 11, 12, 14, 55, 58, $64-68,70,71,75,104,105$, 128

K

Kincheloe, Joe, 1, 7, 9, 12, 14, 18, 34-38, 46, 52, 55-57, 65, 85, 106, 129

knowledge, 9, 17, 48, 52, 57, 65, 97,129 
L

Likes, 1, 5, 14, 29, 43, 57, 60, 62, 64, $75,76,81,84,85,88,96-98$, 102-104, 107, 108, 111, 112, 114, 129,131

limitations, 14, 52, 119, 123, 128

linguistic differences, 124, 125

lived culture, 66, 67, 106

loneliness, 5, 6, 24, 26, 51, 83, 93, $112-114,126$

M

magazines, 40

market strategies, 33, 53

marketing, 4, 37, 39, 41, 57, 94, 95, 98, $103,110,118$

mass media, 3

McLuhan, Marshall, 55, 64, 68-71, $104-106,117,121$

meaning, 5, 7, 20, 24, 35, 45-47, 51, $67,68,75,93,94,105,111$, $114-117$

media, 1-4, 6, 8, 9, 11-15, 17, 22, 23, $25,26,30,34,36-41,43,46,47$, $50,52,55,56,59,64-71,84,86$, 98, 103-106, 108, 110, 111, 114, $116-118,127,128$

culture, 2-4, 6, 8-10, 12, 16, 17, 19, $22,23,35-37,39-42,44,46,48$, $49,51,52,55,56,64-69,85-88$, $103,106,107,109-111,116,118$, 127

effects and cultivation model, 67, 68 representations, 7, 34, 42, 65, 106, 116

sites, $9,11,15,16,18,22,24-27$, $30,39,56$

symbols, $8,17,22,34,37,59,92$, 111

media technology, 2, 23, 26, 46

mental illness, 27

methodology, 14 mimicking, 76, 83, 90

mobile phone, 17

mobilizing, 21, 108, 110

MTV, 50

$\mathbf{N}$

narcissism, 30, 86, 90, 95, 109

negative behavior, 1

negative effects, $11,14,15,26,31,127$

negative consequences, 2, 29, 30, 36, 37,68

neo-liberal discourse, 45, 51, 103, 109

networked public, 17

new media ecology, 15, 17

news, 1, 2, 4, 61, 63, 83, 89, 93, 97, $103,112-114,116,118,128$

news source, $83,93,97,128$

newsfeed, 10, 11, 14, 29, 64, 76, 82, 83, $85,86,93-95,97,98,102,112$, 113,115

non-communication, 47

O

object fetishization, 7, 44-46

Occupy movement, 6

offline world, 5, 8, 24

Oprah, 39

overconsumption, $7,10,33,44-47$, $49-51,93,94,119,123,125$

over-emoting, 77, 86, 95, 110, 115

$\mathbf{P}$

panoptic gaze, 48,49

panopticism, 50, 110, 123

pedagogy, 2, 127

perfected forms, 42

petitions, $6,25,124$

photo albums, 11, 21, 60, 76, 118

photographs, 21, 39, 91

Piaget, Jean, 34, 35

policy, 1, 28, 35, 107, 118

political activism, 25 
political causes, 4, 121, 123, 124, 128

popular culture, 3, 4, 40, 41, 49, 52, 65, 87,111

popularity, $21,25,28,30,33,38,41$, $76,90,97,108,111,112,114$

portfolio, 24, 59

positive effects, 11

postings, $10,30,43,44,55,57,76,88$, $91,93,112-115,118$

power, $1,9,12,24,37,48-52,65,68$, $69,85,105,106,111,119,123$

pressure, 27, 83, 95-97, 114, 116

production, $6,9,11-14,17,27,44-46$, $48-50,52,55,59,60,64-70,75$, 91, 98, 105-112, 114-116, 118, $119,124,126,129$

production modalities, $11,59,60,70$, $75,91,98,106,111,112,114$ profile pictures, 20, 21, 60, 61, 76, 86, $87,91,92,109,111,124$

prosumer, 59, 69, 106, 108, 110

psychological predispositions, 15, 30, $55,106,108,109,115,118,120$ psychological well-being, 21, 22, 56, $73,88,89,93,97,112,115$

$\mathbf{R}$

readings, $11,12,55,58,66-69,75,86$, $106,110,114-116,124,125$

rebellion, 36, 49

reception theory, 67-69

regulation, 1, 18, 19, 119

relationships, $2-5,7,8,10-12,16-18$, $20-23,25,26,28,29,44,45,47$, $51,52,55,57,59,70,73,74,110$, $119,123,126-128$

resistance, 49-51, 87, 120, 124

retargeted advertising, 13, 102, 107

S

safety, 94

scrapbooking, 30, 105 self, 4, 6, 7, 10, 14, 16, 18, 20-22, 24, $27,29,30,33,35,38-53,57$, 60-62, 64, 68, 69, 73, 75, 86-88, $92,95,97,102,103,105$, 108-116, 118, 119, 121, 123-127 bifurcation, 116 branding, 93, 94, 112

esteem, 18, 21, 24, 30, 86, 95, $113-115,125$

fetishization, 7, 14, 33, 44-47, 69, $97,109,127$

policing, 46, 48, 49, 119

promotion, 5, 39, 41, 51, 60, 64, 86, 108-112, 127

sexiness, 19

simulations, 7

slacktivism, 29, 85

smart phone, 6, 83, 94, 118

SNS statistics, 19

SNS/social network sites, 2, 4, 5, 16, $17,19,23$

social, 1, 2, 4-10, 13, 15-26, 28-30, $33-36,38,40,41,44-47,49-51$, $53,56,57,59,60,66-70,73,74$, 76, 83-97, 105, 106, 108-112, $114,116-121,123-129$

capital, 13, 20-22, 25, 28, 40, $41,74,83,87,88,93,97,114$, 116,120

change, 25

connectedness, 20, 22, 41, 87, 88, 90, 96

connection, 20, 21, 87, 90-92, 109, 110

desirability, 41, 59, 60, 87, 88, 90, $109,110,112,114,123$

fragmentation, 25

investigation, 20, 22, 89

network, 25, 28, 30, 83, 86, 88, 89, 93, $94,106,109,110,112,120,126$

norms, 17, 22, 90, 92

reproduction, 106, 119, 127, 128 
surveillance, 4, 20, 76, 83, 84, 89, 90, 109

socialization, 4, 106

socialness, $15,22,56$

status updates, 1, 5, 10, 11, 27, 43, 44, $57,60,61,63,76,86,88,89,92$, 106,119

Steinberg, Shirley, 7, 9, 14, 18, 34, 35, $37,52,106,123$

storytelling, 8, 33, 41

stress, 16, 27

strong ties, 21, 22, 28

student engagement, 23, 26

subjectivity, 1, 5, 11, 12, 43, 48, 52, 65, 67 , $109,111,115,119,120,123,124$

superficial relationships, 26, 28, 29

support, 6, 18, 20, 22, 24-26, 83, 85, 93, 94, 110, 120

surveillance, $4,10,18,20,49,68,76$, 77, 83, 84, 89, 90, 109, 110, 119, 120,123

survey, 11, 14, 20, 21, 57-59, 64, 73-75, 77, 80, 83-99, 104, 109, 112-114, 116, 120, 128, 129, 131 symbolic resistance, 50, 124

T

taboo, 16, 24

technology, 1-3, 5, 9-11, 16, 17, 23,

24, 26, 30, 43, 44, 46, 47, 49, 51,

$52,57,69,70,73,87,95,96$,

100-102, 118-120, 124

technology traces, 23, 95, 96

teen/teenager, 3, 6, 8, 13-19, 22-24, 26,

31, 35-38, 41, 73, 74, 76, 86, 90, 110,127

television, 2, 3, 6, 40, 43, 59, 66

tetrad, 55, 64, 69-71, 104-106,

117-119 text, $3,11,12,14,16,55,59,64$, 66-69, 71, 75, 105-107, 110, 111

textual analysis, 11, 67, 114, 115

textual modalities, $68,69,111,115$, 120,127

timeline, 30, 59, 88, 105, 107

Turkle, Sherry, 3, 5, 6, 8, 13-15, 23-29, 40, 42-45, 47, 51, 56, 68, 73, 74, 92-96, 102, 109, 113, 116

$\mathbf{U}$

university, 1, 14, 15, 19-23, 31, 56, 58, 65,106

updates, 1, 5, 6, 10, 11, 27, 28, 43, $44,57,60,61,63,76,77,86$, $88,89,92,96,106,112,119$, 124

V

video games, 3, 16, 43, 44

violence, 16

W

Walt Disney, 36, 45, 46

weak ties, 18, 21, 28, 89, 93, 114

Williams, Raymond, 48, 49, 51, 52

Willis, Paul, 48, 50, 51, 52, 67, 116

Y

younger adults, 17, 19, 31, 86

youth, 2, 15-18, 22-24, 34-41, 46, 56, $86,88,127,128$

youth culture, 17, 22, 23, 36, 37

youth literacy, 22

$\mathbf{Z}$

Zuckerberg, Mark, 1, 106

Zynga, 107 